G B

$162 T$

$\mathrm{F} 5 \mathrm{~B} 5$

A LIMNOLOGICAL STUDY OF THE FINGER LAKES OF NEW YORK : : By Edward A. Birge and Chancey Juday

From BULLETIN OF THE BUREAU OF HISHERIES, Volume XXXI1, 1912

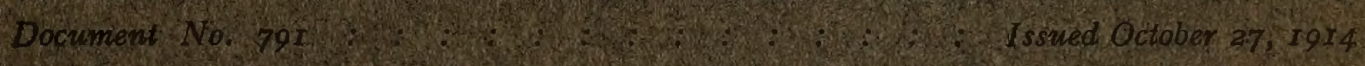

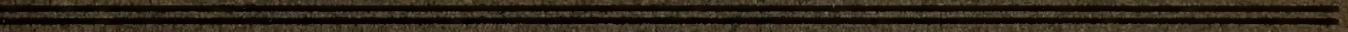




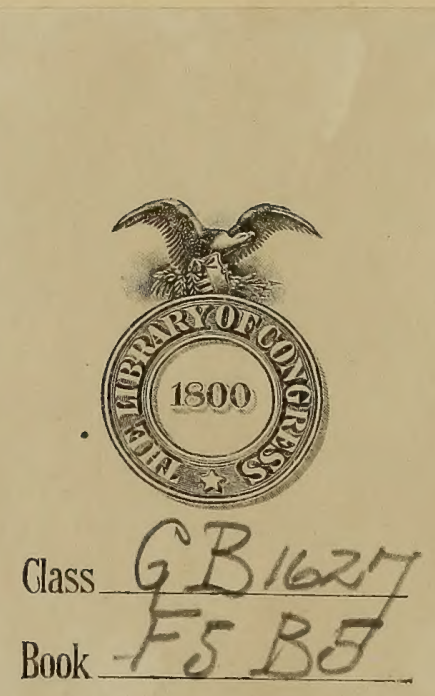








\section{A LIMNOLOGICAL STUDY OF THE FINGER LAKES OF NEW YORK : : B Edward A. Birge and Chancey Juday}

From BULLETIN OF THE BUREAU OF FISHERIES, Volume XXXII, I9I2

Document No. $791:: \quad: \quad: \quad: \quad: \quad: \quad: \quad: \quad$ : Issued October 27,1914

\footnotetext{
$\underline{\underline{ }}$
}

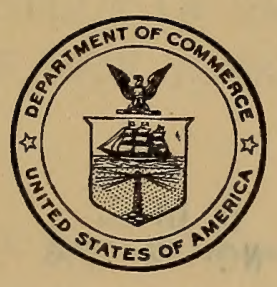


GB 1627

$F_{5 B}$

D. OF D.

NOV $2 \quad 914$ 


\section{A LIMNOLOGICAL STUDY OF THE FINGER LAKES OF NEW YORK}

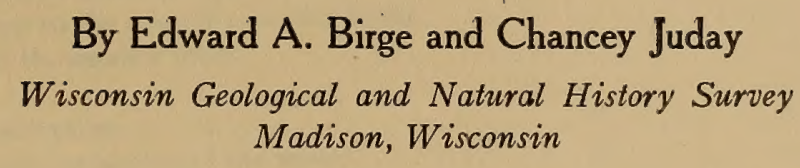

By Edward A. Birge and Chancey Juday

Wisconsin Geological and Natural History Survey

Madison, Wisconsin 

CONTENTS.

$*$

Introduction. . . . . . . Page.

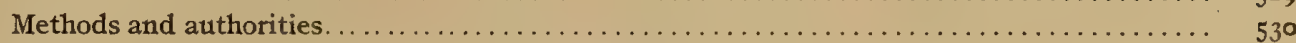

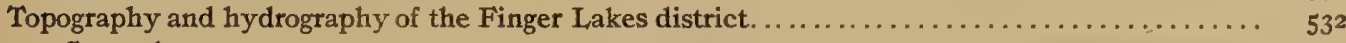

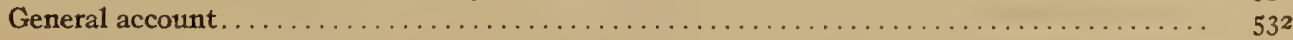

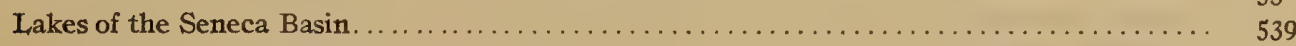

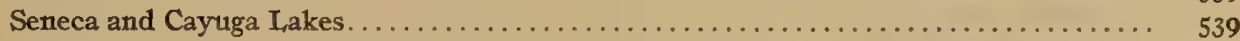

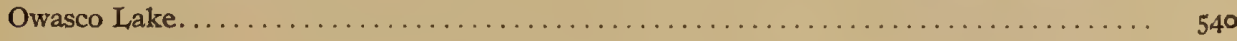

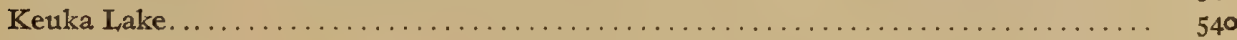

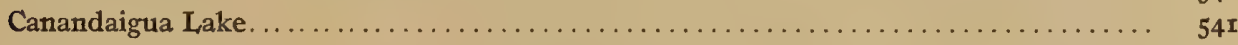

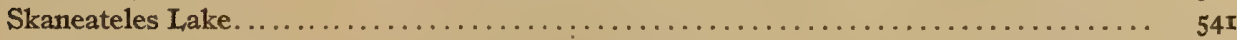

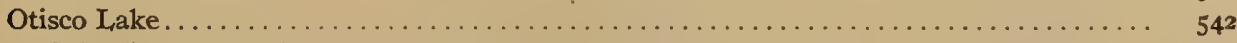

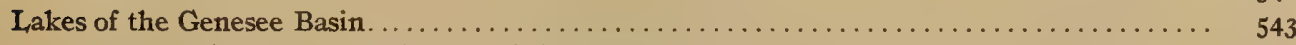

Honeoye, Canadice, Hemlock, and Conesus Lakes.................... 543

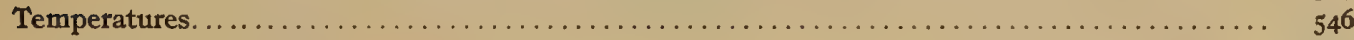

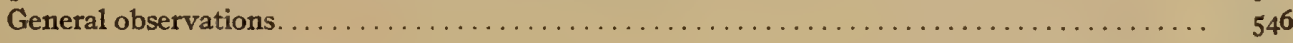

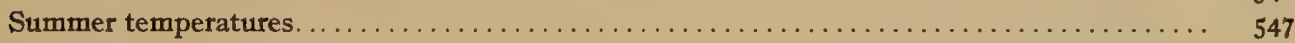

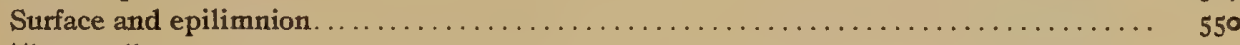

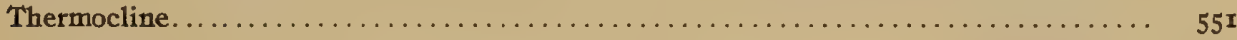

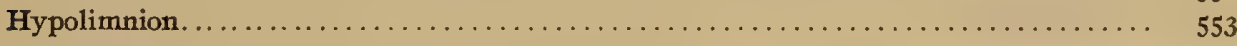

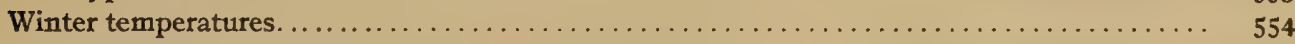

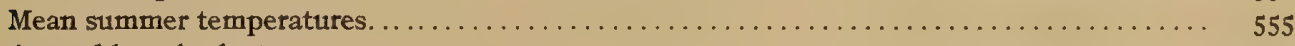

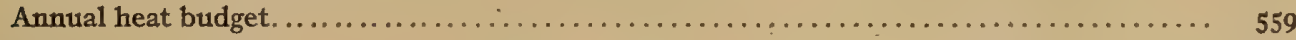

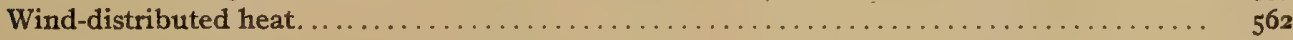

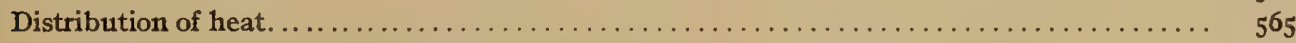

Distribution to thermal regions. . . . . . . . . . . . . . . . . . .

Distribution to the several ro-meter strata........................... 569

Heat supply of the smaller lakes. . . . . . . . . . . . . . . . . . . . . . $5{ }^{2}$

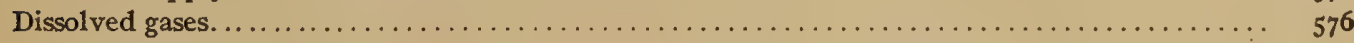

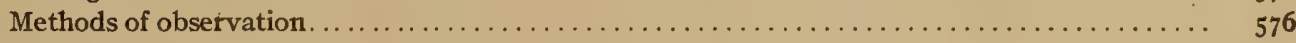

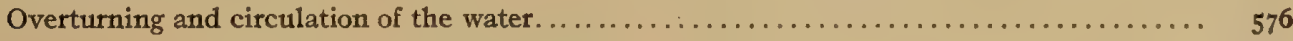

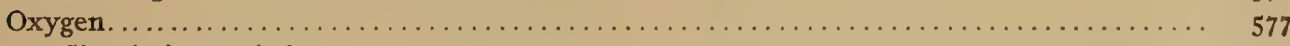

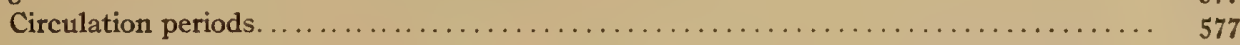

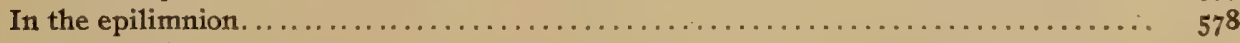

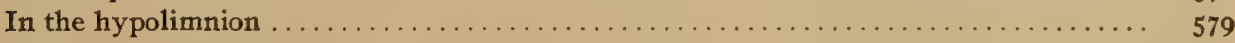

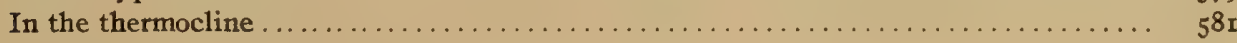

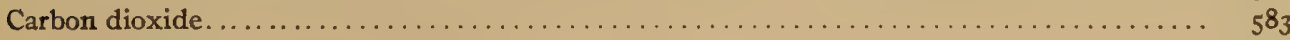

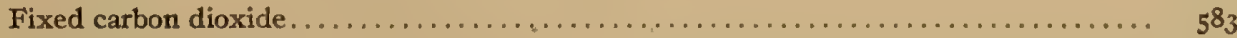

Half-bound carbon dioxide $\ldots \ldots \ldots \ldots \ldots \ldots \ldots \ldots \ldots \ldots \ldots \ldots \ldots \ldots \ldots \ldots \ldots \ldots \ldots \ldots \ldots \ldots \ldots \ldots$

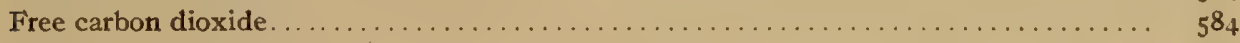

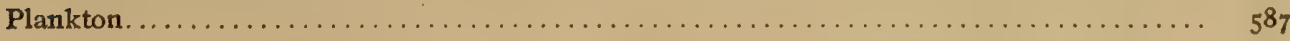

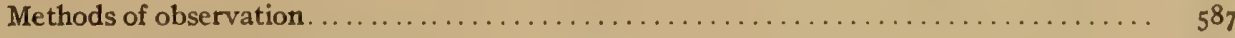

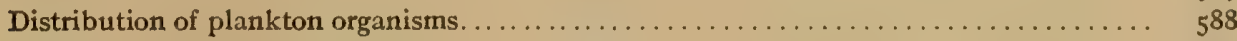

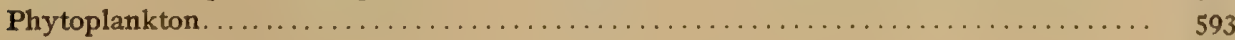

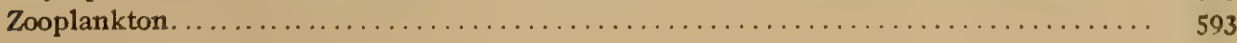

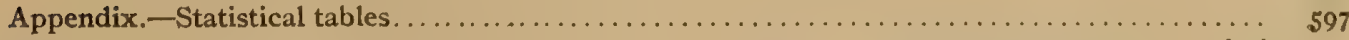

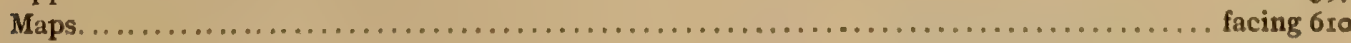


Table I. General table of hydrography.

II. Areas of Cayuga and Seneca Lakes. . . . . . . . . . . . . . . . . . . . . 539

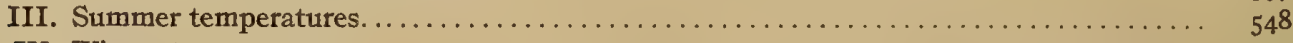

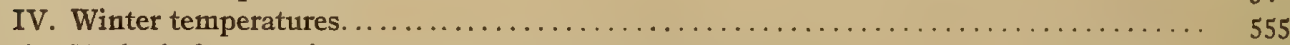

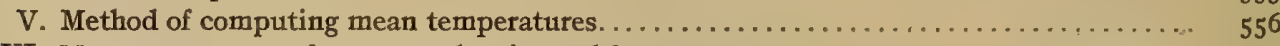

VI. Mean temperature from several series and from one................... 557

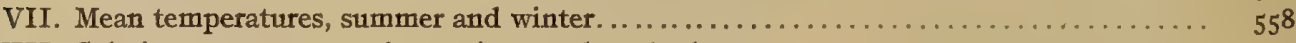

VIII. Calories per square centimeter in gross heat budget. .................. 560

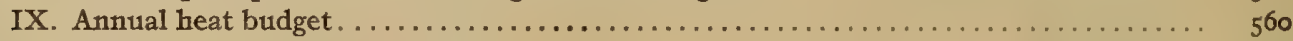

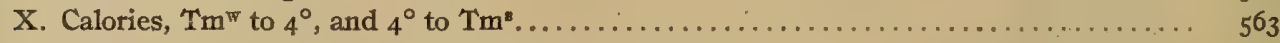

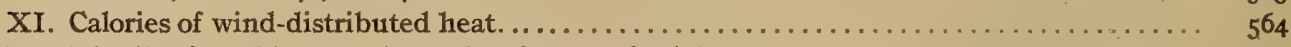

XII. Distribution of heat to thermal regions, major lakes. . . . . . . . . . . . . . . . . 567

XIII. Distribution of heat to ro-meter or 5 -meter strata.................... 570

XIV. Distribution of heat to thermal regions, minor lakes. .................... 575

XV. Hydrographic details of the lakes, metric system..................... 595

XVI. Areas and volumes of the lakes in square miles, acres, and cubic feet.............. 599

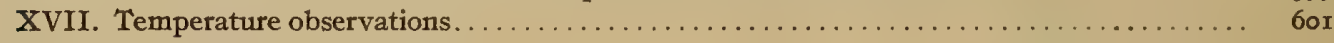

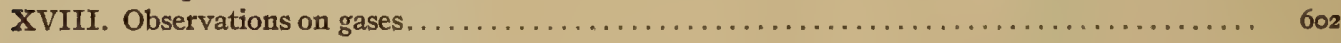

XIX. Analysis of plankton catches. . . . . . . . . . . . . . . . . . . . . . . . 603

XX. Transparency of water. . . . . . . . . . . . . . . . . . . . . . . . . . . . . . . 609

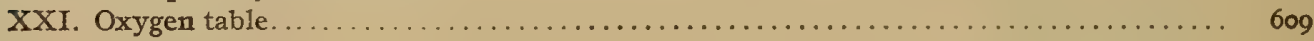




\title{
A LIMNOLOGICAL STUDY OF THE FINGER LAKES OF NEW YORK.
}

\author{
* \\ BY EDWARD A. BIRGE and CHANCEY JUDAY, \\ Wisconsin Geological and Natural History Survey, Madison, Wisconsin.
}

\section{INTRODUCTION.}

In I9Io the authors of this paper were enabled to visit the Finger Lakes district of New York, through a grant from the United States Bureau of Fisheries, and the month of August was spent in work upon the lakes. In February, I9I I, Mr. Juday visited four of the lakes to secure winter temperatures. A week in August and September, I9I I, was used in obtaining a second set of summer temperatures. The temperatures of Skaneateles and Owasco Lakes were also taken in February, 1912, and in the early autumn of that year.

The purpose of the investigation was to extend to these lakes the studies on dissolved gases, plankton, and temperatures, which the authors had already made on the lakes of Wisconsin. ${ }^{a}$ The lakes of New York are peculiarly well adapted for such study. Four of those visited-Canadice, Otisco, Conesus, and Hemlock-are directly comparable with several of the lakes of Wisconsin in size, depth, and biological conditions. The others, beginning with Owasco Lake, form a series whose smaller members are not greatly different from Green Lake, Wis.; but whose largest members, Cayuga and Seneca, are the largest inland lakes ${ }^{b}$ (except Lake Champlain) and the deepest in the United States east of the Rocky Mountains. Still further, these lakes lie in a region whose topography is hilly, but not mountainous. The highest elevations close to the lakes do not exceed 300 meters ( $I, 000$ feet) above the water, and the immediate slopes are, in general, much lower. The lakes, therefore, are not exposed to the peculiar climatic conditions of mountain lakes, but in general these conditions are comparable with those which exist in Wisconsin.

Seneca Lake, the deepest in the district (I88 meters, 618 feet) is much exceeded in depth by lakes in Europe. A score or more are found there which are comparable in size and form, but which reach a greater depth. Some nine European lakes exceed a depth of $x, 000$ feet. Yet Seneca Lake is so deep that from a biological point of view it offers conditions of life not essentially different from those of the deeper European lakes, and physically also it is essentially similar. These lakes are therefore directly

a Birge, Edward A., and Juday, Chancey: The inland lakes of Wisconsin: The dissolved gases of the water and their biological significance. Wisconsin Geological and Natural History Survey, Bulletin Xxx, Scientific Series No. 7, 259 p. z9r.

$b$ It may be noted here that the term "inland lakes" is used by us in contrast to "Great Lakes," which latter name we should apply only to the lakes of the series from Superior to Ontario. 
comparable with the larger and deeper lakes of Europe, although such a comparison is reserved by us for another paper.

There is another circumstance which makes it possible to study the Finger Lakes profitably. The hydrography of the six chief lakes has been determined through surveys made by Cornell University. These will receive more detailed notice in a later section. The successive classes of the College of Civil Engineering, Cornell University, carried on studies of these lakes almost continuously from 1874 to 1897 , devoting to the field work a period each summer following the closing of the college year. The university published maps giving the outlines, soundings, and shore topography (so far as the last was determined) for Cayuga and Seneca Lakes (scale $1: 60,000$ ), Canandaigua and Keuka Lakes (scale $\mathrm{I}: 40,000$ ). Owasco Lake was published privately in similar manner. Otisco and Skaneateles Lakes have remained unpublished. Both the published maps and copies of drawings of the unpublished lakes have been placed at our disposal by Director E. E. Haskell, of the College of Civil Engineering, Cornell University, to whom our thanks are due for many courtesies.

This work has had a singular fate. No limnologist appears to have made use of it, or, indeed, to have known of it. The volume, mean depth, etc., of the lakes can be determined from the data supplied by these surveys; but until the authors of this paper undertook the task it had not been done. The earliest survey was that of Cayuga Lake, begun nearly 40 years ago. It was the first to be made of an inland lake in the United States and antedates most similar surveys in Europe; but it seems to be almost wholly unḳnown, as well as the surveys made later. The lakes are not mentionedin Murray's ${ }^{a}$ account of the lakes of the world or in Halbfass's account of the lakes outside of Europe. ${ }^{b}$ Yet these are the only lakes in the eastern United States which are at all comparable to the more important inland lakes of Europe and the surveys represent a quality of work which has been surpassed by only the best European surveys.

A very careful hydrographic survey of Canadice Lake was made by the department of water supply of Rochester, N. Y., and the authors express their thanks for a copy of this map, as well as for the other courtesies rendered by the department.

This paper represents the joint work of the authors. Mr. Juday is, however, directly responsible for the sections on gases and plankton and $\mathrm{Mr}$. Birge for those on hydrography and temperatures.

\section{METHODS AND AUTHORITIES.}

In the account of the physical geography and hydrography ${ }^{c}$ of the Finger Lakes the elevations above sea level are taken from the maps of the United States Geological Survey. The figures for the areas, depths, and slopes of the lakes are derived from the

a Murray, J.: The characteristics and distribution of lakes. Bathymetrical survey of the fresh-water lochs of Scotland, vol. I. Edinburgh, I9ro.

$b$ Halbfass, W.: Topographie, Hydrographie, Geologie der Ausser-Europäischen Seen, in Der Gegenwärtige Stand der Seenforschung, bd. I, x 912 .

c Tarr, R. S.: Popular Science Monthly, vol. LXvur, p. 387-397; United States Geological Survey, Folio No. r69, p. 4, r9ro.

Watson, T. L.: Fifty-first annual report of the New. York State Museum, vol, 1, p. r59-rir7 (1897), 1899.

Nevius, J. N.: Ibid., p. ri3r-rx52.

Rafter, G. W.: Hydrology of the State of New York. New York State Museum Bulletin 85, rgo5. 
maps of the Cornell survey for all lakes except three. Canadice Lake was surveyed by the Rochester water department, and no hydrographic survey has been made of Conesus and Hemlock Lakes. The facts regarding their area have been taken from the maps of the United States Geological Survey and those of depth come from the observations of the authors.

The style of publication for the maps of the six lakes surveyed by Cornell University was a matter that caused much hesitation. The authors would have preferred for many reasons to use the metric system, but they decided on the use of the foot-andmile scale in order to show the shore topography by means of the maps of the United States Geological Survey. These topographic maps are engraved on this scale, and it was easy to insert the hydrography on the plates, while the cost of reengraving the topography on the metric scale was prohibitive.

All of the primary measurements are based on the metric system. Each sounding was converted from feet to meters before being platted on the working maps. The maps were enlarged to twice the scale of the original or to four times that scale in cases where the slopes were steep and the contours crowded. The measurements of areas were made with great care and repeated. It need not be stated that the number of soundings, especially in Cayuga and Seneca Lakes, is not enough to insure great accuracy of detail in the contours; but as all of these lakes are simple, straight, narrow, steepsided troughs, without islands, bays, or marked irregularities of outline or of bottom, the results are approximately correct, and no subsequent survey is likely to make substantial alterations in them.

The contour interval of Io meters was chosen for the primary measurements because of the nature of the temperature curve. The epilimnion is from 9 meters to 15 meters thick, and for computing temperatures the volume of the o-ro-meter zone, etc., must be known. In the small lakes the contour interval is 5 meters. For determining the volume of the several lakes the areas bounded by the several contours were measured, the volume of each zone was computed, and the total volume of the lakes as given in table $I$ is the sum of the volumes of the several zones.

In the detailed tables of the appendix the areas and volumes of the lakes are given in feet as well as in meters. The primary computations were all made on the metric system and the areas of the lakes at the 50-foot or 25 -foot contour intervals were derived, not from the replatting of the lakes for engraving the maps, but from the hypsographic curves derived from the metric measurements. These areas agree essentially with those shown on the maps, but of course small differences appear.

In preparing the maps for the engraver the Cornell soundings were platted on the outlines of the United States Geological Survey maps and the contours drawn again for this purpose.

The Cornell maps are based upon a detailed survey of each lake; not only were the lakes sounded but their outlines were determined by a careful trigonometrical survey. The sounding line was of wire; an apparatus was provided for releasing the weight when the bottom was reached and a registering apparatus recorded the depth. The first machine employed is no longer in existence, but the second one, and that 
with which most of the work was done, is still in good condition. It was recently calibrated and found accurate. There is every reason to believe that the earlier instrument was equally good. The soundings were well placed and the position of each was controlled by transit instruments on shore and a sextant in the boats. Every care, therefore, was used to secure accuracy in detail.

All of the under-water contours, both for the working maps and for the engraver, were drawn by Mr. L. S. Smith, associate professor of topographic engineering in the University of Wisconsin.

\section{TOPOGRAPHY AND HYDROGRAPHY OF THE FINGER LAKES DISTRICT.}

\section{GENERAL ACCOUNT.}

In the central part of the State of New York lies a plateau composed of nearly horizontal strata of soft Devonian shales and sandstones, whose highest points reach an elevation of about 700 meters $(2,300$ feet) above the sea. That part of this region with which this paper deals is known as the Finger Lakes district. (See sketch map, fig. I.) It is bounded on the west by the valley of the Genesee River, which extends completely across the State. From this it extends about 140 kilometers ( 84 miles) eastward to the eastern tributaries of the Seneca River. It occupies the northern slopes of this plateau, with a maximum breadth of about 70 kilometers (40 miles). The meridian of $77^{\circ}$ lies close to the center of the district, and it is bounded on the north by latitude $43^{\circ}$.

Lake Ontario lies about 40 kilometers ( 25 miles) to the north of this region. The district between the base of the plateau and Lake Ontario is deeply buried in drift whose surface is shaped into innumerable drumlins. The surface of the plateau itself bears but little drift. Its hills have been little eroded, but its valleys have been smoothed, widened, and deepened by the continental glacier.

The waters of the western one-fifth of this district drain into Lake Ontario by the Genesee River, which flows almost directly north to the lake. Across the north front of the remainder of the district flows the Seneca River, which has its origin in Seneca Lake, but is continued to the west by the Clyde River and the creeks that constitute the headwaters of that stream. The two rivers have a course in general almost directly east for roo kilometers (6o miles) flowing between the base of the plateau region and the drift-covered region to the north. The stream has found out for itself a course, twisting about among the groups of drumlins in an imperfectly developed valley, which offers very little slope for its flow, so that large marshes are developed. This valley has furnished the course for the Erie Canal. The Seneca River empties into the Oswego River, which flows nearly north, directly into Lake Ontario.

The chief tributaries of the Clyde and Seneca Rivers come from the plateau to the south, which is deeply trenched by their valleys. Some nine principal valleys extend southward into the highlands for a distance varying from 40 kilometers or less at the eastern and western limits to nearly roo kilometers in the center. These valleys are nearly parallel. (See fig. I.) Those in the center extend almost exactly from north to south. Those to the east diverge eastward and those to the west have a westward inclination. 


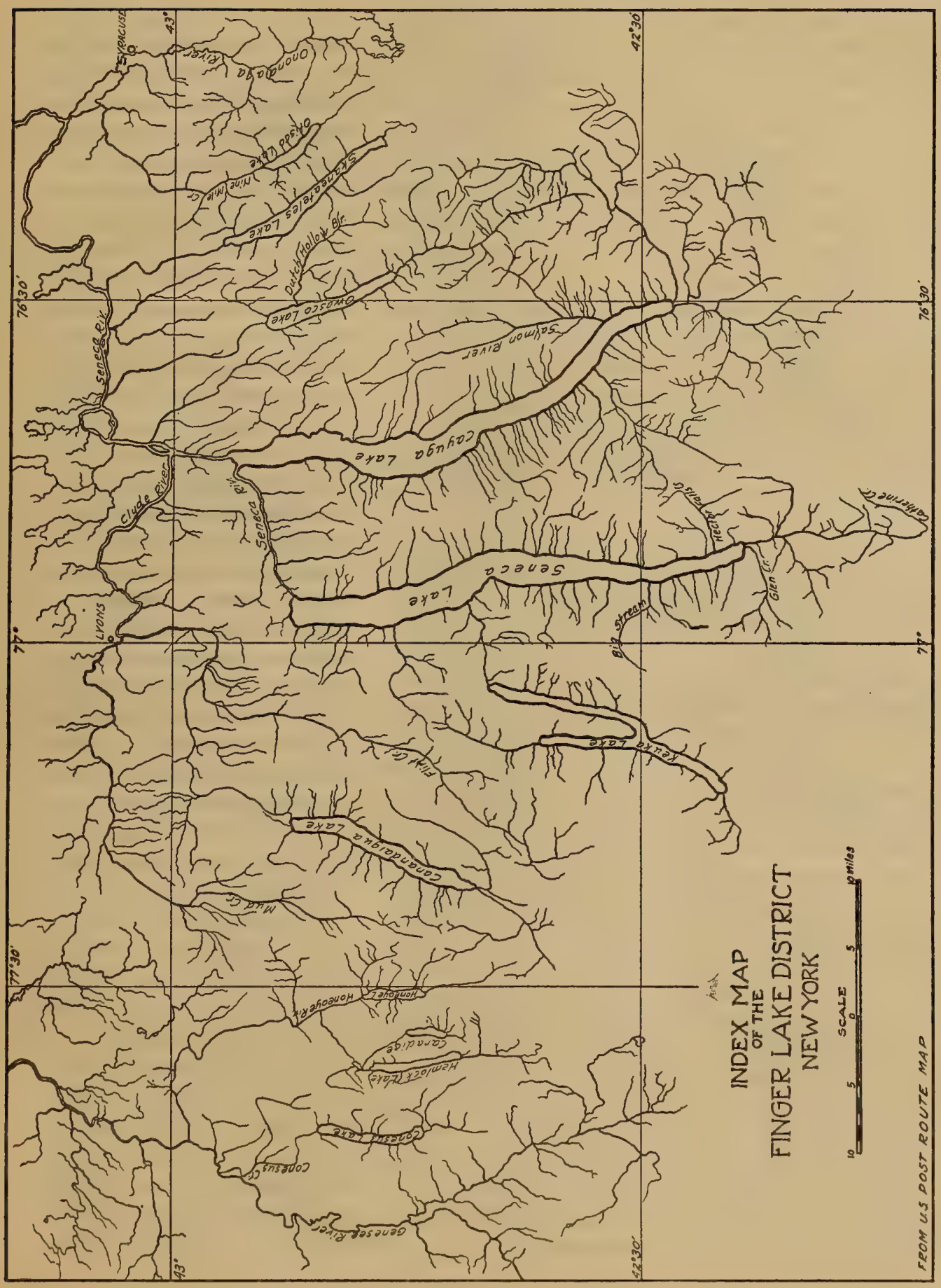




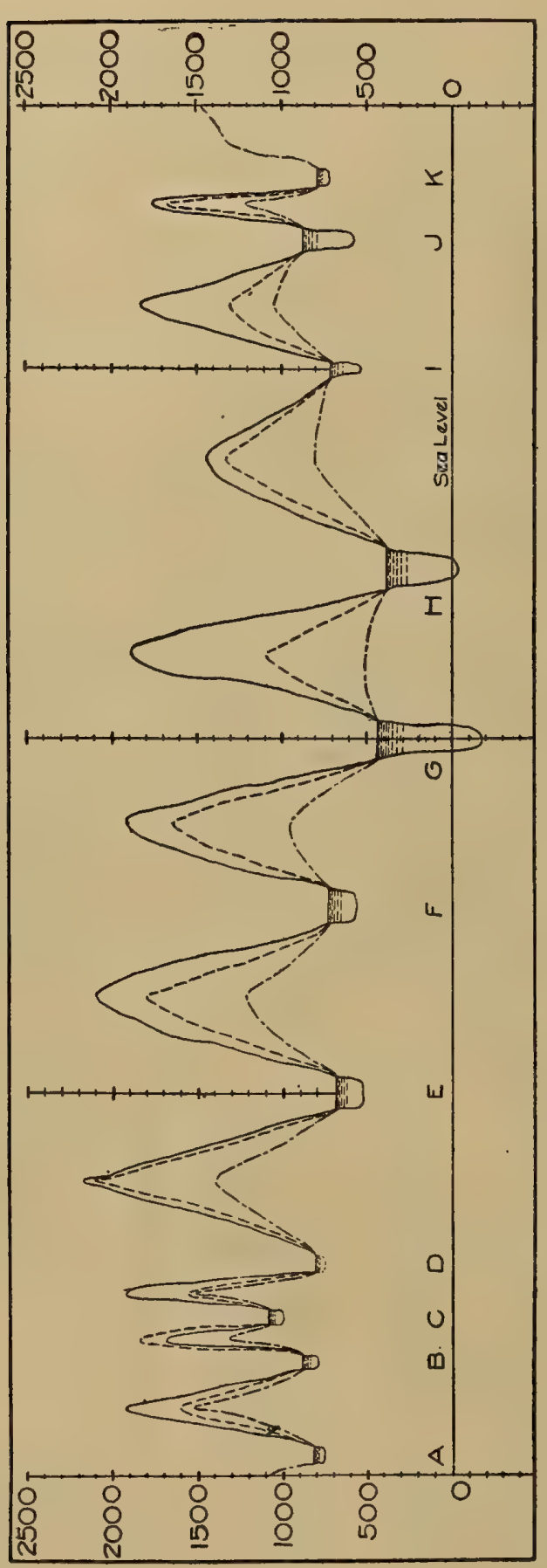

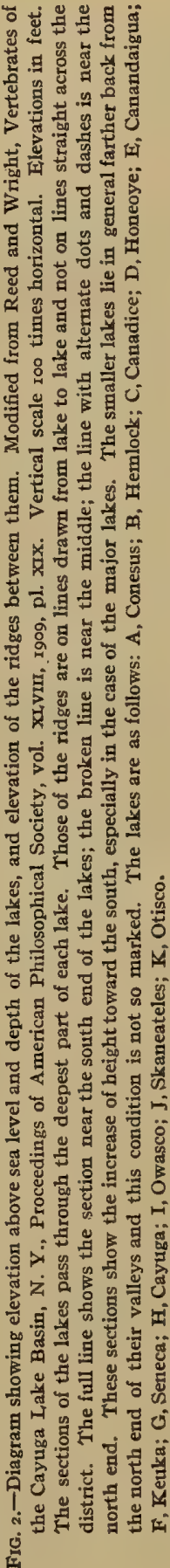

All of these valleys are occupied by streams. In the westernmost valley and in the second one to the east from this arefound two of the creeks that unite to form the Clyde River. In the easternmost valley is found one of the branches of the Onondaga River. The remaining six valleys have been much modified and deepened by glacial action and are filled in part by long, narrow, relatively deep lakes. These are the Finger Lakes, so called from their form and because they diverge somewhat as do the outspread fingers from the hand. The seventh lake of this series, Keuka Lake, occupies a branching valley which seems to have drained originally to the south. It was worked over by the ice in a way similar to the other lake-filled valleys, and now drains by a post glacial stream into Seneca Lake.

The valleys occupied by these lakes are undoubtedly of preglacial origin, but they were profoundly altered by the invasion of the ice. Seneca and Cayuga Lakes extend below the level of the sea (see fig. 2), the deepest parts of the Seneca Basin being 53.5 meters ( 180 feet) below sea level and those of Cayuga 16.4 meters ( 54 feet). These figures do not represent the maximum depth of the valleys. In the flat at Watkins, near the south 
end of Seneca Lake, a boring was carried down over 300 meters ( 1,000 feet) without reaching the rock, and similar borings at Ithaca have found loose material at greater depths than the maximum depth of Cayuga Lake. We are not aware that any similar observations have been made in the other valleys.

Between the westernmost tributary of the Clyde River and the Genesee Valley are four short, steep-sided valleys, deeply cut into the highlands, which here extend well toward the north part of the plateau. Each of these contains a lake similar in form to the lakes of the Seneca Basin, but much smaller and shallower than any of these except one. The outlets of these lakes also flow north, but soon turn west and reach the Genesee River by a short course.

In this district, therefore, lie I l larger lakes, each of them occupying a major valley in the north slope of the highlands (see fig. I), a valley which in all cases but one opens independently upon the front of the highlands. The northern ends of these lakes are near the north end of their respective valleys and, in general, are not far from the same latitude. This is especially obvious in the five lakes that occupy the central and larger valleys. To the south these lakes extend for a longer or shorter distance in proportion to their length, being longer in the center of the region and shorter, in general, toward the east and west limits.

In the center of this district the relatively low land of the Seneca Valley extends southward in a broad lobe. In the two valleys of this region lie Seneca and Cayuga Lakes, nearly parallel to each other and of almost exactly equal length and area. They are by far the largest and deepest lakes of the series. East of Cayuga and west of Seneca lie two other major lakes, Owasco and Skaneateles to the east and Keuka and Canandaigua to the west. East of Skaneateles Lake lies a single lake, Otisco, much smaller and shallower than any of the six; while to the west of Canandaigua come Honeoye, Canadice, Hemlock, and Conesus Lakes, constituting the series of four small lakes belonging to the Genesee Basin.

Thus the largest, deepest, and least elevated of these lakes lie in the center of the group. The elevation of the surface of the lakes increases in general from these toward the east and the west, declining somewhat at the extreme ends of the series. (See fig. 2.)

The lakes which lie immediately east and west of Seneca and Cayuga are similar in depth, though not in area. Owasco is considerably smaller than Keuka, but each is between 50 and 55 meters in maximum depth. The two lakes which lie next to the east and west, Skaneateles and Canandaigua, resemble each other very closely in length, area, depth, and topographic surroundings. Two lakes 70 kilometers apart can hardly resemble each other more closely than do these. As the table shows, they are considerably larger and much deeper than Owasco and much deeper than Keuka, although smaller in area. These six major lakes, in spite of their differences, belong to the same general class, as is shown by their dissolved gases and temperature. The small lakes lying still farther to the east and west are lakes of a different class, as the same series of facts will show. None of them reaches 30 meters in depth, and in area the largest of them is not a quarter the size of the smallest of the major lakes.

The ridges between these valleys rise in general to a maximum height of about 600 meters ( $x, 800$ to 2,000 feet) above the sea or 300 to 400 meters ( 1,000 to $x, 500$ feet) 
above the lakes. Since the lakes extend to the north ends of their respective valleys, where they open into the valley of the Clyde-Seneca River, the altitude of the ridges is in general lower at the northern end, where the valleys are also wider and the slopes of their sides are less steep. (See fig. 2.) To the south the valleys narrow, their sides become steeper, and the height of intervening ridges increases. These characters are most marked in the valleys of the larger lakes, perhaps most conspicuous of all in Cayuga Lake, which at one end extends deep into the highlands at the south and at the other reaches farthest into the valley of the Seneca River, so far, indeed, that it is continued to the north by the extensive marshes that bound its outlet.

The immediate shores of the lakes are smooth and regular. They have a steep slope, which toward the south may rise above the lake to a height of 100 to I50 meters (300 to 400 feet) or more. Above this altitude this slope rises more gradually to the general level of the plateau, and then comes a steeper rise to the higher elevations.

The tributary valleys on the upland slopes are broad, and the lower and steeper slopes are trenched by innumerable narrow gorges. These range in size from gullies which serve to carry off the rains, but are usually dry, to picturesque gorges, cut deep into the rocks and occupied by considerable streams. Of these last the most famous are Watkins Glen at the south end of Seneca Lake and the several gorges at the south end of Cayuga Lake.

The smoothly outlined shores of these lakes show few irregularities or decided projections except where the axis of the lake bends on account of the course of the original valley. Long Point on Seneca Lake is an instance of such a structural projection. Cayuga Lake has a broad expanse of shallow water at the north end, and here there are several points and one small island (the only island in the series of lakes) which represent irregularities of the original shore. The maps show similar conditions in less marked degree at the north end of other lakes. In general, however, the irregularities of the water line are small and are due to flat deltas and spits built by the tributary streams and by the waves. These constitute a characteristic and very beautiful feature of the shores of the lakes. They vary greatly in size according to the drainage basin of the stream that produced them. The maps of the lakes show numerous examples of such points; Myers Point on Cayuga Lake is perhaps the largest; and the flat on the west side of Seneca Lake on which the town of Dresden is situated was built in similar fashion by the outlet of Keuka Lake. In Conesus Lake (fig. 3) two such points opposite each other near the middle of the lake have nearly divided it.

The form of the lakes and their steep banks have so directed the course of the winds that very little work has been done by the waves along their sides. As a result, the wave-cut shelf is very narrow and the water deepens close to the shore and very rapidly. Few large tributaries enter the lakes by their sides; most of the larger streams enter at the south end. (See fig. r.)

The larger lakes of the Seneca Basin take in and give out during the year an amount of heat whose aggregate is enormous. It has been computed that this is equal to the heat generated by the combustion of nearly 150,000 tons of coal for each square mile of the surface of the lake. The total amount of heat from Seneca Lake would equal that from nearly 10,000,000 tons of coal. This heat is absorbed by the water in the 
spring and liberated in autumn and produces a considerable local effect on the climate. The effect is intensified by the narrow valleys with their steep slopes which concentrate and localize the influence of the water. Frosts are delayed in autumn, and in spring the cold water chills the air of the valleys so that vegetation does not start until the danger of killing frosts has passed. The slopes of the lake basins are therefore peculiarly well adapted for raising fruit, and many orchards and vineyards are found there. The steep shores of Keuka Lake, especially, are covered with vineyards, as thick set as those of the Rhine.

The Finger Lakes comprise a group of I I neighboring lakes, similar in form and topographic situation but differing widely in area and depth. Six of them may be classed as major lakes and five as minor, although the lakes in each group differ greatly from each other. The series offers for study lakes whose range of length is from 5 kilometers to more than 60 kilometers and whose range in depth is nearly tenfold. Thus the series extends from lakes of quite ordinary character to those which are inland lakes of the first order in every sense of that term. It is probable that there is no group of lakes in the world which offers to the limnologist such opportunities for working out the problems of his science.

Table I gives the general facts of the hydrography for the several lakes and for Green Lake, Wis., which is frequently compared with the New York lakes in the discussion of temperatures.

TABLE I.-HYdRography OF THE NEW YORK LAKES.

\begin{tabular}{|c|c|c|c|c|c|c|c|c|c|c|c|}
\hline \multirow{2}{*}{ I akes. } & \multirow{2}{*}{\multicolumn{2}{|c|}{ Drainage area. }} & \multirow{2}{*}{\multicolumn{2}{|c|}{$\begin{array}{c}\text { Ellevation } \\
\text { above sea. }\end{array}$}} & \multirow{2}{*}{\multicolumn{2}{|c|}{ Length. }} & \multicolumn{3}{|c|}{ Breadth. } & \multirow{2}{*}{\multicolumn{2}{|c|}{ Area. }} \\
\hline & & & & & & & \multicolumn{2}{|c|}{ Maximum. } & Mean. & & \\
\hline Lakes. & \multicolumn{4}{|c|}{ Depth. } & Dm. & \multicolumn{2}{|c|}{ Volume. } & \multicolumn{2}{|c|}{ Mean slope. } & \multicolumn{2}{|c|}{ Development. } \\
\hline 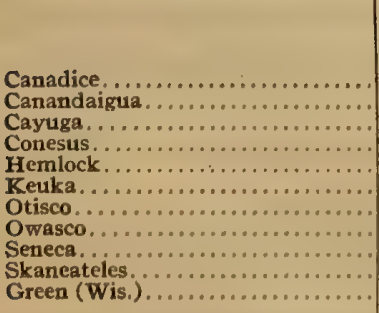 & $\begin{array}{r}\text { Meters. } \\
25.4 \\
83.5 \\
132.6 \\
18.0 \\
27.5 \\
55.8 \\
20.1 \\
54.0 \\
188.4 \\
90.5 \\
72.2\end{array}$ & $\begin{array}{r}\text { Feet. } \\
.83 \\
274 \\
435 \\
59 \\
90 \\
183 \\
66 \\
x 77 \\
618 \\
297 \\
237\end{array}$ & \begin{tabular}{r|r} 
& Meter \\
3 & 16. \\
4 & 38. \\
5 & \\
9 & 54. \\
9 & $\ldots$. \\
3 & $\ldots$. \\
6 & 30. \\
7 & 10. \\
8 & 29. \\
7 & 88. \\
7 & 43. \\
& 33.
\end{tabular} & & $\begin{array}{r}.55 \\
.51 \\
.54 \\
.47 \\
.48 \\
.46\end{array}$ & \begin{tabular}{r} 
Million \\
cubic \\
meters. \\
42.6 \\
$1,640.1$ \\
$9,379.4$ \\
$\ldots \ldots \ldots .$. \\
\hdashline $1,433.7$ \\
77.8 \\
780.7 \\
$15,539.5$ \\
$1,562.8$ \\
984.8
\end{tabular} & \begin{tabular}{|} 
Million \\
cubic feet. \\
I, 503 \\
57,897 \\
331,080
\end{tabular} & $\begin{array}{r}\text { Per } \\
\text { cent. } \\
6.2 \\
7.0 \\
5.2 \\
\ldots \ldots . . \\
7.8 . \\
7.8 \\
2.3 \\
4.4 \\
9.0 \\
8.4 \\
5.4\end{array}$ & $\begin{array}{cc}0 & 1 \\
3 & 33 \\
4 & 0 \\
2 & 58 \\
\cdots & \ldots \\
\cdots & \cdots \\
4 & 28 \\
1 & 21 \\
2 & 31 \\
5 & 08 \\
4 & 48 \\
3 & 06\end{array}$ & $\begin{array}{l}4.58 \\
2.04 \\
2.37 \\
2.74 \\
2.45 \\
x .78\end{array}$ & 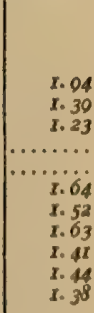 \\
\hline
\end{tabular}


TABLE I.-HYDROGRAPHY OF THE NEW YORK LAKES-Continued.

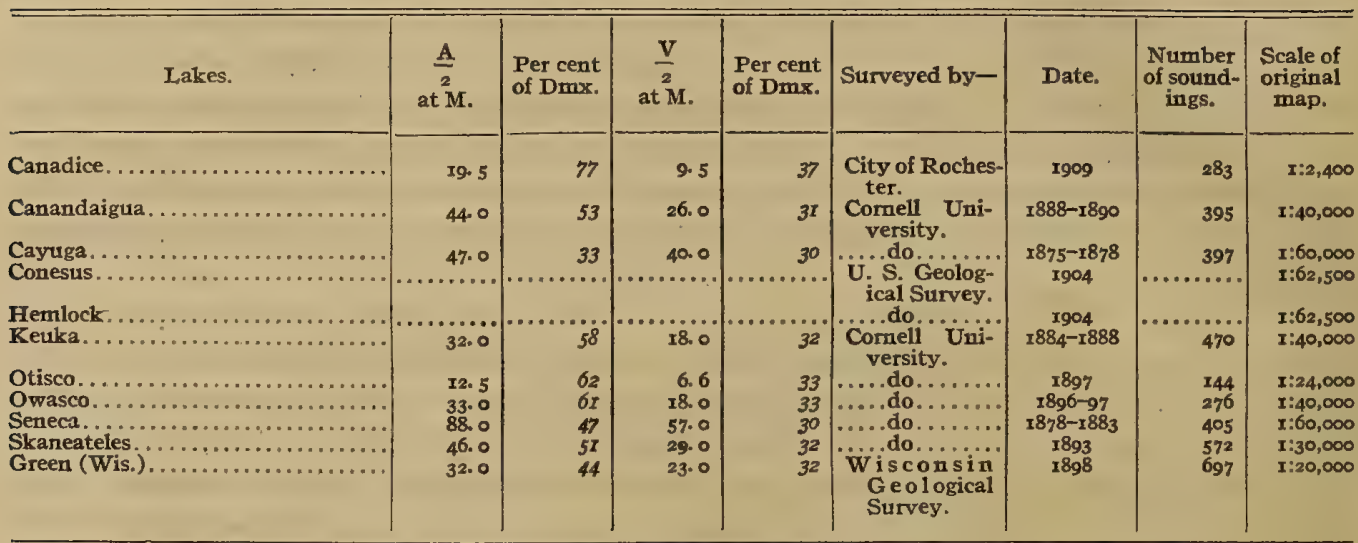

\section{EXPLANATION OF TABLE I.}

In table I the areas of drainage basins were taken from Rafter's Hydrology of New York, except Canadice Lake, whose basin was measured from United States Geological Survey maps, and Green Lake, which was measured from Wisconsin maps. The drainage area of Seneca Lake includes that of Keuka Lake.

Elevations above sea were from the United States Geological Survey maps, except Green Lake. In this case the elevation is that found in Gannett's Dictionary of Altitudes in the United States, and refers to the railway station, which is somewhat below the level of the lake.

Length, depth, etc., were measured or computed from the maps named in the table.

The length of each lake was measured along its axis. That given for Ketka Lake is the length of the east arm and main lake; the west arm is ro.6 kilometers ( 6.6 miles) long. The maximum breadth of Keuka Lake is at the junction of the arms; elsewhere the maximum breadth is $\mathrm{x} .48$ kilometers ( $\mathrm{I} . \mathrm{I}$ miles).

The mean breadth of the lakes was found by dividing the area by the length. The mean depth was found by dividing the volume by the area.

The depths given for Hemlock and Conesus Lakes are those found by the authors. The lakes have not been surveyed, but probably these numbers are near the maximum depth.

$\frac{\mathrm{Dm}}{\mathrm{Dmx}}$ is the ratio of the mean depth to the maximum depth.

The volume assigned to each lake in this table is the sum of the volumes of the several strata as given in the tables of detailed hydrography (p. 597). These are computed from theformula $v=h \frac{(\mathrm{A}+\mathrm{B}+\sqrt{\mathrm{AB}})}{3}$, in which $h$ is the contour interval, $\mathrm{A}$ and $\mathrm{B}$ are the areas of the bounding planes of the stratum.

The mean slope was computed according to the formula of Gravelius $a \mathrm{~S}=\frac{\mathrm{H}}{\mathrm{A}} \frac{\left(\mathrm{T} / 2 l_{0}+l_{1}+l_{2}+\ldots \ldots \ldots+l_{\mathrm{n}}-\mathrm{x}+\mathrm{I} / 2 l_{n}\right)}{n}$, in which $\mathrm{H}$ is the depth of the lake, $\mathbf{A}$ its area, and $l_{0}, l$, etc., the length of the successive contours.

The mean slope of the areas between the several contours in the detailed tables of hydrography was calculated from the formula $S=\frac{h}{a} \frac{\left(l_{1}+l_{2}\right)}{(2)}$, in which $h$ is the contour interval, $a$ the area between the contours, and $l_{1}, l_{2}$ the length of the contours.

Shore development is the ratio of the perimeter of the lake to the circumference of a circle whose area equals that of the lake. Volume development is the ratio of the volume of the lake to that of a cone whose base equals the area of the lake and whose height is the maximum depth of the lake. If the sides of the lake were vertical the volume development would be 3 or the volume would be that of a cylinder of equal base and altitude. The formula is $\frac{3 \mathrm{Dm}}{\mathrm{Dmx}}$ and the numbers of this column are therefore three times those in the column $\frac{\mathrm{Dm}}{\mathrm{Dmx}}$. That part of the number which follows the decimal point is, in these lakes, the same as Peucker's figure for "mittlere Wölbung."

$\frac{A}{2}$ at $m$. This column shows to the nearest meter or half meter the depth at which the area of the lake basin is reduced to one-half of that of the lake's surface.

$\frac{V}{2}$ at $m$. shows in like manner the depth of the plane which divides the volume of the lake into two equal parts.

The columns headed "per cent of Dmx" show the ratio of these depths to the maximum depth of the lakes. See account of Otisco L,ake (p. 542) for other statistics.

a Gravelius, H.: Die mittlere Böschung. Zeitschrift für Gewässerkunde, bd. 1X, p. 26\%. 
LAKES OF THE SENECA BASIN.

Seneca and Cayuga Lakes (pl. cxim, cxiv). - These are the largest and deepest lakes of the group and closely resemble each other in surface dimensions. Seneca Lake, however, is nearly 56 meters deeper than Cayuga, the ratio of the maximum depths of the two lakes being I: $\mathbf{I . 4 2}$. The mean depth of Cayuga Lake is even less, being to that of Seneca in the ratio of $I$ : 1.63 , and their volumes have about the same ratio. The map shows a large area of shoal water at the north end of Cayuga Lake, which is not found in Seneca Lake. The outlet of Cayuga Lake, also, passes at once into the extensive Montezuma marshes, another indication of the flat condition of the country at the north end of the lake.

The topography of the shores of these lakes is very similar. The country is relatively flat at the north end. (See fig. 2 as well as the plates.) The shores rise toward the south and for the southern half or two-thirds of their length, the lakes are bounded by a steep slope, often precipitous at the bottom, which reaches in places roo meters or more in height. Above this steep slope there is for much of the way a more or less definitely marked shelf, and above this there is another rise to more considerable isolated heights. There are no high hills which crowd down toward the water as is the case in most of the other lakes. The lakes have the appearance of a broad, quiet river, with steep banks of nearly uniform height. Their scenery is therefore rather tame as compared with that of the other major lakes; but at the southern end of both lakes the entering streams have cut deep gorges which are famous for their beauty. The lateral tributaries of these lakes are larger than those of the smaller ones and points built out by them into the lakes are correspondingly larger. At the south end of each of these lakes there is a flat or delta built out into the water by the large streams which enter from the south.

The authorities which we have consulted give the area of Cayuga Lake as slightly larger than that of Seneca, but our very careful measurements, both from the Cornell maps and those of the United States Geological Survey, reverse this relation. The following table shows the details for each lake:

Table II.-Areas of Cayuga and Seneca lakes.

\begin{tabular}{|c|c|c|}
\hline \multirow{2}{*}{ Authority. } & \multicolumn{2}{|c|}{ Area in square miles. } \\
\hline & Cayuga. & Seneca. \\
\hline 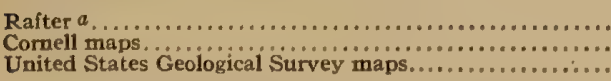 & $\begin{array}{l}66.8 \\
66.4 \\
66.0\end{array}$ & $\begin{array}{l}66.0 \\
6 \% .7 \\
66.3\end{array}$ \\
\hline
\end{tabular}

a Rafter, G. W.: Hydrology of the State of New York. New York State Museum Bulletin 85, 1905, p. 2 ×6.

The transparency of these lakes, as measured by Secchi's disk in I910, was 5.I meters for Cayuga Lake and 8.3 meters for Seneca.

These lakes are part of the canal system of New York, and their outlets are controlled by the works at the entrance of the canals into the lakes.

$46512^{\circ}-14-2$ 
Our observations on Seneca Lake were made in the deep water off North Hector. In Cayuga Lake they were made off Sheldrake and King Ferry.

For the details of the hydrography, see p. 598.

Owasco Lake (pl. cxiI).-Owasco Lake is the smallest of the six major lakes, having about 70 per cent of the length of Skaneateles and Canandaigua Lakes. Its mean breadth is, however, somewhat greater, so that its area is about 70 per cent of that of Skaneateles Lake, its neighbor to the east. It is also the shallowest lake (54 meters, I 77 feet), although Keuka Lake exceeds it by less than 2 meters in maximum depth, and a little more than I meter in mean depth. It has the form typical of these lakesa broader, rather shallow northern part extending into the lower country, and a narrow south part with steep sides. The valley, however, lies in that depression of the highland which includes the north parts of Seneca and Cayuga Lakes. Its banks are, therefore, on the whole, lower than those of any of the other lakes, although of the same general character. The valley extends about 30 kilometers (I 8 miles) to the south, and with steeper slopes than any of those found immediately adjacent to the water. Near the lake the steep slope at the bottom never exceeds roo meters, and is usually much less, and above this the slopes are gradual and do not rise to elevations much exceeding 200 meters above the lake. The lake itself is about roo meters above Cayuga Lake, its neighbor to the west, and less than half as much below Skaneateles Lake.

The outlet is controlled by a dam, and the lake is the source of water supply for the city of Auburn, which lies at its north end. The south end of the lake is somewhat silted up by alluvium brought down by the inlet, as is shown by the form of the 25 -foot contour, and the valley is probably deeply filled with loose materials.

In a report made in 1909 to the city of Auburn, Mr. G. P. Whipple computed the volume of Owasco Lake as equal to about $200,000,000,000$ gallons, which would equal about $2,670,000,000$ cubic feet. This computation is based on the same survey as ours, and is somewhat smaller than our estimate. (See table I.) Whipple's diagram, however shows the volume of the lake as slightly larger than our figures.

Our observations in rgro were made off Wyckoff, and temperatures were taken there in the winters of I III and I9I2. Four series of temperatures were taken in I9II, the first near Rice Point at the south, and the last near the northern limit of the Ioo-foot contour.

For the details of the hydrography, see p. 598.

Keuka Lake (pl. cxv).--Keuka Lake, which drains into Seneca Lake, lies about 80 meters above it. The stream which carries its water flows through a narrow postglacial gorge and empties into Seneca Lake near Dresden.

Keuka is the largest of the lakes after Cayuga and Seneca, and it is also the narrowest. It is the only lake whose outline is irregular. Its west arm, though the shorter, is the deeper, the I5o-foot contour extending close to the northern end. The lake lies, as a whole, farther to the south than does any other of the district, and both branches of the basin are narrow to the extreme north end, since the valley does not widen out on the northern face of the plateau. It is one of the shallowest of the six major lakes, being less than 2 meters deeper than Owasco. The under-water slopes of 
the basin are very steep, as are also those above water; and these steep slopes begin close to the northern end of the lake and extend through its length. Bluff Point, which divides the two arms of the lake, is one of the finest hills to be found adjacent to the lakes, and has been most characteristically shaped by glacial action.

The waters of Little Lake, which is shown on the map, drain into the Susquehanna River, and thus reach Chesapeake Bay, while those of Keuka Lake ultimately reach the Gulf of St. Lawrence.

Observations were made on Keuka Lake in the deepest water off Grove Springs.

For the details of the hydrography, see p. 598.

Canandaigua Lake (p1. CxvI).-Canandaigua Lake repeats the typical form of the Finger Lakes-a basin, relatively broad and shallow at the north end, with flat lowlying shores. To the south the hills rise and steepen and come down close to the lake. The hills on the east side rise with a steep slope almost to their summits, South Hill showing a rise of nearly 400 meters in I kilometer, while other slopes are nearly as steep for shorter distances. No lake has so many high hills adjacent to it. Burr and South Hills lie to the east, and on the west are Powell and Stid Hills. Between these is Bristol Hill, which reaches a height of about 500 meters ( $\mathrm{r}, 604$ feet) above the lake. Its summit is just to the west of the limits of the map, due west from Lapham Point. Between these hills are deep valleys, of which Vine Valley on the east side is the most conspicuous. These high hills, with their valleys, make the scenery of Canandaigua Lake more diversified than that of any other Finger Lake. No single view, indeed, is finer than that of Bluff Point from Keuka Lake, but in variety of scenery Canandaigua excels.

The transparency of the lake in I9Io was 3.7 meters, the lowest found in the major lakes.

Observations on gas and plankton were made in the deepest water and not far from Grange Landing. In both $\mathrm{I} 9 \mathrm{I} \mathrm{I}$ and $\mathrm{I} 9 \mathrm{I} 2$ four series of temperatures were taken, of which the southern was near Cooks Point, and the northern near Hope Point.

For the details of the hydrography, see page 597.

Skaneateles Lake (p1. cxI).-Skaneateles Lake is the easternmost of the six major lakes and is almost a replica of Canandaigua, the westernmost. Its length is almost the same, its breadth slightly less, and its area correspondingly smaller. Its depth, both mean and maximum, is greater, in spite of which the shores to the south are not so high as those of Canandaigua, nor are there the deep lateral valleys that diversify the steep walls of the latter basin. The highest and steepest slopes are reached only at the extreme south end of the lake and extend up the valley beyond the water. Here on the west side is found a slope about 250 meters high with a gradient of about $1: 3$. This is, as usual, exceeded by the under-water slopes, which reach near Carpenters Point a maximum of $\mathrm{I}: \mathrm{I} .5$ for a height of 60 meters.

The transparency of the lake in I9IO was I0.3 meters, by far the greatest found. This had no apparent effect on the distribution of temperature.

Skaneateles Lake serves as a reservoir for part of the canal system of New York, and its outlet is controlled by a dam, which raises the water perhaps about 2.5 meters 
( 8 feet) above its natural low level of 70 years ago. The water of this lake, with that from Otisco Lake, is also used for the water supply of the city of Syracuse, which lies some 27 kilometers to the northeast.

Our observations in I9lo were made off Carpenters Point. The later temperature observations were taken off Mandana.

For the details of the hydrography, see page 599 .

Otisco Lake (pl. cxI).-Otisco Lake is quite similar in situation and form to the six major lakes, but is wholly different in area, depth, and biological character. The lake is used as a source of water supply for the city of Syracuse, which lies about 27 kilometers to the northeast. The height of the water is controlled by a dam, which may raise the water 3 meters or more above its original level. This dam is placed some I.5 kilometers below the original outlet and has thus caused a shallow extension of the lake at the south end. The sides of the original lake are steep, and the increase in height of the water adds little to its breadth. At the south end of the lake the floor of the valley slopes very gradually and here the dam has caused a broad, shallow expanse which varies greatly in area with the rise and fall of the water as it is drawn upon for the use of the city.

Across this shallow expanse and close to the original south end of the lake there runs a causeway pierced only by a narrow opening. There is thus a considerable area of shallow water which is practically separated from the main body of the lake.

In the genaral table of the lakes the statistics for Otisco Lake are based on the Cornell survey and include the entire lake. The level of the water shown by this survey was not correlated with the level of the crest of the dam, or if such measurements were made (as they probably were) the records have disappeared. The water was probably about I meter below the spillway at the time the soundings were taken. They therefore do not represent the maximum possible depth of the lake, but are probably quite as great as the ordinary depth.

For all purposes of limnology the southern extension of the lake beyond the causeway has no significance, however valuable it may be as a storage for water supply. For the purposes of our discussion, the dimensions of the lake must be recalculated, including that part of the lake which lies between the dam and the causeway. The results are as follows: Length, 7.33 kilometers; breadth, maximum, 1.22 kilometers; mean, 0.93 kilometers; area, 6.84 square kilometers; depth, maximum, 20.r meters; mean, II.2 meters; volume, 76,440,000 cubic meters; shore development, 1.76 ; volume development, I.64; mean slope, $2.4 \mathrm{I}$ per cent, $\mathrm{I}^{\circ}{ }^{\prime} 23^{\prime}$. These measurements are employed in the table of hydrography, page 597.

Otisco Lake occupies only a small part of its valley, which extends far beyond the lake both to the north and the south. Its steepest slopes begin at about the same point as do those of the Skaneateles valley, and since the lake is little more than onethird as long, they lie wholly to the south of the water. In general they are more broken and diversified than are those of the other eastern lakes. There is hardly a view in this picturesque and beautiful region finer than is that which the Otisco Valley 
offers as the traveler from Skaneateles first enters it from the south, high up on the slopes of its western side.

Otisco Lake was visited only once. The work was done off Amber, in the deepest water. The lake abounds in plankton, as is indicated by the absence of oxygen and plankton in the deeper water. Its transparency in 1910 was 3 meters, the least shown by any of the lakes, but not much less than several of them.

For the table of hydrographic details, see page 597 .

\section{LAKES OF THE GENESEE BASIN.}

Honeoye, Canadice, Hemlock, and Conesus Lakes (fig. 3).-These four small lakes lie to the west of Canandaigua Lake (fig. I), in narrow valleys, at an average altitude decidedly greater than that of the lakes of the Seneca Basin (fig. 2). One of them, Honeoye Lake, was not visited by us. The lake is shallow, as is shown by the large deltas which have been built out into it by the small streams along its sides.

Conesus, the westernmost lake, lies farthest to the north, and therefore comes nearest to the mouth of its valley. The valley is shallow and has gradual slopes, not exceeding $\mathrm{r}: 5$ for a height of roo meters (over $300 \mathrm{feet}$ ). The highest hills adjacent to the lake do not reach a height greater than 160 meters (530 feet) above its surface. The most interesting topographic feature of the lake is the fact that near its center two streams, entering opposite each other, have built out large deltas, which have nearly divided the lake. The water is shallow; we found no depth greater than 18 meters. We made soundings along the center of the southern half of the lake, and the greatest depth of the lake is probably little, if at all, greater than that found by us. The transparency of the water was 6.3 meters, which was exceeded only by Skaneateles and Seneca Lakes. The oxygen and plankton of the lake show the regular characters that belong to a shallow lake.

Canadice and Hemlock Lakes lie close together in the center of this group. They are separated by the height of Bald Hill, which lies between them, much as Bluff Point lies between the two arms of Keuka Lake, and which has a form quite similar to that of Bluff Point ( $\mathrm{pl} . \mathrm{cxv}$ ). It rises, however, to a greater height, since its summit is nearly 600 meters ( 1,850 feet) above the sea, and it rises more than 230 meters $(760$ feet) above Canadice Lake and about 290 meters ( 950 feet) above Hemlock Lake. The water of these two lakes furnishes part of the supply for the city of Rochester, which lies about 45 kilometers ( 28 miles) to the north.

Hemlock Lake is long, narrow, nearly straight, and is singularly uniform in breadth. The walls of the valley are steep, the steepest slopes rising 300 meters or more in $\mathrm{x}$ kilometer. None of the slopes are precipitous, but many of them are about as steep as is possible for a wooded slope to lie. Marrowback Hill, on the west of the lake, is as steep as Bald Hill on the east and reaches a height some 30 meters (roo feet) greater. The sides of both these hills are uniform and are unbroken by valleys or projections. Toward the north end of the lake are a few small streamlets whose valleys are almost invisible, and even these are not found along the southern two-thirds 


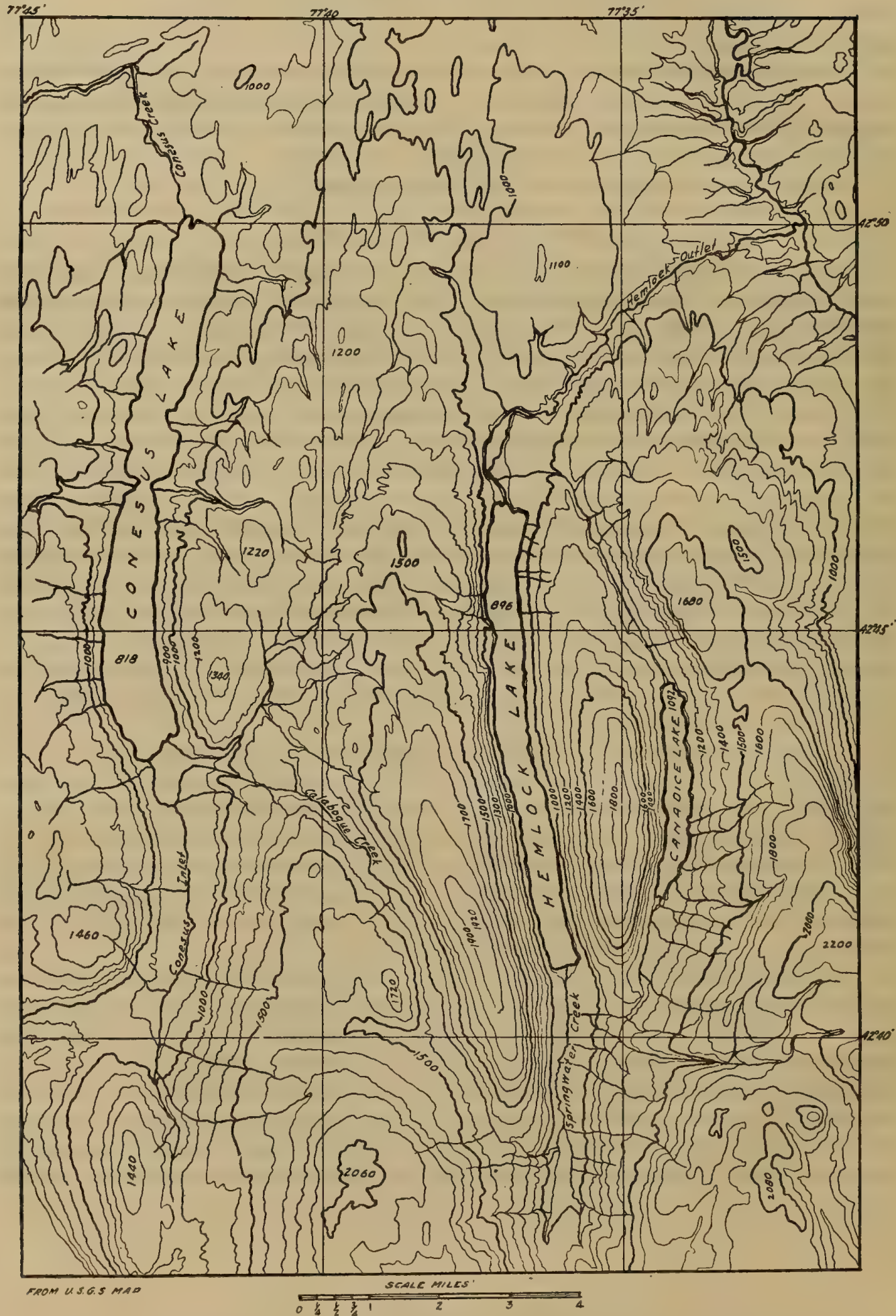

Fig. 3.-Contour map of western lakes of the Genesee Basin from topographic sheets of the United States Geological Survey. Scale about $x: 155,000 ; x$ inch $=2.5$ miles; $I \mathrm{~cm} .=1.6 \mathrm{~km}$. Contour interval roo feet. Elevations in feet above the sea level. Numbers on tops of hills indicate highest contour shown on United States Geological Survey map. The height hetween Canadice and Hemlock Lakes is Bald Hill; that west of Hemlock Lake is Marrowback Hill. 
of the lake. There are, therefore, no deltas built into the lake, but the steep wall of the valley rises immediately from the water on both sides of the lake.

The outlet of Hemlock Lake is controlled by a dam, which may raise the water to a height of about . 6 meters ( 5 feet) above its natural level. No hydrographic survey has been made of the lake. This is the more regrettable since the form and topography of the lake adapt it admirably to the study of the temperature seiche. Not only is the lake straight and of uniform breadth and depth, but the shape and depth of the valley are such that all winds that affect the water must blow parallel to the long axis of the lake.

The maximum depth of the lake as found by us was 27.5 meters ( 90 feet), and this was said by the officials of the Rochester water department to be the deepest water of the lake. The observations on Hemlock Lake were made near the middle of its length.

The transparency in I 910 was 4.7 meters.

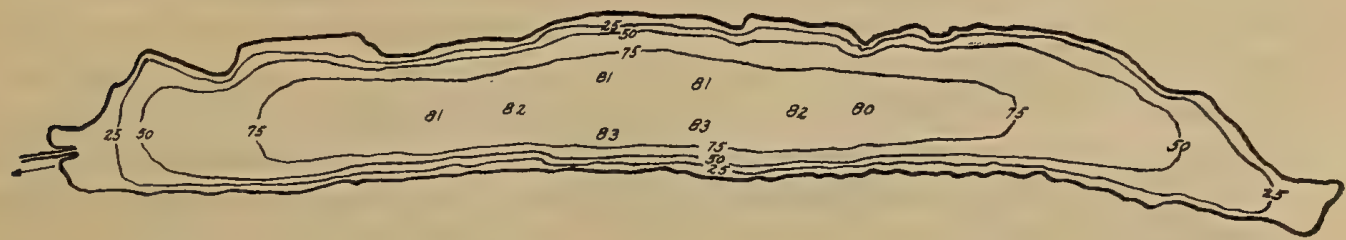

FiG. 4.-Hydrographic map of Canadice Lake. From survey by city of Rochester department of water supply. Contour interval, 25 feet. Scale, about $x: 64,000$. Note the steep sides and flat bottom of the lake. The outlet of the lake is at the north end.

Canadice Lake (fig. 4) is the smallest of the lakes which we visited and the only lake of the Genesee Basin which has had a hydrographic survey. This was done with great care by the department of water supply of the city of Rochester, whose officials were so kind as to place their maps at our disposal.

The valley of Canadice Lake is a simple trough, with smooth steep walls, almost exactly like the valley of Hemlock Lake, though the eastern slopes of Canadice Valley carry somewhat larger streams and have cut somewhat deeper into its sides. The slopes under water are even steeper than those above it and the ratio between the maximum and the mean depth of the lake (see table $\mathrm{I}$ ) is considerably greater than for any other lake. More than three-fourths of the maximum depth must be passed before the plane is reached whose area is one-half that of the surface. In correspondence with this relatively great depth and volume Canadice Lake shows a biological character more resembling that of the larger lakes than does any other of the smaller lakes. It carries a good deal of oxygen to the bottom. The temperature of the deep water is low in spite of the fact that its total gains of heat are higher than would be expected from its area.

The lake was visited once and observations were made near the north end. The transparency of the lake was 4 meters.

For the details of the hydrography of the lake, see page 597. 


\section{TEMPERATURES.}

GENERAL, OBSERVATIONS.

Temperature observations were made in these lakes on the following dates:

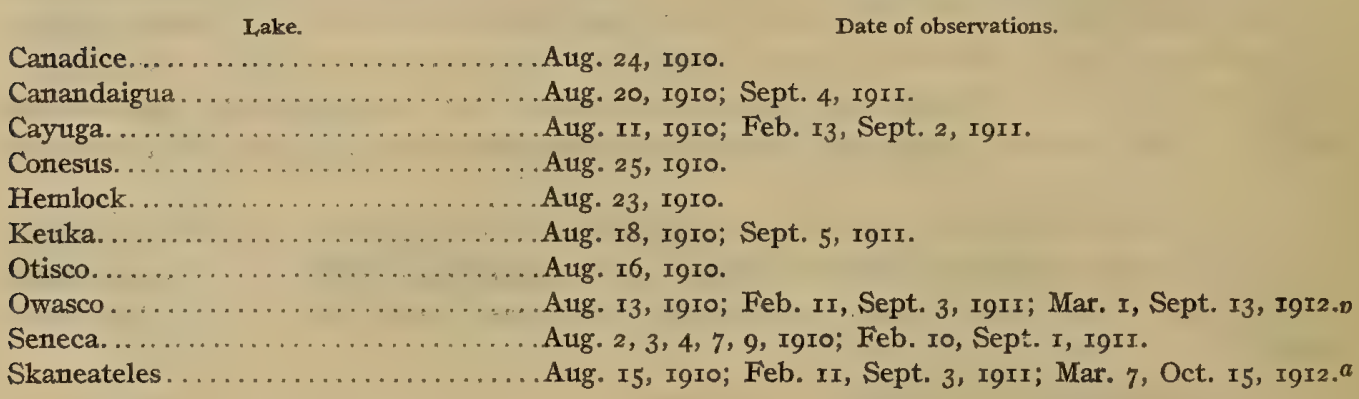

The details of the observations are given in the tables of the appendix (p. 6or). It will be seen that in all of the lakes temperatures were taken in August, 1910, and in four of the lakes series of temperatures were taken only at that time. Two other lakes were visited also in early September, r9I. Four others were visited in both summers and in February, 1911, and two of these also in March, 1912, and in the fall of that year. The attempt was made to secure series of temperatures which would show approximately the maximum summer temperature of the water, and in the case of those visited in the winter, the minimum temperature also. The most important conclusions to be drawn from the observations, as will be shown later, concern the annual heat budget of the lakes and the distribution of the heat in summer.

The study of the New York lakes was made in order to test in larger bodies of water the principles of lake temperatures established for the inland lakes of Wisconsin. Since the phenomena of the Finger Lakes exactly conform to these principles, we have not hesitated to use them as illustrations of these laws, though we should not have deduced the laws from them alone. The full discussion of these underlying principles belongs to the report on lakes of Wisconsin now under preparation, but several of them are briefly discussed in connection with this report.

The following principles are therefore assumed as demonstrated for lakes in the general climatic and topographic situation of the Finger Lakes. It is not asserted that they hold for lakes situated under other conditions.

I. Every deeper lake has an equithermal period of several weeks in summer, covering as a maximum August and parts of late July and early September, during which the daily gains and losses of heat nearly balance, when the mean temperature of the lake is substantially constant, and when the epilimnion has a nearly constant thickness. A series of observations taken on one day during this period gives a good idea of the general temperature condition of the lake during the whole period.

a The observations of $19 \times 2$ were made by Mr. J. W. Ackermann, superintendent of water works, Auburn, whose kind assistance is herewith acknowledged. 
2. This condition recurs annually, unless under extraordinary conditions of weather, and the annual differences are not great enough to invalidate or seriously weaken general conclusions based on a single year.

3. A series of temperature observations taken in summer under good conditions of weather, and near the center of oscillation of a lake of regular form, gives a fair idea of the mean temperature of the water of the lake.

4. In lakes of this type, all heat gained which is above $4^{\circ}$ and which is found below a depth of 5 meters, has been conveyed there by mechanical agencies; by currents due, directly or indirectly, to wind. Such heat may be called wind-distributed heat. The same is true of most of the heat found between the depth of $\mathrm{I}$ meter and 5 meters. There is as yet no clear evidence that thermal convection currents aid appreciably in carrying heat downward.

5. The thickness of the epilimnion in lakes of different size and otherwise comparable is a fair measure of the relative efficiency of the wind in distributing heat.

SUMMER TEMPERATURES.

As a result of the normal conditions of weather acting on the lake, it divides in summer into three well-known thermal regions.

I. The epilimnion, a stratum in which the temperature is nearly uniform. The surface is usually the warmest part of the stratum. Under summer conditions the fall of temperature in this region varies from a small fraction of a degree to several degrees. The amount varies chiefly with the temperature of the surface and is therefore subject to diumal variation. It is greatest in the afternoon of a hot, calm day; least in the early morning, when the surface may be cooler than the stratum immediately below it.

2. The thermocline, the stratum of rapid cooling, whose limits are somewhat arbitrarily fixed as those of the region in which the fall of temperature equals or exceeds I degree per meter. Its upper limit is usually fairly definite, but below it grades off into the third region and its lower limit is often somewhat arbitrary. From 60 to 70 per cent, or even more, of the fall in temperature is usually found here. The thermocline is subject to variation in thickness under the action of wind and of oscillations due to temperature seiches. At the center of the lake where these influences are least felt, it is still subject to oscillations of considerable amount. These may cause an increase or decrease of the thickness of the thermocline, and at its bottom isotherms may be drawn in or excluded by its extension or contraction.

3. The hypolimnion, the region below the thermocline and extending to the bottom of the lake. In this region the temperature falls slowly, the temperature curve soon approaching a straight line. The amount of fall in this region varies greatly according to the conditions of the spring warming. It may be less than $3^{\circ}$, even in a layer more than 60 meters thick, or it may be as much as $6^{\circ}$. It may be as little as i I per cent of the total fall in temperature or it may be nearly 40 per cent. 
BULLETIN OF THE BUREAU OF FISHERIES.

TABle III.-SUMmer TeMperatures OF THE NEW YORK LAKES.

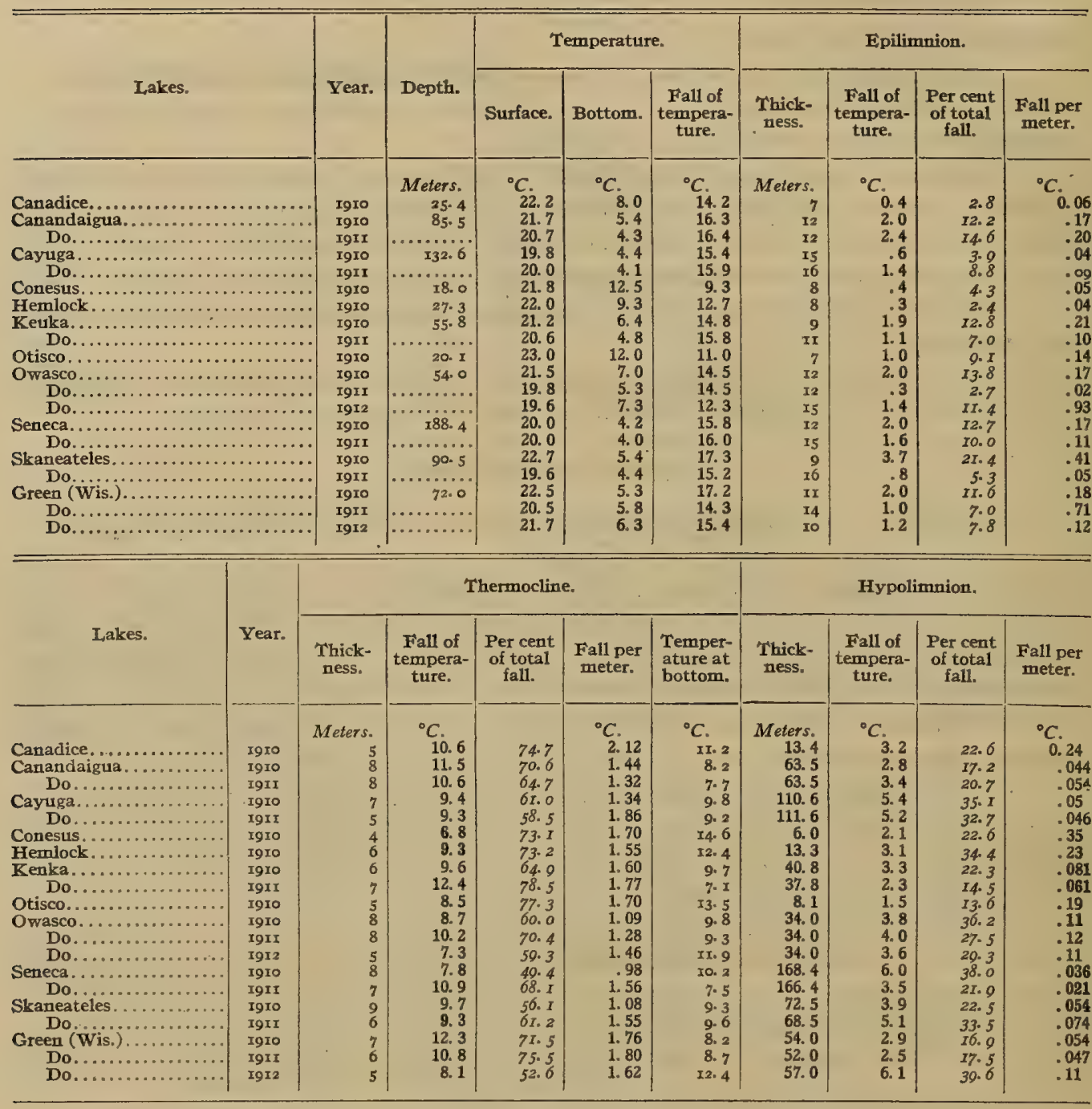

Figures 5 and 6 give the temperature curves of the six major lakes to the depth of 50 meters for the summers of I9Io and I9Ir. All of them show the typical midsummer temperature curve of an inland lake. They show a striking resemblance to each other in form and there is less difference in the relative thickness of epilimnion and thermocline than might be expected. Keuka Lake departs in both years most widely from the others, and reasons can be assigned for this fact, but any of the other lakes might conceivably occupy any place in the set of curves. This close resemblance is an indication of the fact that the various lakes have absorbed nearly equal amounts of heat. The same fact is also indicated by the lower parts of the curve, which indicate in general 
warmer water for the shallower lakes. Keuka and Owasco Lakes, which hardly exceed 50 meters in depth, are the warmest at the bottom in 19ro. Skaneateles Lake accompanies them in I9II, but the observations were not at the best place. (See p. 540.) Seneca and Cayuga, the deepest of the lakes, are the coldest, and are both at about the

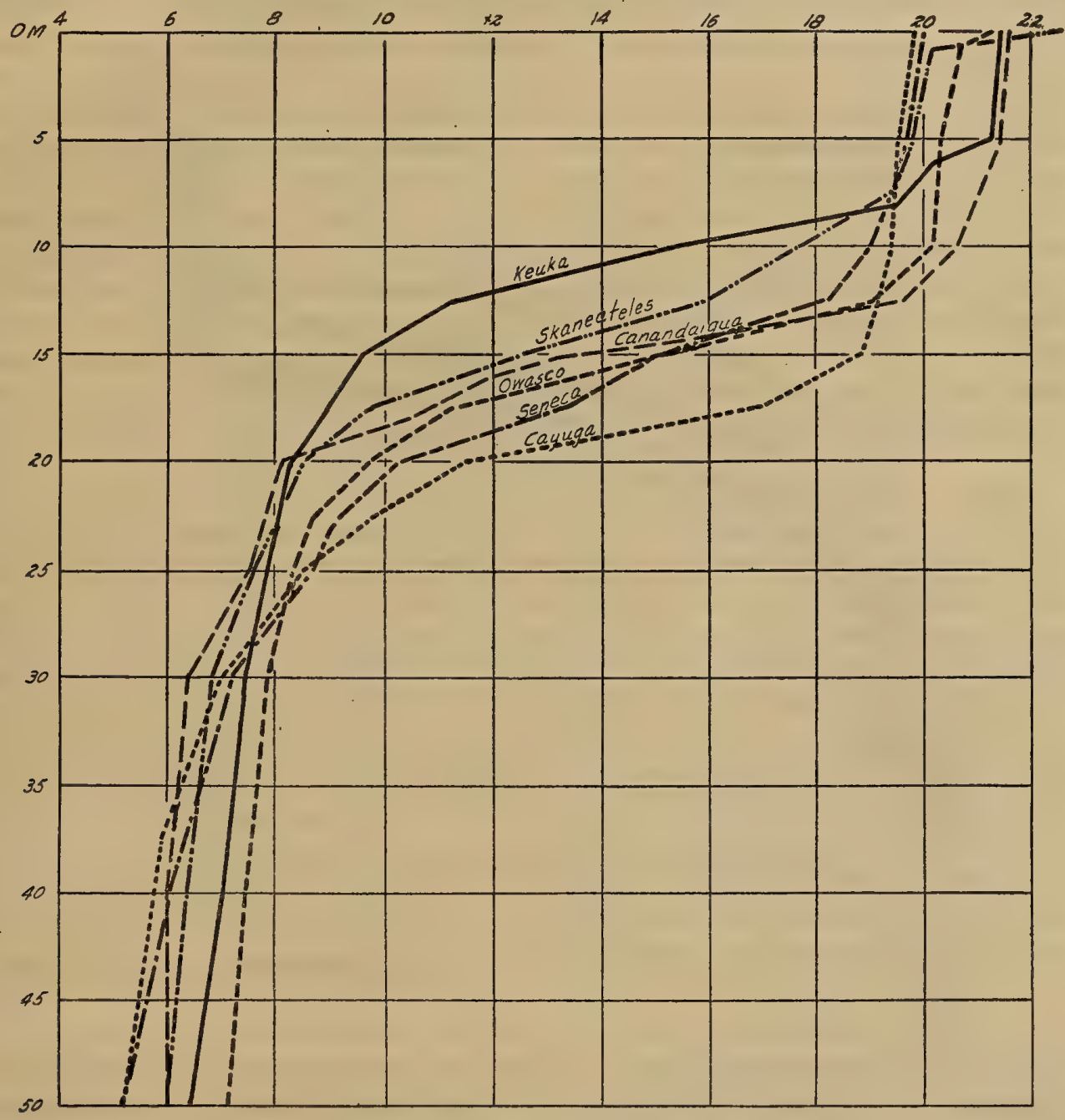

Fig. 5,-Temperature curves of the six major Finger Lakes in 19ro, shown to the depth of 50 meters. One vertical space represents 5 meters in depth; one horizontal space represents $2^{\circ}$ C. See p. 548 .

same temperature. These facts of bottom temperatures should be expected. on general principles, as stated by Wedderburn. ${ }^{a}$ But the resemblance of the upper part of the curves is greater than would be anticipated.

a Wedderburn, E. M.: Temperatures of Scottish lochs. Bathymetrical survey of the fresh-water lochs of Scotland, vol. I, p. 97. Ėdinburgh, rgro. 
Surface and epilimnion. - The table shows that the surface temperatures of these lakes varied about as would be expected considering their size and depth. During the time necessary to visit the lakes no considerable depression of temperature occurred which would cool the surface, so that the observations in the different lakes are comparable.

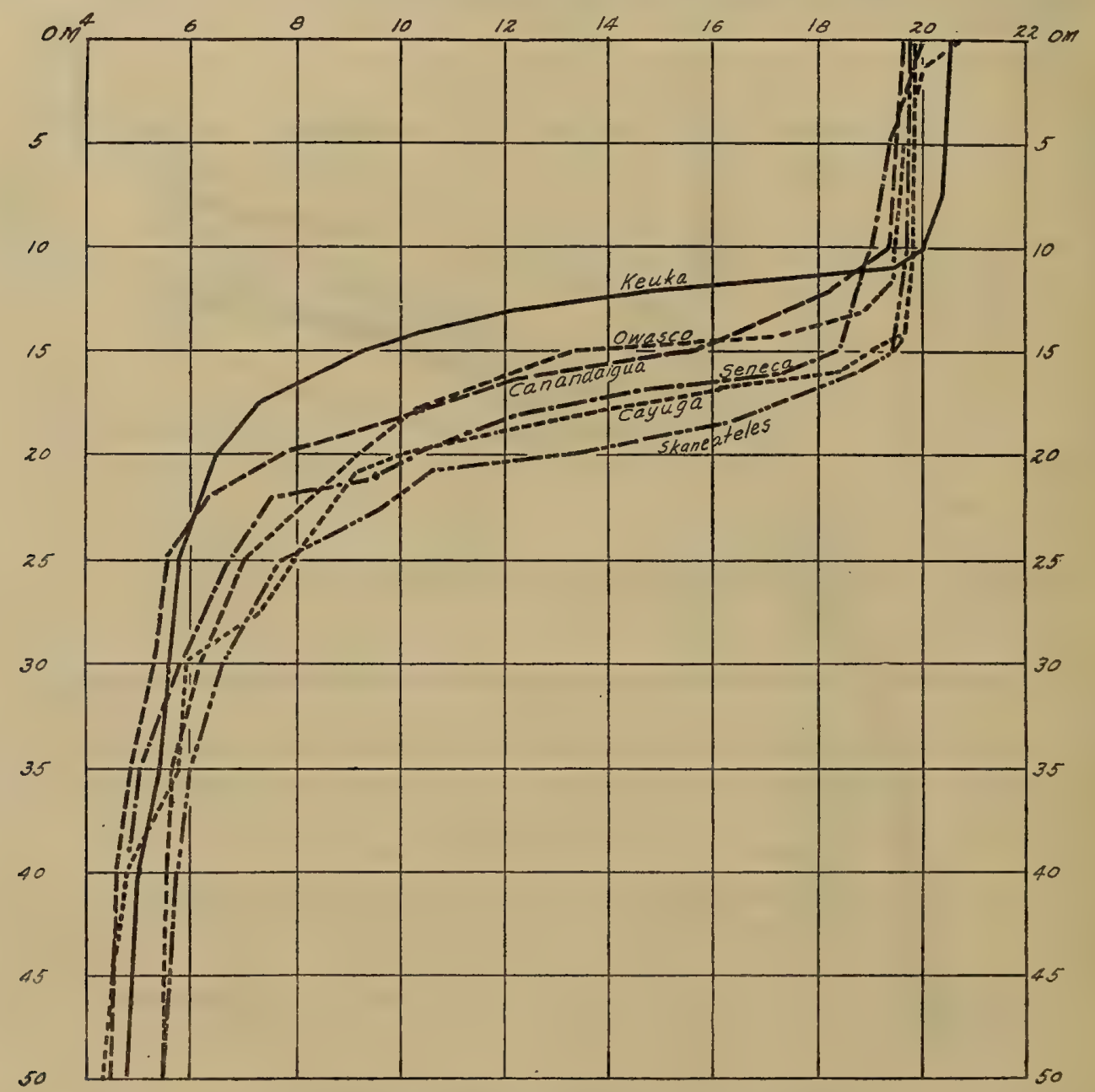

Fic. 6. -Temperature curves of the six major Finger Lakes in Igrr, shown to the depth of 50 meters. One vertical space represents 5 meters in depth; one horizontal space represents $2^{\circ} \mathrm{C}$. See p. 548 .

During 19 Io the weather was without a cold period until after the first week in September, and in I9I I the first weeks of September were among the warmest of the season, and no marked depression of temperature occurred during August. There is therefore every reason to believe that the series represents the approximate maximum of the season, a maximum which would be surpassed during a succession of calm, hot days, but which 
would not be exceeded in ordinary summer weather. The surface temperature of steep-sided lakes is necessarily lower than that of lakes with shallow margins, and that of the smaller lakes is, for similar reasons, usually higher than that of the larger.

If we consider the six main lakes only, the mean thickness of the epilimnion in rgro was II.5 meters (9 to $\mathrm{I}_{5}$ meters); in I9II it was $\mathrm{I}_{3.7}$ meters (II to 16 meters). In twelve series of temperatures taken in six lakes in I9Io and I9II, the mean thickness was 12.6 meters. No constant difference due to area or depth appears in the list. Keuka Lake had the thinnest epilimnion in both years, a condition undoubtedly due to the fact that it is narrower than any of the other lakes, and that its shores are on the whole higher and steeper than the others. The wind has therefore less opportunity to distribute the warm surface water. The effect of the same cause is found also in the fact that the annual gains of heat in Keuka Lake are the smallest of the six, as will be shown later, and also in its relatively low bottom temperature. Cayuga Lake indicates rather doubtfully a tendency toward an epilimnion a little thicker than the others. I believe this will be found to be the fact when a sufficient number of observations have been made. There is nothing conclusive, however, in the observations given, as they are quite within the range of accidental variation.

I have added to the table of New York lakes the facts for Green Lake, Wisconsin, which lies in a climate not essentially different from that of central New York. These show that the epilimnion in these years had a thickness almost exactly the same as those of the New York lakes. Green Lake has a length of about II.4 kilometers while those in New York vary from about 18 kilometers to more than 60 kilometers. Their mean breadth is of the same order of magnitude as that of Green Lake, and is therefore relatively less. This, however, makes little difference in the effect of wind in favor of Green Lake, since the long axis of Green Lake lies across the prevailing direction of the wind, or at least obliquely to it, while the New York lakes are much more nearly parallel to it. This fact, coupled with the greater length of the lakes, should make the influence of the wind as great for any of the lakes and much greater for some of them. In Seneca Lake, for instance, the currents induced by wind are often so strong that even when no wind is blowing a deep-sea thermometer will not sink perpendicularly unless extra weight is attached to the line. This condition never occurs in the Wisconsin lakes.

It appears, therefore, that I 2 to I 5 meters is about the maximum thickness which can be expected in the epilimnion of an inland lake before the temperature of the water begins to decline. Such a statement applies only to lakes which lie under the topographic and climatic conditions of the lakes discussed. Variations are found and the thickness must be measured by meters and not by centimeters; but in any ordinary season the observer may confidently expect to find the thermocline about where he found it in previous years. It may be a little higher or lower, but the thickness of the epilimnion in the same lake will always be of the same order of magnitude.

Thermocline.-We understand by the thermocline that thermal region of the lake lying immediately below the epilimnion, in which the temperature falls rapidly. This 
word was proposed by the senior author of this paper in 1897 as an equivalent for Richter's term "sprungschicht," and was so defined. " In this sense it has been included in the New Oxford Dictionary and also in the Century Dictionary. In I91 2 Wesenberg-Lund ${ }^{a}$ redefined the word so as to restrict it to the meter of maximum fall of temperature, retaining the word "sprungschicht" for the larger stratum. We see no sufficient reason for this change, which would force a writer in English to invent a new equivalent for "sprungschicht" or else employ some long paraphrase for that term, such as Wedderburn's "discontinuity layer." We therefore retain the term "thermocline" in its original sense, in which it has been adopted by English dictionaries.

The terms "epilimnion," "thermocline," and "hypolimnion" are derived from that thermal condition of the lake which extends from early midsummer to the beginning of the homothermal period in autumn. Like all conditions that arise as a result of growth, this one comes on gradually, and its beginnings are not easy to define. In this paper the situation is treated and discussed as it appears in late summer during the equithermal period. Table II shows that the thermocline in the six major lakes (or seven with the addition of Green Lake, Wis.) was from 5 to 9 meters thick; that the fall of temperature in it was from $7.3^{\circ}$ to $\mathrm{I} 2.3^{\circ}$; and that this fall represented from about 40 per cent to nearly 80 per cent of the difference of temperature between the surface and the bottom of the lake. In the smaller lakes it is 4 to 6 meters thick, but contains a decline of temperature nearly as great as that of the larger lakes and one which represents a higher average percentage of the total fall.

These figures have little significance in their details; since, as already stated, the thermocline is subject to constant alterations of thickness due to the oscillations of the water of the lakes. These changes may continually and rapidiy alter the average rate of fall of temperature, and the total number of degrees included in the thermocline; the position of the meter of maximum descent of temperature, and the amount of fall included in it. The figures therefore represent in their range of variation about what might be expected in lakes of this size under average conditions of summer weather. Any of the major lakes might, under suitable conditions, show a thermocline like that of any one on the list.

The general result, however, shows more than the single observation. The thermocline lies deeper in the larger lakes than in the smaller, and on the average is over I.5 meters thicker. This region represents the stratum in which the effects of the direct wind circulation die out, just as the epilimnion is the stratum in which a direct wind circulation is made possible by the cooling effect of night and of cool periods. It might be thought that in the larger lakes the greater influence of the winds would make the descent of temperature in the thermocline more gradual. This is true to a limited extent, as is best seen in the thermocline of Seneca Lake. It is more evident when large lakes are compared with very small ones. In general, however, the greater effect of wind in the larger lakes is rather to increase the thickness of the epilimnion than to

a Brönsted, J. N., and Wesenburg-I,und, C.: Chemisch-physikalische Untersuchungen der dänischen Gewässer. Internationale Revue der gesamten Hydrobiologie und Hydrographie, bd. IV, Igrז, Biologisches Supplement, sr. $\pi$, p. 26z. Leipzig, IgII- $x_{2}$. 
modify the character of the thermocline. This means that as soon as the thermal resistance to mixture is strongly felt the work of the wind is rapidly cut off, more slowly in the larger lake, but not at all in proportion to its increased size.

The last column in table III under the head of thermocline gives the temperature at the bottom of that region. It will be noted that these temperatures differ and show no relation to the temperature of the ground water.

Hypolimnion.-In the hypolimnion the temperature falls at first rapidly; then more slowly, the curve approaching a straight line. The lower part of the very deep lakes may have a temperature nearly, or quite, the same through a considerable thickness of water. The division between thermocline and hypolimnion is not very definitely marked and is variable. The division of heat between these two regions is correspondingly uncertain.

If similar climatic conditions are assumed, the temperature at the bottom of the lake varies with two factors, the size and the depth of the lake. On the size of the lake depends the efficiency of the wind until a certain area has been reached. This we have placed at the length of about ro kilometers for lakes with a mean depth of 30 meters or more. Six of the Finger Lakes reach or exceed this area and depth, and therefore have the maximum bottom temperatures possible under the conditions of the season of observation. Two of the lakes, Canadice and Otisco, are both too small and too shallow to permit the wind to have the maximum effect; and two others, Conesus and Hemlock, are too shallow.

In the six larger lakes the bottom temperature in general follows the depth of the lakes, the shallower lakes having a higher temperature. In I 9 Io it varied from $7.0^{\circ}$ in Owasco Lake to $4.2^{\circ}$ in Seneca Lake; and in I9I I from $5.3^{\circ}$ to slightly above $4^{\circ}$ in the same lakes. Owasco and Keuka Lakes have nearly the same maximum depth, but the bottom temperature of Keuka Lake is decidedly lower than that of Owasco in spite of its much greater length. This is due to the same cause that produced the thin epilimnion in Keuka Lake (p. 55I). Skaneateles and Canandaigua Lakes, which have substantially the same length and depth, have also closely similar bottom temperatures, while the two larger and deeper lakes, Cayuga and Seneca, follow in the order of their depth.

In I9I I all of the bottom temperatures were lower than in r9Io. The difference was almost the same in Owasco and Keuka Lakes (I. $7^{\circ}$ and $1.6^{\circ}$, respectively), and the same is true for Skaneateles and Canandaigua Lakes (I.0 and I. $I^{\circ}$, respectively). Cayuga Lake was about $0.3^{\circ}$ lower in I III and Seneca Lake was between $0 . I^{\circ}$ and $0.2^{\circ}$ lower. In I9I I the temperature of Seneca Lake below Ioo meters was very little above $4^{\circ}$. The mercury was slightly above the mark, but the reading would be less than $4.05^{\circ}$. Our deep-sea thermometer was not provided with an accessory thermometer for giving the temperature of the mercury at the time of reading and so making correction for the expansion of the mercury in the tube. It is therefore not improbable that the true temperature of the bottom water of Seneca Lake in I 9 I I was slightly below $4.0^{\circ}$.

The widely different temperatures of the hypolimnion in I9IO and IgI I undoubtedly reflect the difference of the weather in the spring of those years, though there are no 
direct observations to support the conclusion. In r9ro March and April were warm and May was unusually cold. The average of reports of the weather stations at Auburn, Geneva, Hemlock Lake, and Ithaca, all of them in the Finger Lake district, show that April, x910, was $2.7^{\circ} \mathrm{C}$. warmer and May $1.7^{\circ} \mathrm{C}$. cooler than the average temperature for those months. In I9I I these conditions were exactly reversed; March and April were somewhat, but not greatly, colder than the average, and May of that year was exceptionally warm. The average of the four stations named shows for April a deficiency of $0.4^{\circ} \mathrm{C}$. and for May an excess of $4 . \mathrm{I}^{\circ} \mathrm{C}$. This excess was more noteworthy since the first five days of the month were much colder than the average for that period.

The high temperatures of the hypolimnion and the bottom water in rgro and their lower condition in I9I I were due to these differences in the weather. The exceptional heat of May, I9II, caused the surface water to warm so rapidly that it prevented the distribution of heat to the deeper water, while the earlier part of the season was so cool that the lakes had warmed but little when the warmer weather began. In IgIo the high temperatures of March and April came while the lakes were still below $4^{\circ}$, or close to that temperature, and the cool weather in May favored the distribution to deeper water of the heat acquired earlier or during that month.

Owasco Lake in I9I 2 had a bottom temperature slightly higher than in 1910 , and that of Skaneateles Lake was much above that of riro (see p. 565). No definite general features of the weather in spring can be assigned as the cause; and this is commonly the case, since bottom temperatures ordinarily depend on special events in the weather rather than on its general character.

A word may be said regarding the temperature seiche as an agent for warming the hypolimnion. No observations have been made as yet which show that the temperature seiche has any noteworthy influence in this direction. The warming of the bottom water is effected chiefly in the early part of the season, before the thermocline is established, and while the differences in temperature between surface and bottom are slight. Under these conditions the direct effect of wind is great and that of the temperature seiche is nonexistent or feeble. When the epilimnion has been formed and the temperature seiche can operate vigorously, the thermocline forms the zone of friction, or mixture, of the cooler and warmer water. Its mean descent is very slow, so far as observations have told the facts, after it gets far enough down to escape the ordinary direct influence of the wind, until it begins to sink again in consequence of the autumnal cooling of the lake. Thus it appears that but little work is done by the tenperature seiche in carrying the warm water downward, and this work, whether great or small, is mainly expended in extending the lower limits of the epilimnion and has little, if any, effect on the lower water.

\section{WINTER TEMPERATURES.}

Seneca and Cayuga Lakes are rarely frozen over except at the ends, and to a small extent along the shores. Local records show that Cayuga Lake was completely frozen in the following winters: $1796,1816,1818,1836,1856,1875,1884,1904,1912 .{ }^{a}$ The 
length of time that the ice remained is not stated. Seneca Lake has the following record:
1855, closed February 24, opened March I $_{5}$
1875, closed February 9-10, opened March 14.
I885, closed February 24, opened March 6.
I9I2, closed February II, opened March ro.

Partially closed: $1856,1865,1904$. Skimmed over with thin ice in spring: May 7,1829 , May 4, 1856, May 5, I86I, May 15, I872, May 6, I873, April 26, 1884. ${ }^{\circ}$ We are not sure that this spring freezing extended over the entire expanse of the lake.

The other lakes freeze regularly, though the central parts of deeper ones may remain open in mild winters. Freezing usually occurs in January or early February.

Table III gives the important facts for the winter observations made on these lakes. The surface temperature of the lakes which were frozen is that of the water which rose in a hole cut through the ice. The temperatures of the frozen lakes are no doubt subject to less error than are those taken in the open water and more closely represent the mean temperature of the water of the lake. But the lakes were visited during a rather warm and calm period, so there is no reason to believe that any are seriously wrong.

The temperature of Owasco Lake seems very low in $\mathrm{xgII}$, but table $\mathrm{xX}$ (p. 560) shows that the lake had lost the same amount of heat per unit of surface as Cayuga Lake. In the same table losses of heat in Seneca Lake seem to be low and those of Skaneateles Lake are high. Yet until we know the range of winter temperatures there is no reason to suspect serious error in either. In I9I I Skaneateles Lake was only partly frozen and the process of cooling was still going on. In I9I 2 the lakes all froze over early on account of the unusually severe winter and this fact would lead us to expect rather high temperatures for the water of the lakes observed at that time.

TABLE IV.-WINTER TEMPERATURES.

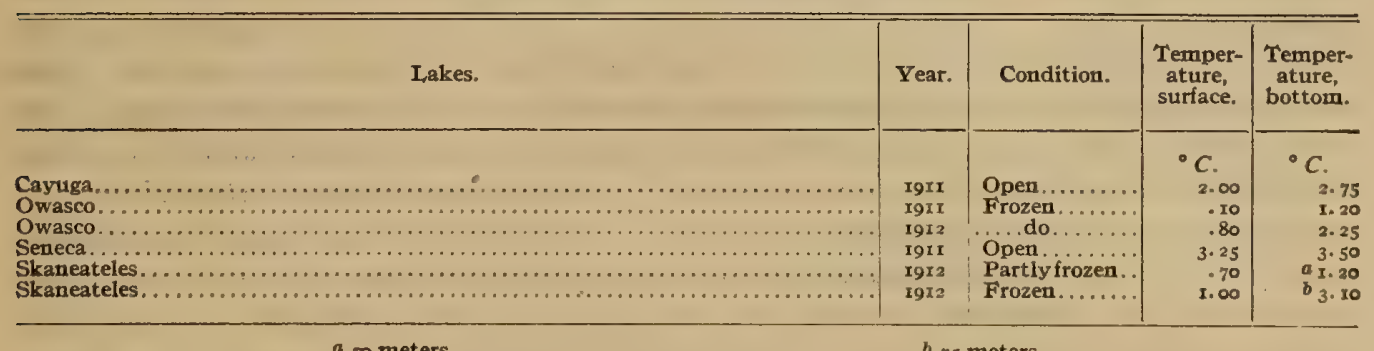

a 50 meters.

b 75 meters.

MEAN SUMMER TEMPERATURE.

From a series of temperatures taken in the deepest water of the lake, the mean temperature of the water of the lake may be computed. If the mean temperature of each stratum is multiplied by the per cent of that stratum in the total volume of the

$46512^{\circ}-14-3$ 
lake and the several products are added, the result will show the mean temperature of the water. This is shown by the following example:

Table V.-Method of Computing Mean Temperature of lake: Canandaigua Lake, august 20, IgIo.

\begin{tabular}{|r|r|r|r|}
$\begin{array}{c}\text { Depth in } \\
\text { meters. }\end{array}$ & $\begin{array}{c}\text { Temper- } \\
\text { ature. }\end{array}$ & Volume. & Product. \\
\hline & & Per cent. & \\
$0-10$ & 21.30 & 0.221 & 4.707 \\
$10-20$ & 14.50 & .184 & 2.668 \\
$20-30$ & 7.40 & .165 & 1.221 \\
$30-40$ & 6.25 & .147 & .907 \\
$40-50$ & 5.85 & .126 & .737 \\
$50-60$ & 5.75 & .094 & .540 \\
$60-70$ & 5.65 & .049 & .277 \\
$70-84$ & 5.45 & .014 & .076 \\
Mean temperature $\left(T \mathrm{Tm}^{\mathrm{s}}\right)=$ & 11.13 \\
\hline
\end{tabular}

These results are, of course, accurate in proportion as the temperatures recorded give a fair picture of the mean temperature of the several strata and in proportion as the hydrographic survey gives a correct account of the volume of the lake. Extreme accuracy can not be claimed in this case for either factor, but the results are approximately correct.

The question has been recently raised, whether a single series of temperatures can give a correct idea of the mean temperature of the water of the entire lake. In a recent review Halbfass ${ }^{a}$ states that the presence of the temperature seiche makes clear "die Bedeutungslosigkeit einer Beobachtungsserie in vertikaler Richtung in einem vereinzeltem Punkt eines Sees." This statement is entirely too strong, according to my observations, and, indeed, Halbfass in a later paper modifies the statement. No one in recent years would have believed that a single set of observations, or even numerous sets, made at one end of a lake would show the mean temperature of the water, least of all would such a series be trusted if taken during a windy period. This was true long before the temperature seiche was known. Our recent knowledge of the temperature seiche shows that conditions similar to those called out directly by wind may exist at almost any time on account of the oscillations following the influence of winds; hence comes need for increased caution; but it is by no means clear that a single series of temperatures taken under ordinary weather conditions, at or near the center of oscillation of a lake, are "without significance." No one would claim minute accuracy for a result based on such a series; but there is as much reason as ever to believe that from such a series there can be derived a temperature for the water of the lake, which though not minutely exact, is approximately correct-close enough for all purposes of a general discussion. The result is of the right order of magnitude, as the following instances show.

We can not find that many observers have taken series of temperatures with a view of testing the accuracy of results derived from a single series near the middle of

a Halbfass, W.: Intemationale Revue der gesamten Hydrobiologie und Hydrographie, vol. v, x9xa, p. 47x, Jan., I913. 
the lake as compared with a mean temperature derived from numerous sets of observations, but we have done much work with this end in view. In the New York lakes, series of three or four sets of observations were taken along the axes of three lakes. The results are shown in the following table. In each lake the stations are named from south to north; the mean temperature is computed to the depth of the water at the end stations; and the result from the center station is placed in italics.

TABLE VI.-MEAN TEMPERATURES OF IaAkES AS COMPUTED FROM THE SEVERAL SERIES OF OBSERVATIONS, AND FROM THEIR MEAN.

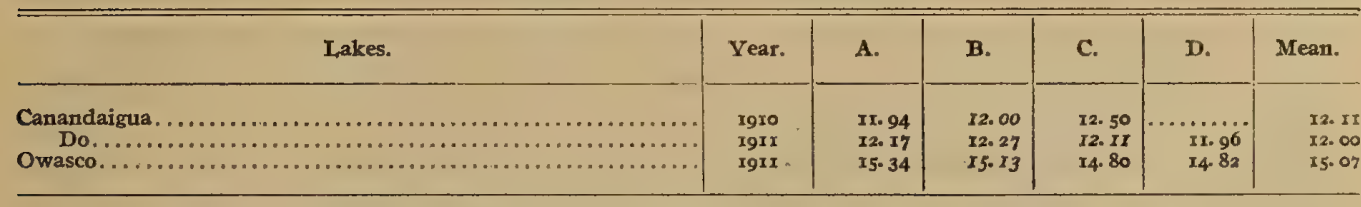

EXPLANATION OF TABLE,-The first series is computed to the depth of 50 meters; the second, to 40 meters; the third, to 30 meters, this being the depth of the lake at the end stations. Figures in italics indicate the center station.

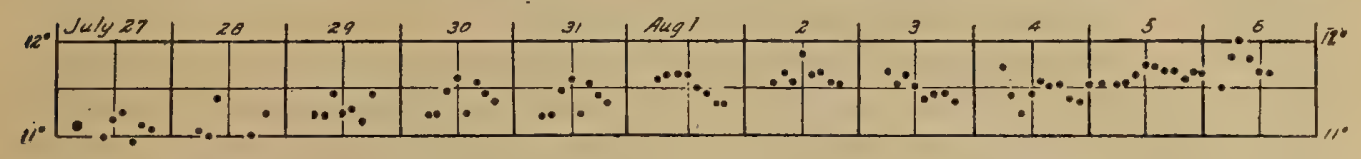

FrG. 7.-Mean temperature of Green Lake, Wis. From observations at center of lake in rgrr. Computed to depth of 60 meters, the maximum depth at the center. All temperatures lie between $I I^{\circ}$, or slightly below, and $\mathrm{I}^{\circ}$. 'The position of the dots along the horizontal axis of the diagram indicates the day and hour of the observation.

The above table shows that the mean temperature deduced from the center series differed by less than I per cent from that derived from three or four series. Similar results have been reached in more numerous cases in the Wisconsin lakes. In Lake Mendota in I9I I, I9I2, and I9I3, observations were regularly taken at ro to I 2 different stations so placed as to give the distribution of heat in this lake, which is 9 kilometers long, 6 kilometers wide, and 24 meters deep. In series taken during these years at approximately regular intervals of time on 36 dates from June to September, the maximum departure of the mean temperature derived from the ro or 12 series from that derived from the single series at the center was less than 3 per cent and this was reached only once; and the mean departure was less than I per cent. The maximum differences were in June, when the lake was warming, and the distribution of heat was more irregular than later. In July, August, and September, the maximum departure was about I. 5 per cent and the mean 0.8 per cent.

In five similar series taken in Green Lake, Wisconsin, the maximum departure of the mean temperature derived from the middle series and that derived from all was 5 per cent and the mean was less than 2 per cent.

From July 26 to August 5 , 191 I, observations to determine the temperature seiche were made on Green Lake. During this work 83 series of temperatures were taken at the middle station. The results are shown in figure 7 . 
The diagram shows variations between the several observations; and also displays a slow but steady warming of the lake, as would be expected at that date. But for all purposes of a general discussion any one of these results might have been taken as representing the temperature of the lake quite as well as their mean, or as the mean of the several series of observations taken during this period at points along the whole length of the lake.

This general result has been found to be true for observations taken at this time of year in all lakes during many years. It is therefore fair to conclude that the mean temperature of the water of a lake of simple form in late summer may be derived from a single series of observations taken at or near the center of oscillation of the water.

In the New York observations the least satisfactory series is that of Skaneateles Lake in I $9 I \mathbf{I}$, when time did not permit me to go to the center of the lake. Seneca Lake offered the least favorable situation for taking the temperature in that the deepest water of this lake lies to the south of the center, about one-third of the distance from the south end. At so great a distance from the middle the water is subject to considerable oscillations. During i9 Io five series of temperatures were taken from August 2 to August 9. The mean temperature as deduced from the separate series ranged from $7.37^{\circ}$ to $8.05^{\circ}$, with a mean of $7.71^{\circ}$-a variation of about 4.5 per cent on each side of the mean. This variation was wholly due to variations in the apparent distribution of the heat and not to actual changes of temperature in the lake, since the temperature of the o-ro meter layer was practically constant at $19.5^{\circ}$ to $19.6^{\circ}$. The $10-20$ meter stratum varied from $13.2^{\circ}$ to $16.3^{\circ}$-enough to give a difference of $0.28^{\circ}$ in the mean temperature. The $20-30$ meter stratum varied from $7 \cdot 3^{\circ}$ to $10.2^{\circ}$, which would give a variation of about $0.25^{\circ}$ in the mean temperature. Thus the oscillations in the stratum between Io meters and 30 meters account for about 80 per cent of the range of the temperature, and relatively little is due to changes above or below the depths named. This variation is considerably greater than would be expected in case of the other lakes in which temperatures were taken at the center, or several series were taken along the axis of the lake.

The following table shows the mean temperatures of the lakes as deduced from the observations taken, both for summer and winter.

Table VII.-Mean Temperature of The, Water of The New York Lakes, as ObServed in SUMMER AND IN WINTER.

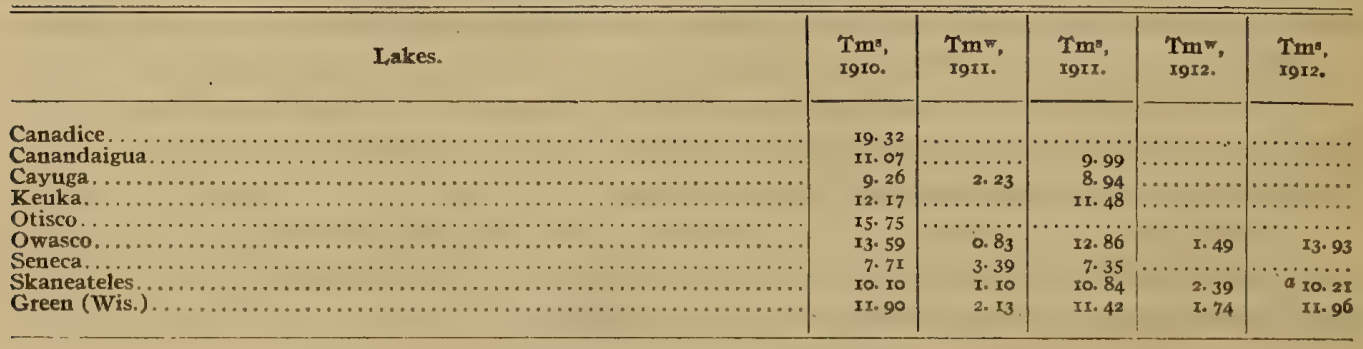

a Oct. 18 , and therefore below Tms. See p. 565 . 
Table vir shows that the mean temperature of the deeper lakes is lower in summer and higher in winter than that of the shallower, and that the difference between summer and winter temperatures (or the annual range of temperature) is smaller in the case of the deeper lake. This must obviously be true if lakes are similar in other respects but differ in depth. ${ }^{a}$ The relation in these lakes between area, depth, and mean temperature is much more interesting than this simple statement indicates and will be described on a subsequent page.

\section{ANNUAL HEAT BUDGET.}

Forel was the first limnologist-first in this as in so many other matters-to determine the amount of heat absorbed by a lake. He computed the number of calories necessary to raise a column of water of unit base in the deepest part of the lake to the temperature found in summer and he compared on this basis the amount of heat gained by different lakes. This method obviously permits accurate comparison only between lakes of similar area and depth. Halbfass in 1905 improved the method in that he determined the mean temperature of the whole mass of the water of the lake. Knowing the volume of the water he was able to compute the total number of calories contained in the lake and also those gained or lost by the lake as it warmed or cooled. In an elaborate paper he gave the result of this method as applied to many European lakes. ${ }^{b}$ If this method is employed it is still necessary to select for comparison lakes of similar area and volume.

In our judgment, if the heat budgets of lakes are to be compared at all, it is best to employ units of measurement of such a character that all lakes may be compared with each other, and such that this comparison may, if possible, reveal the relation of area and depth to the amount of the heat budget as well as the relation of geographical position and climate. Since all heat is taken in and given out by the surface of the water it seems best to us to express the amount of heat in the water and its variations in terms of calories per unit of that surface; and on the whole we have decided to employ the same units as those used by the meteorologist for measuring the energy received by the earth from the sun-the gram-calorie and the square centimeter.

If the mean temperature of the water of a lake is known, it is easy to compute the amount of heat which was received by the lake in order to produce this temperature. If the mean temperature of the water is multiplied by the mean depth in centimeters, the result will be the number of gram-calories which the lake must receive on each square centimeter of its surface in order to raise the temperature of the water from $o^{\circ} \mathrm{C}$. to the temperature observed. The following table gives this result for the six major New York lakes and also for Green Lake, Wisconsin.

\footnotetext{
a For a clear statement of this see Wedderburn, E. M., Temperatures of Scottish lochs, in Bathymetrical survey of the fresh-water lochs of Scotland, vol. 1, p. 97, r9xo.

b Halbfass, W.: Ërgebnisse neuerer simultaner Temperaturemessungen in einigen tieferen Seen Eiropas. Petermanns Mitteilungen, 2910, bd. II, D. 59.
} 


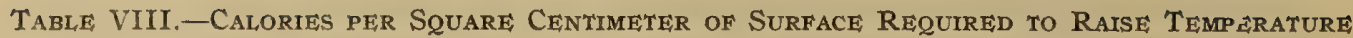
OF WATER OF LAKE FROM ZERO TO SUMMER TEMPERATURE.

\begin{tabular}{|c|c|c|c|c|c|}
\hline Lakes. & $\begin{array}{c}\text { Dm. } \\
\text { meters. }\end{array}$ & $\begin{array}{l}\operatorname{Tm}^{8} \\
\text { I9I0. }\end{array}$ & $\begin{array}{c}\text { Calories } \\
\text { xgro. }\end{array}$ & $\operatorname{Tm}_{x=1}^{8}$ & $\begin{array}{l}\text { Calories } \\
\text { IgIr. }\end{array}$ \\
\hline
\end{tabular}

It will be seen that the order of the lakes is substantially the same in each year and that the order is that of their depth, as was the case also with their mean temperatures. Keuka, Owasco, and Green Lakes, whose depths are nearly the same, are very close in the amount of heat which they have received. Keuka Lake is the lowest in both years, a result due, like the thinness of the epilimnion, to its sheltered position.

This result represents what may be called the gross heat budget. It can be readily computed but it is of very little value since it does not represent any actual gains of heat. The winter temperature is never as low as zero, and other things being equal, it will be higher in the case of the deeper lake. The most important fact to be known is the annual heat budget of the lake-the amount of heat necessary to raise its water from the winter to the summer temperature-and to determine this we must know both the minimum and the maximum temperature of the water. In case of a lake whose surface freezes, the minimum temperature is that at the time of freezing, although in case of a large lake no great error would result from using any temperature taken during the ice period. In case of a lake that does not freeze, the date and value of the minimum temperature can be ascertained only by a study of the lake during the winter, but a series taken in February will not be far wrong. Such observations were made on four of these lakes in the winter of $1910-1 \mathrm{I}$ and two in the winter of I9II-I2, with the results shown in the following table. The minimum temperature derived from observations taken in a single winter may be compared with the temperature both of the preceding and following summer; and thus two results can be obtained from three sets of observations. This method has been followed in the table.

TABLt IX.-Difference BetweEn Summer and Winter Temperatures of the Several, Lakes. [Annual heat budgets stated in gram-calories per square centimeter of the surface of the lake.]

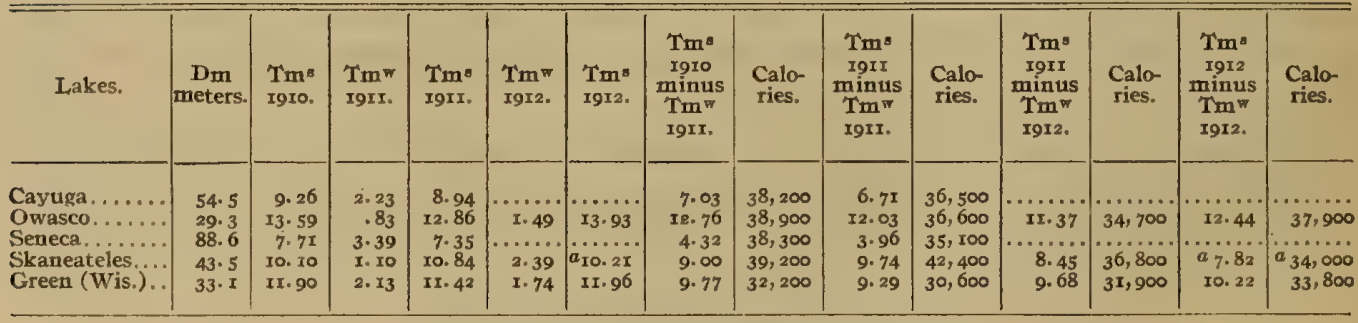

a Taken Oct. I8, and therefore below Tms. See p. 565 . 
The table shows a surprising agreement of the heat budgets of the four lakes compared in г910. The difference between the highest and the lowest result is only $\mathrm{I}, 000$ calories, or less than the heat which may be furnished to the surface of the lake on a bright summer's day. The agreement in I9r is nearly as cl.se, with the exception of Skaneateles Lake, and the temperature of that lake was taken at some distance to the north of the center and may possibly be too high, though this result does not appear in the comparisons for 1912. (See also p. 565.) It would be expected that individual variations much greater than $\mathrm{I}, 000$ calories would occur, since both the maximum and minimum temperatures must vary, and if in any individual case a high maximum and a low minimum came in the same season very considerable differences in the heat budget might be present.

The table also shows that the heat budget of successive years is strikingly similar in the case of the same lake. This is especially noticeable in the case of Owasco Lake. It also appears that the heat budget is independent of the depths of the lakes, and also of their other dimensions within the limits of the lakes compared.

The table seems, therefore, to warrant the following conclusions:

I. The annual heat budget of the major New York lakes lies, in general, between 35,000 and 40,000 gram-calories per square centimeter of surface. It may fall below the minimum or rise above the maximum stated, but in general the figures will fall between these numbers.

2. For lakes of the form and size of these the heat budget is apparently independent of surface dimensions between the limits of 16 and 60 kilometers of length, and is independent of depth between the limits of 30 and 90 meters mean depth. It is probable that a lake much shallower than 30 meters would have a smaller heat budget, but a greater depth than 90 meters would produce no effect.

3. Green Lake, Wis., shows results constantly lower than the New York lakes. This is due rather to a high winter minimum than to a low summer maximum. It seems right, therefore, to place this lake in the same general class as the others and to state the following law:

Inland lakes of the first class include those whose area and depth are such as to permit the maximum annual heat budget possible under the weather conditions of the season. Such a budget for lakes in the climatic and topographical conditions of the eastern United States ordinarily equals or exceeds 30,000 gram-calories per square centimeter of the lake's surface, and ordinarily lies between 30,000 and 40,000 gramcalories. Such lakes, under the conditions stated, will be ro kilometers or more in length and will have a mean depth of 30 meters or more.

This statement applies to lakes of simple outline whose length is five or more times their mean breadth. Lakes of irregular outline can not be compared with those of simple shape, and lakes whose proportions are essentially different from those given are not present in this region in sufficient numbers for study.

4. It is obvious that for more accurate results a careful study of the temperatures of these lakes must be made, so that a mean temperature curve can be determined for each lake and compared with the temperature of the air and with the heat derived from 
the sun. Such a study will warrant far more definite conclusions and will probably modify details of the statement given above; but the work would consume several years and would require the combined efforts of many observers.

\section{WIND-DISTRIBUTED HEAT}

The heat budgets of lakes can also be profitably compared in another way, which avoids the necessity of knowing the winter minimum temperature.

The gains of heat in a lake of the temperate type may be divided in two parts, those below $4^{\circ}$ and those above. So long as the temperature of the water is below $4^{\circ}$, the surface water becomes denser as it warms; it tends to sink and thus carry the heat into the deeper water. The increase in density is small and the movement, if not aided by the wind, would be slow; but, under the meteorological conditions of early spring, gravity and wind together distribute the warm surface water very rapidly through the water of the lake. Thus there results a rapid and uniform warming of the water. During cold periods the lake loses heat; but since the surface water is only slightly warmer, if at all, than the lower strata, and since any cooling of the surface produces an inverse stratification, the losses which occur during such periods and during the night are ordinarily not great. Thus under usual conditions a lake moves rapidly and steadily up to the temperature of $4^{\circ}$ during the spring.

But after this point is reached the situation wholly changes. Increase of temperature in the water means decreased density. Gravity, so far from being an aid to distribution, becomes an opponent; and the wind is left to do substantially the whole work not only without the aid of gravity, but against the resistance which gravity offers.

This resistance is least at $4^{\circ}$ and grows with increasing rapidity as the temperature rises above $4^{\circ}$. It follows that the action of the wind is most effective in early spring and becomes less efficient as the season advances and the lake warms. In April, and May also, the mean temperature of the air is above that of the surface of the lake, and losses of heat to the air are at a minimum. Thus in ordinary seasons by far the greater part of the heat which sun and sky furnish to the surface of the lake in April may be stored in its water and is easily carried to considerable depths. The amount thus stored has never been measured for the New York lakes; but for those of Wisconsin as much as 80 per cent or even more may thus be accumulated during April, and during May from 50 to 60 per cent of that which reaches the surface.

As the season advances the mean temperature of the surface rises above that of the air. The thermal resistance of the water to mixture increases and the mean velocity of the wind declines. The gains of heat fall off correspondingly. Not more than 15 or 20 per cent of the heat which falls on the surface of the lake is stored up in June, perhaps not more than 5 per cent in July, while in August the gains and losses of heat nearly

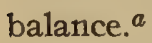

But during much of this period of decrease in storage, the quantity of heat delivered to the surface of the lake is increasing, that for July being ordinarily near the maximum

$a$ The general principles of this statement hold for all lakes. Numbers and dates will vary somewhat with the area and depth of the individual lake. 
for the year and that for August not greatly below this. It follows that there is a great surplus of heat, potentia!ly available for warming the lake, which is lost to the lake because the means for distributing it are inefficient.

If 40,000 gram-calories represents the maximum heat budget of such a lake, this is little more than half the amount of heat delivered by sun and sky between April I and August 31. If 25,000 to 30,000 gram-calories represents a fair average for the winddistributed heat, this again is less than half the heat delivered during that part of the warming period after the water of the lake has passed $4^{\circ}$.

The following conclusions are therefore warranted:

I. All lakes, whatever their area or depth, are on an approximate equality so far as their capacity for absorbing heat is concerned until their water has reached the temperature of maximum density, or $4^{\circ}$, and this temperature is reached by all lakes early in the open season.

2. The amount of heat absorbed after the temperature of $4^{\circ}$ is passed, depends primarily on the efficiency with which the heat is carried from the surface to the deeper water, and this work is mainly effected by the wind.

3. If we compare the gains of heat above $4^{\circ}$ made by different lakes, we compare their wind-distributed heat, and so are able to compare the efficiency of their means of distribution. If the climatic and topographic conditions are similar, the efficiency of the means of distribution will increase with the dimensions and the depth of the lake up to a certain point.

4. Since lakes reach the temperature of $4^{\circ}$ early in the season, a comparison of their gains above $4^{\circ}$ serves much the same purpose as a comparison of their annual heat budgets.

To these statements there are several qualifications, none of which have been worked out quantitatively and only one of which need be stated.

The amount of heat needed to raise the temperature of a lake from its winter condition to $4^{\circ}$ may vary very greatly, especially in case of lakes that freeze. It is probable that more complete observations will show a greater proportionate range of variation in the amount to which lakes cool below the temperature of $4^{\circ}$ than in the rise above $4^{\circ}$. The following table shows the facts for the lakes in question.

TABle X.-Calories per Square Centimeter of Surface Required to Raise Water of Lakes FROM WINTER TEMPERATURE TO $4^{\circ}$ AND FROM $4^{\circ}$ TO SUMMER TEMPERATURE.

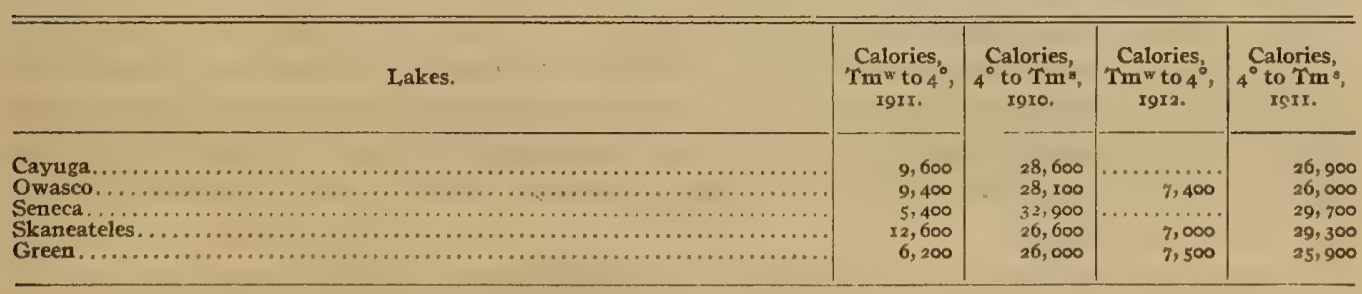

It appears, therefore, that it may require as much as a month's supply of heat, or even more, to raise the temperature of the lake from its winter condition to $4^{\circ}$. In such cases as that of Skaneateles Lake in 1910 , it is possible that the lake may reach 
$4^{\circ}$ so late that the whole season of later warming may be thrown over into the period when days are long and winds are light. Thus there might be a correspondingly small amount of wind-distributed heat. As a matter of fact, this result did not happen in the case cited, since Skaneateles Lake gained its full quota of heat in I9I I and this will usually be the case.

The last heat gained by a lake is in the epilimnion and therefore is near the surfacein the New York lakes not below 5 meters. The wind velocity from mid-July on through August is not essentially less than it is during the preceding six weeks. The surface is still receiving a great amount of heat, and the increasing length of the night adds to the chances of distribution. Thus in general a lake gains by the middle of August all of the heat that the wind can get into its depths; and whether a lake starts to accumulate its wind-distributed heat two weeks or so earlier or later makes little if any difference in the general result. In any case the heat is supplied to the deeper water of the lake early in the season before the velocity of the wind has greatly fallen.

TAble XI.-Calories PER SQuare Centmater of Surface NeEded to Raise Water of Lakes FROM $4^{\circ}$ TO SUMMER TEMPERATURE, OR THE AMOUNT OF WIND-DISTRIBUTED HEAT.

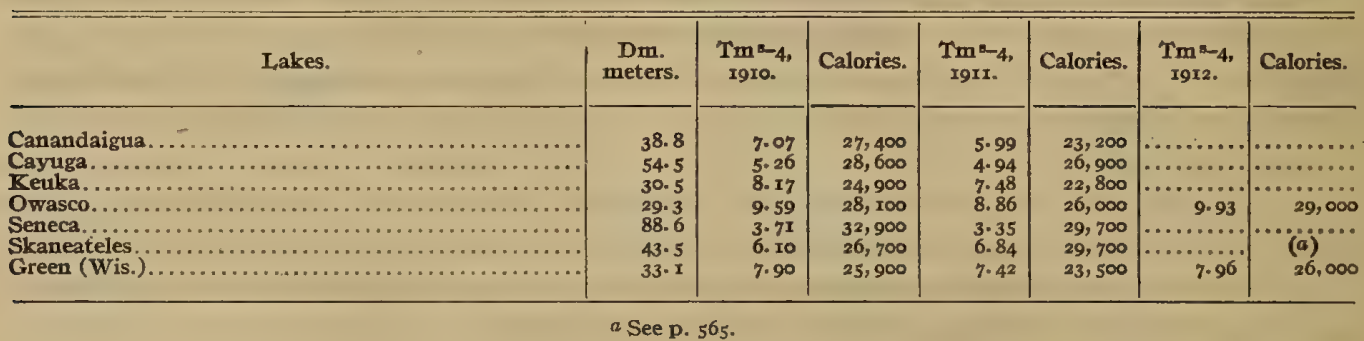

Table XI shows that Keuka Lake has the smallest amount of wind-distributed heat in both years and Seneca Lake the largest. So far as the former lake is concerned, it seems probable that this will be the regular condition, the narrowness of the lake and its steeper banks reducing the influence of the wind. It is not so certain that the result in Seneca Lake will be confirmed by further study, although this conclusion seems probable. No two lakes can be more nearly equal in area or similar in topographical condition than are Seneca and Cayuga Lakes. But three factors contribute to give Seneca an advantage in gaining heat during the early part of the seasonsteeper slopes, greater depth, and greater volume. The result of these was that Seneca Lake absorbed more heat into its deeper water than did Cayuga in rgro. The water of Seneca Lake below 30 meters received $\mathrm{r}, 600$ calories per square centimeter of the surface of the lake more than the corresponding water of Cayuga, and in I9I I the excess was about 300 calories.

The steeper sides of Seneca Lake give it an advantage in distributing heat to the deeper water, since the large shoal areas at the north end of Cayuga Lake tend to keep the return currents near the surface; but the chief advantage of Seneca Lake is in the greater reduced thickness (p. 566) of its several strata. If the results for Cayuga and 
Seneca Lakes are compared in table XIr, it will be seen that the water of Cayuga Lake has a higher temperature than the corresponding stratum of Seneca Lake, but the strata of Seneca have the greater reduced thickness and so contain more heat.

But for the present the most important conclusion from the table lies in the general fact that for lakes ro kilometers or more in length and 30 meters or more in mean depth, the annual gains of wind-distributed heat are on the whole independent of area or depth and range from something below 25,000 calories to something above 30,000 calories. It is not asserted that in these lakes different areas and depths have no effect. The contrary is true, as is shown above, but in general these effects lie within the range of the variation due to local conditions in wind and weather. No doubt under exactly similar conditions the largest and deepest lake will gain most heat, but the effects of area and depth are such that they may be overcome by variations of weather. In I9I0, for instance, Owasco Lake, the smallest and shallowest of the New York group, stands third in the amount of heat, and in I9I I Skaneateles Lake is equal to Seneca Lake and is much above the far larger and deeper Cayuga Lake.

From these facts we may give a second definition for inland lakes of the first class: In inland lakes of the first class the wind-distributed heat, $\operatorname{Dm}\left(\mathrm{Tm}^{8}-4\right)$, is about 25,000 gram-calories per square centimeter of surface and usually exceeds that sum. Such lakes will be, under the climatic conditions of the eastern United States, ro kilometers or more long and will have a mean depth of 30 meters or more. If such a lake falls below 25,000 calories, the deficiency will be due to exceptional conditions of topography or weather. If its gains rise above 30,000 calories, this result will also be exceptional. Further study is needed to make these statements more accurate in detail. Such study will show the presence and limits of the influence of area and depth within this class of lakes.

In 1912 temperatures were read in Skaneateles Lake on October 18 , too late for the maximum temperature of the upper water. The water at the bottom was $6.3^{\circ}$, much higher than in I9IO or I9II. The temperatures below the depth of 40 meters would be practically unaltered on October I8. If these are taken as they were found, and if we assume that the temperature of the water above 40 meters was the same in 1912 as in 1910 , then $\mathrm{Tm}^{\mathrm{B}}$ for 1912 would be $10.72^{\circ}$. If we, in like manner, assume for 1912 the same temperature for the upper water as in I9II, then $\mathrm{Tm}^{\mathrm{s}} \mathrm{Ig} 12$ would be $1 \mathrm{I} .33^{\circ}$. On the basis of the latter figures the maximum annual heat budget between $\mathrm{Tm}^{\mathrm{W}}$ I9II $\left(\mathrm{I.IO}^{\circ}\right)$ and $\mathrm{Tm}^{\mathrm{s}}$ I9I2 $\left(\mathrm{II}^{\circ} 3^{\circ}\right)$ would be 44,500 gram-calories. This shows that under favorable conditions the annual heat budget of these lakes may go as high as 45,000 gram-calories per square centimeter. The wind-distributed heat in I 912 for Skaneateles Lake on these assumptions would be 29,200 gram-calories and 31,800 gram-calories, respectively.

\section{DISTRIBUTION OF HEAT.}

Distribution to thermal regions (fig. 8). -The formula for the amount of winddistributed heat is $\mathrm{Dm}\left(\mathrm{Tm}^{3}-4\right)$. The product is the number of gram-calories per square centimeter of surface which the lake must receive that its temperature may 
rise from $4^{\circ}$ to its summer temperature. In what proportion is this heat so received distributed to the three main thermal regions?

In order to answer this question the mean temperature of each region must be known, and to determine this the reduced thickness of each region must be ascertained.

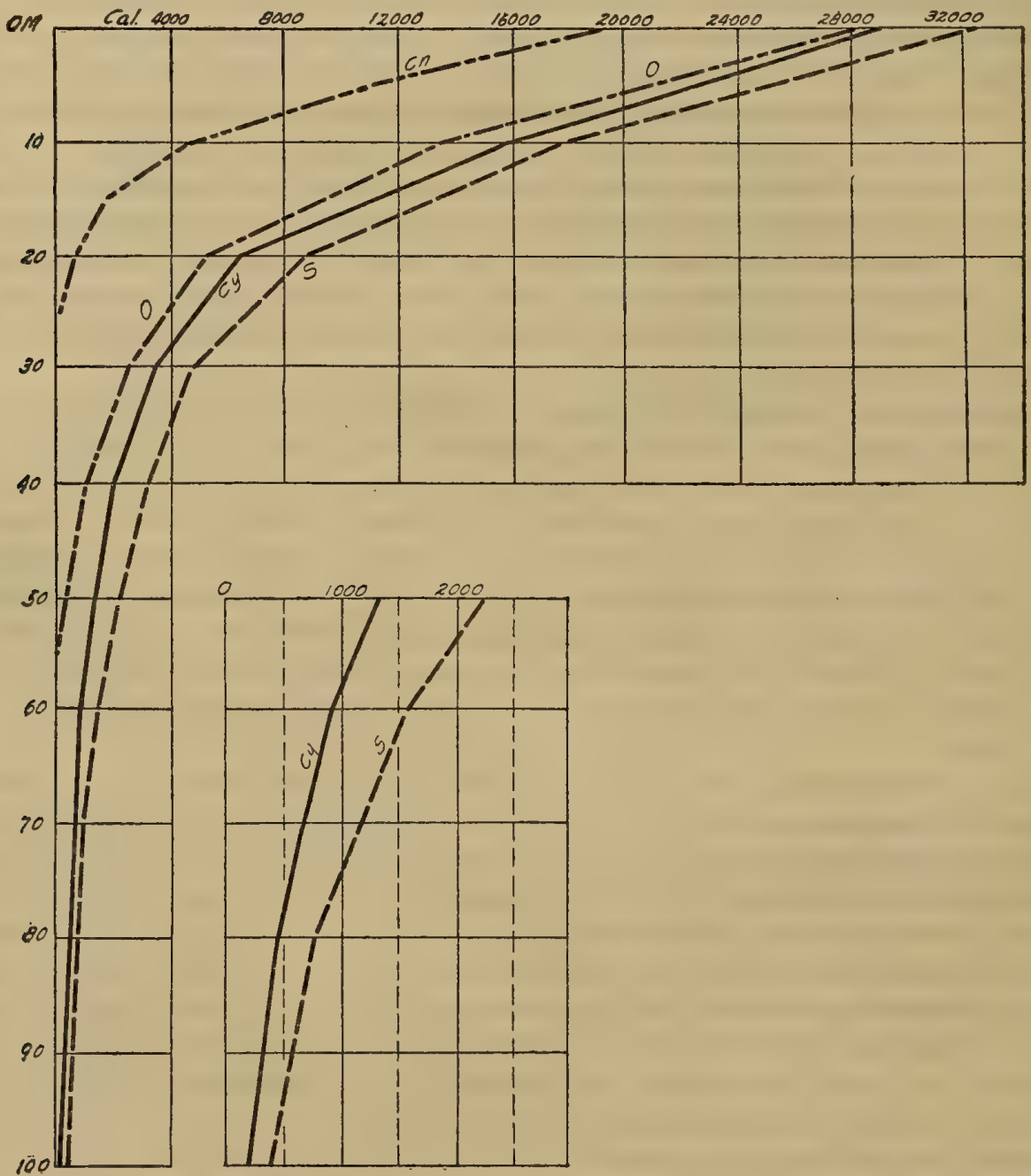

FYG. 8.-Distribution of wind-distributed heat in $x 910$, in Canadice $(\mathrm{Cn})$, Owasco (O), Cayuga (Cy), and Seneca (S) Lakes. Depth in meters; heat in gram-calories per square centimeter of surface of the lakes. Diagram extends to ro meters. The curves of Seneca and Cayuga Lakes, from 50 meters to roo meters, are repeated on a more open scale. (See p. 572.)

In table XII the column marked "Extent" shows the thickness of each thermal region as measured in meters below the surface of the lake; the column marked " $\mathrm{R}$. T." (reduced thickness), shows its thickness as referred to the area of the surface of the lake. 
It is ascertained, like the mean depth of the lake, by dividing the volume of the water of the region by the area of the surface. The reduced thickness of the region thus differs from its mean thickness in that the reduced thickness of the region is in all cases referred to the area of the surface of the lake, while the mean thickness of a given stratum would be its thickness referred (ordinarily) to its own upper boundary plane. Table XII shows the distribution of the calories received by a unit of the surface of the six major lakes to their thermal regions.

Table XII.-Showing Extent and Reduced Thickness of the Three Thermal Regions in the Six Major Lakes, Their Temperature, and the Number of Calories per Square CentiMETER OF SURFACE OF THE LAKE Distributéd TO EAch Reigion.

[The sums of the calories in each lake may differ slightly from those given in the general table, owing to the different method of computation.]

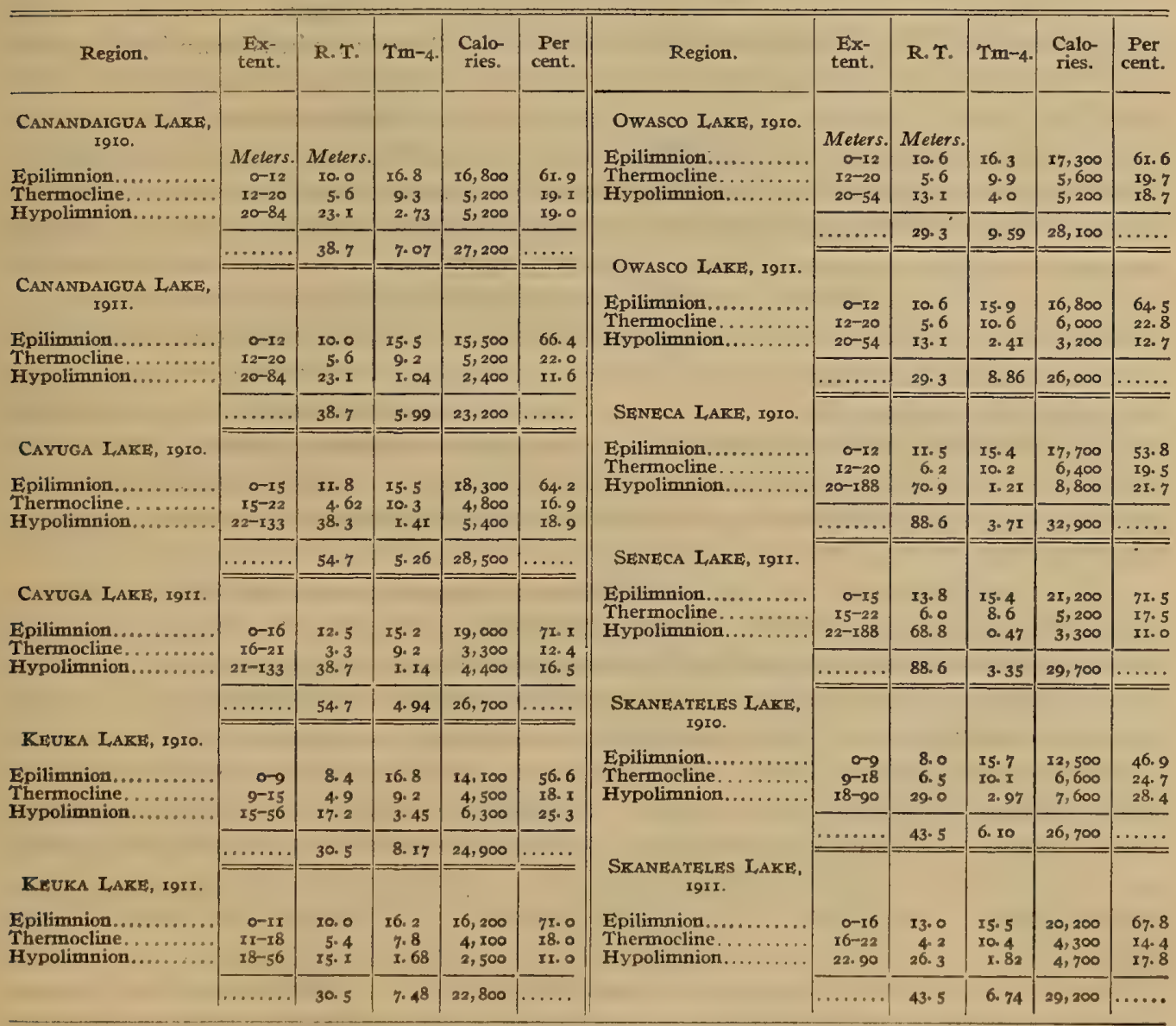


Inspection of table XII shows that the mean temperature of the epilimnion and the thermocline are not very variable in the six major lakes. In the first region $\mathrm{Tm}^{\mathrm{s}}-4$ equals $15.66^{\circ}$, as the mean of 12 observations, ranging from $15.2^{\circ}$ to $16.8^{\circ}$. For the thermocline the mean is $9.56^{\circ}$, ranging from $7.8^{\circ}$ to $10.6^{\circ}$. The differences in the amount of heat stored by a lake in these regions are due much more to the thickness of the stratum than to its temperature. For instance, in Seneca Lake in rgro the temperature of the thermocline was $19.4^{\circ}$, and in Skaneateles Lake in 1910 it was $19.7^{\circ}$. But its thickness in Seneca Lake was 15 meters, and only 9 meters in Skaneateles; and the wind-distributed heat in the epilimnion of the former lake was therefore over 75 per cent greater than that of the latter.

It appears from the table that a very large part of the wind-distributed heat is in the epilimnion. The upper ro or I 5 meters of a lake, even 60 kilometers long and nearly 200 meters deep, contain 50 to 70 per cent of the heat, or even more. If to this stratum is added that which lies immediately below it and has derived its heat from it, it appears that the upper 20 meters contain 70 to 80 per cent, or even 90 per cent, of the winddistributed heat. (See table xrrr.) This limitation of the heat to the upper strata is responsible not only for the sharply-defined thermocline, but also for the general uniformity in the amount of wind-distributed heat in the heat budget of the several lakes. A large percentage of the heat is always near the surface in summer. During the period of light winds and summer weather, when heat is furnished far in excess of the capacity of the distributing agents, so much is lost in any case that there is enough for any lake to get the maximum possible supply, and any deficiency is likely to be due to the distributing agents, and not to lack of supply. Still more, any loss caused by a short cool period during the summer may be quickly repaired, since no violent wind is needed to distribute the heat to water near the surface. Indeed, such a cool period may well be the indirect cause of the gain of heat. It allows the heat already in the lake to be distributed to a greater depth, while the surface will rapidly renew its supply during the succeeding warm days.

The heat distributed to the hypolimnion is extremely variable both in quantity and in the per cent it constitutes of the total heat. If the sums of the calories found in the epilimnion and thermocline are compared for the 12 observations, it will be found that the mean is 22,200 . The mean departure of each observation from the mean is about 8 per cent; the maximum departures are +19 per cent and -16 per cent; and the range is about 35 per cent of the mean. In the case of the hypolimnion the mean amount of heat is 4,900 calories. The mean departure of each observation is 28 per cent of this sum, the maximum is +80 per cent and -50 per cent, with a range of 130 per cent of the mean. Not only so, but the difference in the same lake in successive years is even more striking. The hypolimnion of Seneca Lake received 8,800 calories per square centimeter of surface in 1910 , and only 3,250 calories in $191 \mathrm{I}$. Keuka Lake had 6,300 calories in I9Io and 2,700 calories in I9I I. The mean of the six lakes for I9II was hardly more than half as great as that for I9I0 (6,400 and 3,400 calories), and the largest amount in 1911 ( 4,800 calories in Skaneateles Lake) was below the 
smallest of the former year $(5,000$ calories in Cayuga Lake). This distribution illustrates several principles.

x. The amount of heat received by the hypolimnion depended on the vicissitudes of weather during the early part of the warming period. (See p. 553.)

2. The lakes of the district were all similarly affected in each year.

3. In spite of this general similarity there are great individual differences, and neither the size nor the depth of the lake seem to be decisive in influencing the amount of heat given to the hypolimnion. In rgro Skaneateles Lake, with a hypolimnion 72 meters in maximum thickness and 29 meters in mean thickness, received 7,600 calories. Seneca Lake, with a hypolimnion 168 meters in maximum thickness and $7 \mathrm{I}$ meters in mean thickness, received only 8,800 calories. This was true in spite of the fact that Seneca Lake is far larger and its hypolimnion began only 2 meters farther from the surface. In I9I I Seneca Lake received less heat in its hypolimnion than Skaneateles Lake $(3,250$ calories and 4,800 calories, respectively); less than Cayuga Lake ( 4,400 calories); and practically the same as Owasco Lake ( 3,150 calories), the smallest and shallowest of the lakes.

Distribution to the several ro-meter strata.-It will be of interest to consider the distribution of heat by the wind to different depths below the surface, as well as its distribution to the different thermal regions. This distribution may be expressed in two ways:

I. The heat absorbed by each square centimeter of the surface may be followed through the lake and the amount determined which is absorbed by or passed through each successive stratum, and the result may be expressed in calories per square centimeter of the surface of the lake.

2. The boundary planes of the successive strata of the lake become smaller in proportion to their distance from the surface. It is possible, therefore, to state not merely the number of calories per square centimeter of the lake's surface which pass through any given plane, but also the number of calories which pass through each centimeter of the plane itself.

An example will make this clear. The water of Cayuga Lake absorbed 28,600 gram-calories through each square centimeter of the surface in 1910; 12,800 calories were left in the o-Io meter stratum. Thus there remained at ro meters 15,800 calories of those received by each square centimeter of the surface, and this amount was distributed to the water below the depth of ro meters. But the area of the lake at io meters is 72.5 per cent of the surface area, and the number of calories which passed through each square centimeter of this plane is correspondingly greater. Through each square centimeter of the ro-meter plane there passed 21,800 calories, or $\frac{15,800}{0.725}$. 
TABLE XIII.-Distribution of Heat to THE SEveral IO-Meter or 5-Meter Strata.

[In the tables the upper figures of columns 2 and 4 show the number of calories per square centimeter of surface of the lake necessary to raise the temperature of the water from $4^{\circ}$ to the summer temperature in rgro and $\mathrm{rgII}$, and the remaining figures show the number of such calories remaining at the several depths. Columns 6 and 7 show the number of calories present at each depth per square centimeter of the area at that depth. They are derived from the numbers of columns 2 and 4 by dividing them by the per cent of area given in column 3, tables $\mathrm{XV}-\mathrm{xvII}$. Columns ro and $\mathrm{I2}$ show the number of calories per square centimeter of surface left between the depths specified. They are computed in the same way as the data in table xrr. The data for Otisco and Canadice I,akes refer only to rgro.]

CANANDAIGUA LAKE.

\begin{tabular}{|c|c|c|c|c|c|c|c|c|c|c|c|c|}
\hline \multirow{2}{*}{$\begin{array}{l}\text { Depth, } \\
\text { meters. }\end{array}$} & \multicolumn{4}{|c|}{$\begin{array}{l}\text { Calories per square centimeter of sur- } \\
\text { face remaining at depth named. }\end{array}$} & \multicolumn{2}{|c|}{$\begin{array}{l}\text { Calories per square } \\
\text { centimeter of area } \\
\text { at depth named. }\end{array}$} & \multirow{2}{*}{$\begin{array}{l}\text { Depth, } \\
\text { meters. }\end{array}$} & \multirow{2}{*}{$\begin{array}{l}\text { R. } \mathbf{T} \text {, } \\
\text { meters }\end{array}$} & \multicolumn{4}{|c|}{$\begin{array}{l}\text { Calories per square centimeter } \\
\text { of surface left between depths } \\
\text { named. }\end{array}$} \\
\hline & x910 & $\begin{array}{c}\text { Per } \\
\text { cent. }\end{array}$ & IgII & $\begin{array}{l}\text { Per } \\
\text { cent. }\end{array}$ & xgro & I9II & & & x910 & $\begin{array}{l}\text { Per } \\
\text { cent. }\end{array}$ & IgII & $\begin{array}{l}\text { Per } \\
\text { cent. }\end{array}$ \\
\hline 0 & & & 2 & & & & & 8.56 & 14. & & & 58.2 \\
\hline 10 & 12,800 & 46.7 & 9,700 & 41.8 & 16,900 & 12,800 & $10-20$ & 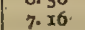 & 7,400 & 27.0 & 7,300 & $3 T .5$ \\
\hline 20 & 5,400 & 19 & 2,400 & IO. & 8,0 & 3,5 & & 6.43 & 2,200 & 8.0 & 1,300 & 5.6 \\
\hline 30 & & II. 7 & 1,100 & 4. & 5, & 1,8 & & $5 \cdot 7 \mathrm{I}$ & 1,300 & 4 & 550 & 2.4 \\
\hline 40 & 1,900 & 6.0 & 550 & 2 & 3,5 & 1,00 & $40^{\circ}$ & 4.88 & 900 & & 290 & $\begin{array}{l}\text { I. } 2 \\
\text { I. }\end{array}$ \\
\hline $\begin{array}{l}40 \\
50\end{array}$ & 1,000 & 3. 6 & 260 & $X .1$ & 2,30 & 600 & $50-60$ & 3.65 & 620 & 2. & 175 & .8 \\
\hline 60 & 380 & I. 4 & 85 & .4 & 1,300 & 290 & $60-70$ & I. 90 & 300 & I. I & 70 & $\cdot 3$ \\
\hline 70 & 80 & .3 & 15 & .06 & 760 & 140 & $70-84$ & .53 & 80 & .3 & 15 & \\
\hline & & & & & & & & & & & & \\
\hline
\end{tabular}

\section{CAYUGA LAKE.}

\begin{tabular}{|c|c|c|c|c|c|c|c|c|c|c|c|c|}
\hline 0 & 28,600 & 100.0 & 26,900 & 200.0 & 28,600 & 26,900 & $0-10$ & 8. 34 & 12,800 & 44.8 & 13,400 & 40.8 \\
\hline Io & 15,800 & 55.2 & 13,500 & 50.2 & 21,800 & 18,600 & I0- 20 & 6. 88 & 9,400 & 32.9 & 9,000 & 33.5 \\
\hline 20 & 6,400 & 22.4 & 4,500 & 16.7 & 9,800 & 6,900 & $20-30$ & 6. 28 & 3,000 & 10.5 & 2,600 & 9.7 \\
\hline 30 & 3,400 & $I I .0$ & 1,900 & $7 \cdot x$ & 5,600 & 3,100 & $30-40$ & 5. 75 & 1,400 & 4.0 & 900 & $3 \cdot 4$ \\
\hline 40 & 2,000 & 7.0 & 1,000 & 3.7 & 3,700 & 1,800 & $40-50$ & 5. II & 700 & 2. 4 & 350 & I. 3 \\
\hline 50 & 1,300 & 4.6 & 650 & 2.4 & 2,700 & 1,400 & $50-60$ & $4 \cdot 52$ & 400 & $x: 4$ & 180 & .7 \\
\hline 60 & 900 & 3. 2 & 470 & 1.8 & 2,100 & 1,100 & $60-70$ & 4. 05 & 250 & $\because 0$ & 140 & .5 \\
\hline 70 & 650 & 2.3 & 330 & I. 2 & 1,700 & 860 & $70-80$ & 3.62 & 190 & .6 & 130 & .5 \\
\hline 80 & 460 & 1.6 & 200 & .7 & 1,300 & 590 & $80-100$ & 5.88 & 290 & I. 0 & 120 & .4 \\
\hline 100 & 170 & .6 & 80 & .3 & 690 & 320 & $100-133$ & $4-2 I$ & 170 & .6 & 80 & .3 \\
\hline $\mathbf{r} 33$ & & & & & & & & $\cdots$ & & $\cdots$ & & \\
\hline
\end{tabular}

KE,UKA LAKE.

\begin{tabular}{|c|c|c|c|c|c|c|c|c|c|c|c|c|}
\hline Io & 9,900 & 30.8 & 7,800 & 34.2 & 11,800 & 9,200 & $10-20$ & 7.84 & 5,300 & $21 \cdot 3$ & 5,700 & 25.0 \\
\hline 20 & 4,600 & 18.5 & 2,100 & 0.2 & 6,300 & 2,900 & $20-30$ & 6.44 & 2,500 & $I I . I$ & 1,300 & $5 \cdot 7$ \\
\hline 30 & 2,100 & $7 \cdot 4$ & 800 & 3.5 & 3,800 & 1,400 & $30-40$ & 4. 39 & 1,400 & 4.6 & 570 & 2.5 \\
\hline 40 & 690 & 2.8 & 230 & I. 0 & 2,100 & 720 & $40-50$ & 2. 26 & 600 & 2.4 & 200 & .0 \\
\hline 50 & 90 & .4 & 30 &.$I$ & 600 & 200 & $50-56$ & $\cdot 37$ & 90 & .4 & 30 &.$I$ \\
\hline 56 & & & & & & & & & & & & \\
\hline
\end{tabular}

OWASCO LAKE.

\begin{tabular}{|c|c|c|c|c|c|c|c|c|c|c|c|c|}
\hline 20 & 5,400 & 19. 2 & 3,400 & 10.3 & 8,400 & 5,300 & $20-30$ & 5.95 & 2,800 & 0.0 & 2,200 & 5.7 \\
\hline 30 & 2,600 & 0.3 & 1,200 & 4.6 & 4,700 & 2,200 & $30-40$ & 4.60 & 1,700 & 6.2 & 830 & 3.2 \\
\hline $40^{\circ}$ & 860 & 3. $x$ & 370 & I. 4 & 2,200 & 960 & $40-54$ & 2.62 & 850 & 3. I & 370 & I. 4 \\
\hline 54 & & & & & & & & & & & & $\cdots$ \\
\hline
\end{tabular}


A LIMNOLOGICAL, STUDY OF THE FINGER LAKES.

TABLE XIII.-Distribution OF Heat To THE SEVERAL to-MeTer or 5-Meter Strata-Continued. SENECA LAKE.

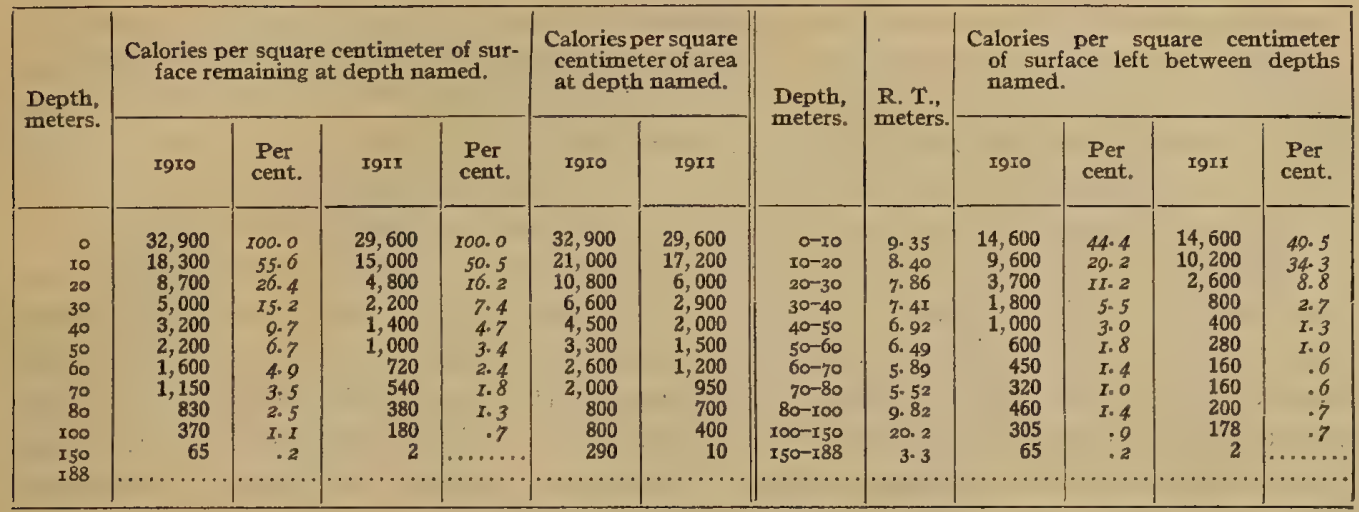

SKANEATELES LAKE.

\begin{tabular}{|c|c|c|c|c|c|c|c|c|c|c|c|c|}
\hline 0 & 26,700 & 100.0 & 29,700 & 100.0 & 26,700 & 29,700 & $0-10$ & 8. 75 & 13,700 & $5 X \cdot 3$ & 13,600 & 45.8 \\
\hline Io & 13,000 & 48.7 & 16,100 & 54.2 & 17,000 & 21,300 & $x 0-20$ & 7. 14 & 6,400 & 24.0 & 9,900 & 33.3 \\
\hline 20 & 6,600 & 24.7 & 6,200 & 20.9 & 9,800 & 9,200 & $20-30$ & 6.39 & 2,300 & 18.6 & 3,100 & 10.4 \\
\hline 30 & 4,300 & 16. I & 3,100 & 10. 5 & 7,100 & 5,100 & $30-40$ & 5. 75 & 1,500 & 5.6 & 1,200 & $4 \cdot I$ \\
\hline 50 & 1,700 & 6.4 & 1,000 & $3-4$ & 3,700 & 2,200 & $50-60$ & $4 \cdot 28$ & 730 & 2.8 & 510 & I. 8 \\
\hline 60 & 970 & 3.6 & 490 & 1.6 & 2,500 & 1,300 & $60-70$ & 3.37 & 560 & 2. I & 340 & I. $I$ \\
\hline 70 & 410 & I: 5 & 150 & .5 & 1,400 & 520 & $70-80$ & 2. 13 & 330 & I. 2 & 110 & .4 \\
\hline 80 & 80 & .3 & 40 &.$I$ & 550 & 220 & $80-90$ & .56 & 80 & $\cdot 3$ & 40 &.$I$ \\
\hline
\end{tabular}

CANADICE LAKE, IgIO.

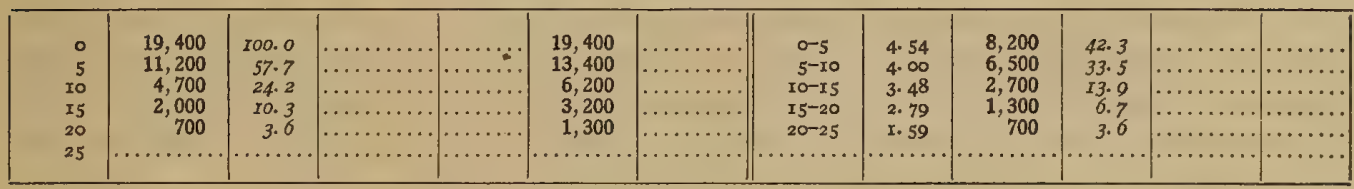

OTISCO LAKE, Igro.

\begin{tabular}{|c|c|c|c|c|c|c|c|c|c|c|c|c|}
\hline 0 & 17,000 & 200.0 & $\ldots$ & $\ldots$ & 17,000 & & $0-5$ & 4. 22 & 7,900 & 46.5 & & \\
\hline 5 & 9,100 & 53.5 & $\ldots$ & $\ldots \ldots \ldots$ & 13,000 & & 5-10 & 3.25 & 5,400 & $3 r .8$ & $\ldots$ & $\ldots \ldots$ \\
\hline ro & 3,700 & 21.8 & & & 6,200 & .. & $10-15$ & 2. 79 & 2,900 & 17.1 & $\ldots$ & $\ldots$ \\
\hline I5 & 800 & 4.7 & & & 1,550 & & $15-20$ & .94 & 800 & $4 \cdot 7$ & $\ldots$ & $\ldots$ \\
\hline 20 & & $\cdots$ & & & & & & ......... & . & $\ldots \ldots$ & & \\
\hline
\end{tabular}

The above table shows the amount and per cent of the total heat absorbed by the surface which is left in each ro-meter stratum of the lakes studied. The rapidity with which the heat declines is evident, and shows how hard the wind finds the task of overcoming the thermal resistance. A single illustration shows this in a striking manner. We may allow I, ooo calories per square centimeter as a full (not a mean) supply to the surface for a single summer day. We find in the various major lakes that this amount was distributed in 1910 to the water below a depth of 35 to 60 meters, and below 30 to 50 meters in 1911 . Thus the work of the entire season was necessary to carry to $46512^{\circ}-14-4$ 
a depth greater than the number stated an amount of heat equal to one maximum day's supply in summer.

Nor is this all. The upper ro meters contain from 45 to 65 per cent or more of the heat absorbed. This region is that in which nocturnal cooling, the action of waves, and the direct penetration of the sun aid in distributing the heat. At depths where these agencies cease to act the influence of the wind declines very rapidly.

It is worth while to call attention to the fact that the distribution of heat is strikingly similar in each year and that the two years show marked differences.

Figure 8 (p. 566) shows in graphic form the results for 1910 in the case of Owasco Lake and Seneca and Cayuga Lakes, respectively the largest and deepest and the smallest and shallowest of the lakes. The greater quantity of heat in Seneca Lake was due almost wholly to the greater amount distributed to the hypolimnion, that in the epilimnion and thermocline being about equal in both lakes. It thus appears that in general the distribution of heat is independent of the area or depth of the lakes, in the case of lakes of the first class. The mean of observations made in Green Lake, Wisconsin, during Io or 12 years falls midway between the results for Cayuga Lake in I9ro and I III, and shows that this lake also belongs to lakes of the first class. The curve of heat distribution for Canadice Lake is added to show the facts for a smaller lake.

\section{HEAT SUPPLY OF THE SMALLER LAKES.}

We must now consider the heat supply of the two smaller lakes, of which we have hydrographic surveys, Canadice and Otisco. We are unable to discuss their annual heat budget, as no winter observations have been made on them, but the amount of wind-distributed heat can easily be ascertained. It will be remembered that Otisco Lake has an available length of about 7.33 kilometers and a mean breadth of 0.93 kilometers; its maximum depth is 20.1 meters, and its mean depth II.2 meters. The corresponding figures for Canadice Lake are: Length, '5.I2 kilometers; mean breadth, 0.5I kilometers; maximum depth, 25.4 meters; mean depth, I6.4 meters. The ratio $\frac{\mathrm{Dm}}{\mathrm{Dmx}}$ is about 0.53 in Otisco, which is not far from the mean of that in case of the six deeper lakes. In Canadice Lake $\frac{\mathrm{Dm}}{\mathrm{Dmx}}=0.64$, a number nearly one-third higher than the mean of the other lakes and about I 6 per cent greater than the highest one. This fact is of great influence on the heat supply of Canadice Lake.

Both lakes are small and shallow as compared with those which have been discussed. Their mean temperature is correspondingly high (Otisco, I9.2 ${ }^{\circ}$; Canadice, $15.8^{\circ}$ ). Both temperatures, and especially that of Otisco, are much above that of the deeper lakes. The mean depth, however, is so small that the total amount of wind-distributed heat, $\mathrm{Dm}\left(\mathrm{Tm}^{\mathrm{s}}-4\right)$, is much smaller. In Canadice this sum is $\mathrm{i}, 400$ gram-calories per square centimeter of surface, and in Otisco Lake the amount is still smaller, 17,000 gramcalories. It appears therefore that Canadice Lake accumulates about 80 per cent as much heat per unit of surface as the larger lakes and Otisco Lake about 65 per cent as much. 
No discussion of these facts would be possible if it was based on the single series of onservations made on each of these lakes, but these can be interpreted in the light of the almost innumerable observations on Wisconsin lakes, and considered in this light they are extremely interesting.

The influence of the small size of the lake is apparent in the shallow epilimnion7 meters, or a little more than half its thickness in the larger lakes. The same general relation is shown by other similar facts. The temperature of the lower water is raised above $4^{\circ}$ by mixture; and the depth at which this water reaches temperatures of $10^{\circ}$ or $15^{\circ}$ in August will give, like the position of the thermocline, the approximate value of the mixing power of the wind. In I9Io the temperature of $15^{\circ}$ lay at about ro meters in Canadice Lake, I I meters in Otisco, I8.5 meters in Cayuga, I 5 meters in Seneca and Owasco. The temperature of $10^{\circ}$ lay at 14 meters in Canadice, from 20 to 25 meters in the other lakes. In Otisco the bottom water at 20 meters had a temperature of I $2^{\circ}$. The bottom of the epilimnion marks the lower limit of the direct distribution of heat in summer, and its position in the various lakes is the best measure of the relative influence of the wind on them. The depth of the successive isotherms also marks the approximate levels of wind influences. As would be expected, these levels are higher in the smaller lakes, and their smaller dimensions form the first reason for their smaller gain of heat.

The second reason lies in the smaller mean depth of the lake and the smaller reduced thickness of each stratum. In a shallow lake the heating surface is greater in proportion to the depth than in a deeper lake, and it might therefore be expected that the former lake would be proportionately higher in temperature, and that the number of calories gained per square centimeter of surface would be the same in the two lakes so that the product $\mathrm{Dm}\left(\mathrm{Tm}^{\mathrm{s}}-4\right)$ would be nearly constant for all lakes as it is for those of the first class. It might be expected, for instance, that if Canadice Lake ( $\mathrm{Dm}=\mathrm{I} 6.4$ meters) gained 19,400 calories of wind-distributed heat, then in Otisco Lake, with a mean depth of Ir.2 meters, $\mathrm{Tm}^{\mathrm{s}}-4$ would be high enough to make the product about the same, so that the two lakes would gain the same amount of heat from an equal heating surface. This might be expected the more readily as Otisco is the larger lake and has a relatively larger surface; but so far from reaching this result, Otisco Lake has gained only about I7,000 calories, or nearly 9 per cent less than the deeper lake.

There are two reasons for this disadvantage of a shallow lake. First, the temperature of the epilimnion is determined not only by the relation of insolation and wind action, but even more by losses to the air. A shallow epilimnion ordinarily reaches a higher temperature than a thicker one, but the difference in the temperature is not so great as in the reduced thickness, so that the total amount of heat in the epilimnion is smaller. The losses to the air prevent the temperature from rising above a certain point. If, for instance, the epilimnion of Canadice Lake were to have as much heat as even that of Keuka, whose epilimnion is the thinnest of the six major lakes, Im-4 would have to be $22.3^{\circ}$, and $\operatorname{Tm} 26.3^{\circ}$. This is an obviously impossible temperature as the mean of any considerable stratum, since in our latitudes it is reached only by a very thin surface layer in the hottest part of bright calm days. It rarely persists overnight. 
This difference between the deep and shallow lakes, however, is relatively less apparent in the epilimnion than in the thermocline and hypolimnion. In these regions the second disadvantageous factor of the shallower lake comes in with more influence. The gains of heat of the water in and below the thermocline depend wholly on mechanical mixture. There are no gains from the sun and no losses to the air and practically no losses by conduction. Hence the thermal resistance to mixture ${ }^{a}$ is the factor which resists the transfer of heat downward, and the influence of the wind, direct or indirect, is the force which carries the heat down. But the thermal resistance increases much more rapidly than the temperature rises and soon puts an end to the force of the wind in carrying the heat downward. If we compare the thermocline of Otisco and Canadice Lakes, we find that the region is included between the same levels in both lakes and that the temperature is not greatly different (Canadice, $12.9^{\circ} ;$ Otisco, $13.2^{\circ}$ ). The advantage in temperature is on the side of the shallower lake. But the reduced thickness of the region in Otisco Lake is only 3.05 meters as against 3.76 meters in Canadice. The total amount of heat in the region is therefore about $I 7$ per cent less.

If the thermocline of Otisco Lake were to derive as much heat from each square centimeter of surface as did that of Canadice, $\mathrm{Tm}-4$ for that region must be $15 \cdot 7^{\circ}$, or $2.5^{\circ}$ above that actually reached. A great amount of energy is needed to produce this increase from $13.2^{\circ}$ to $15.7^{\circ}$ by mixture. The increase of temperature is about 19 per cent but the work to be done in effecting this increase is much greater than that.

The work to be done in warming a stratum of water which lies below the direct influence of the sun is done against gravity which resists the descent of the warmer and lighter water. The net work done in warming a stratum of water to a given degree may be measured by the energy which would be needed to transport the mass of water, thus warmed, to the place where it is found, against the resistance of denser water at a temperature of $4^{\circ}$. We may think of such a stratum as pushed down to its place through water at $4^{\circ}$, somewhat as a sheet of cork might be forced down through the water. The weight to be moved is the difference in weight between the warmed water and water at the temperature of maximum density. The distance through which it is carried is the mean distance of the stratum in question from the surface.

In this case the difference in the amount of work necessary to warm the thermocline to $13.2^{\circ}$ and $15.7^{\circ}$ is proportional to the difference in loss of weight of water at these temperatures. A liter of water at $13.2^{\circ}$ weighs $62 \mathrm{r}$ milligrams less than at $4^{\circ}$, and this is the weight of each liter to be used in computing the work done in warming the thermocline. At $15.7^{\circ}$ the weight of a liter is 982 milligrams less than at $4^{\circ}$. Thus over one-half must be added to the work which was done in warming the water to $13.2^{\circ}$, if $2.5^{\circ}$, or about 19 per cent, are added to the heat.

A similar statement may be made for the hypolimnion. If this region in Otisco Lake is to receive as many calories per square centimeter of the surface of the lake as does that of Canadice, its temperature will rise to $12^{\circ}$. But to effect this rise would require, if measured on the same basis as in the former example, more than three times

a Birge, Edward A.: An unregarded factor in lake temperatures. Transactions Wisconsin Academy of Sciences, vol. xvi, pt. 2, p. 989. I910. 
as much work as that which was actually available for warming it. This is obviously a demand impossible to satisfy.

Thus the shallow lake has a double disadvantage. Its smaller reduced thickness for any given stratum diminishes the volume of water into which heat may be distributed from the surface. This deficiency of volume can not be compensated by an equivalent rise of temperature, since the amount of energy present to mix the water is soon exhausted by the rapid rise of thermal resistance to mixture as the temperature increases.

The shallow lake has an advantage in one respect, probably a small advantage but one whose amount has not been determined. What may be called its mixing areas are more efficient because of the gradual slope of the bottom. Consider the condition of the lake with direct thermal stratification, whose form is that of an oblong tank with vertical sides. A wind blowing the surface water to one end would depress the isotherms there. The cold water would swing back and oscillate, but there would be very little friction between the strata and little mixture and correspondingly little warming of the lower water. In an actual lake with sloping bottom, the narrower ends concentrate and give force to the movements of the water caused by the wind and increase the amount of mixture due both to the direct and indirect effects of the wind. As the warm water is forced downward at the ends, it squeezes out the cooler water in a relatively thin layer between the descending surface of the epilimnion and the gradually sloping bottom of the lake. As the cool water swings back, its edge pushes in like a wedge between the bottom and the epilimnion. Both movements are attended with relatively great friction and corresponding mixture of the warmer and cooler water. Thus the ends of the lake constitute its chief mixing areas, and they are the region where the gradual warming of the thermocline and hypolimnion goes on most rapidly. Relatively little warming is effected in the open water of the lake or on its steep sides where movement, which is chiefly lateral, is attended with little resistance and consequent mixture. In this respect, therefore, the shallow lake has an advantage over the deeper one whose slopes are steeper. The shallowness of the water is also an advantage in the spring before the thermocline is formed, in that the water is nearer the surface and so more readily accessible to the influence of the wind. Thus its temperature rises above that of the deeper lake, but it never reaches a point, under conditions otherwise equal, high enough to give it as great a total amount of heat per unit of surface as the deeper lake accumulates.

Table XIV.-EXTENT, REDuced Thickness, and HEAT Supply of the THERmal, Regions of CANADICE AND OTISCO LAKES.

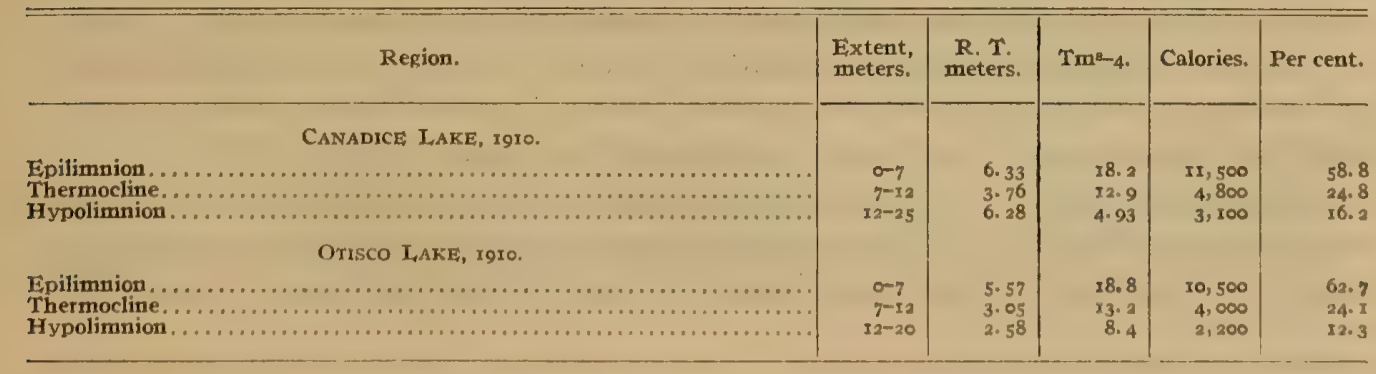


DISSOLVED GASES.

METHODS OF OBSERVATION.

During the month of August, I9Io, observations were made on ro of the Finger Lake for the purpose of ascertaining the amount of dissolved oxygen and carbon dioxide in their waters. The samples of water for these determinations were obtained either by means of a pump and hose or with a closing water bottle. With one exception the former method was used at all depths in the shallower lakes-that is, those not exceeding 30 meters (IOo feet) in depth-and in the upper water of the deep lakes. The water bottle was used on Otisco Lake and in the lower strata of the deep lakes.

The Winkler method was used for the determination of the quantity of dissolved oxygen and the Seyler method for the carbon dioxide. These methods have been fully described in a previous publication, ${ }^{\alpha}$ and further consideration of them is not necessary here. A new table of oxygen saturations (table XxI, p. 609) is included as a substitute for the previous one. It is based upon the more recent determinations of Fox, ${ }^{b}$ who gives the results for degrees centigrade from $-2^{\circ}$ to $+30^{\circ}$. The intervening tenths of degrees have been interpolated.

\section{OVERTURNING AND CIRCULATION OF THE WATER.}

The Finger Lakes belong to the temperate type, in which the water is subject to an overturning and a complete vertical circulation in the autumn and also in the spring. These phenomena are such important factors in the general distribution of the dissolved gases that they deserve a brief description here as a preliminary to the discussion of the gases. When the surface water begins to cool in late summer or early autumn, it becomes heavier than the water below it and tends to sink, thereby producing convection currents. Through the agency of these currents and the wind the water of the epilimnion is thoroughly mixed, and as the temperature of this stratum declines with the advance of the season more and more of the lower water becomes mixed with the upper; that is to say, there is a downward movement of the thermocline and the epilim. nion becomes thicker at the expense of the hypolimnion. This process continues until the temperature of the epilimnion approaches that of the hypolimnion, when the whole body of water may be set into rotation by a strong wind. This phenomenon is known as the autumnal overturning, and it is followed by a complete circulation of the water, which continues until the lake becomes covered with ice. Seneca and Cayuga Lakes do not freeze over completely very often-on an average only about once in 20 yearsso that their waters are subject to disturbance by the wind during the entire winter.

As long as the temperature of the water remains above $4^{\circ}$ in the autumn both the twind and the convection currents are concerned in the production of the circulation,

a Birge, Edward A., and Juday, Chancey: The Inland Lakes of Wisconsin: The dissolved gases of the water and their biological significance. Wisconsin Geological and Natural History Survey, Bulletin xxa, Scientific Series No. 7, 259 p. rgrr.

$b$ Fox, Charles J. J.: On the coefficients of absorption of the atmospheric gases in distilled water and sea water. Part $I$. Nitrogen and Oxygen. Conseil Permanent International pour L'Exploration de la Mer. Publications de circonstance, No. 4I, 1907, 23 p., I pl. 
but below that temperature the former is the only active agent. When the surface water cools below $4^{\circ}$ it becomes lighter than the warmer water beneath it and tends to float on the latter; that is, there is a resistance to mixture owing to the difference in their temperatures. As a result, it requires a strong wind to disturb the water to any considerable depth. But in spite of this resistance to mixture the wind is able to disturb the water at all depths, even in the deepest lakes, and cause the late autumn and winter temperatures to fall well below $4^{\circ}$. (See table IV, p. 555.) The winter stratification is inverse; that is, the coldest water is at the surface and the warmest at the bottom.

In spring conditions again become favorable for an overturning and circulation of the water. In the lakes which freeze over in winter a preliminary step in this process is the removal of the covering of ice. Substantially all of the direct warming takes place close to the surface, and as the temperature rises this water becomes heavier than that below and tends to sink, thus producing convection currents; but this holds true only as long as the temperature remains below $4^{\circ}$ or the point of maximum density. After the whole body of water reaches a temperature of $4^{\circ}$ any warming of the surface layer makes it lighter than the cooler water below and it tends to float on the latter. This eliminates convection currents as a factor in producing a general circulation, but they still play a more or less important rôle in mixing the water of the upper stratum when cooling takes place at the surface at night or during cool periods. The wind is now the only agent involved in the production of a complete vertical circulation.

As the season advances the temperature of the upper water rises so that it offers a greater and greater resistance to mixture with the cooler water below. As a consequence the tendency of the lower water to take part in the circulation grows correspondingly smaller and smaller. Finally the thermal resistance to mixture becomes so great that the wind is no longer able to mix the warm upper water with the cooler water below and the lake becomes separated into three distinct strata, viz, the epilimnion, the thermocline, and the hypolimnion. (See p. 547.) This is known as a direct thermal stratification, and it persists from early summer until the autumnal overturn takes place.

The autumnal circulation is much more thorough than the vernal. This is due to the fact that the mere cooling of the water in the autumn, as long as its temperature is above $4^{\circ}$, produces convection currents which tend to mix the various strata. In the spring, however, general convection currents are formed only as long as the water remains below $4^{\circ}$, which is generally only a comparatively short period of time. Small, spring-fed lakes, in fact, in which the temperature of the bottom water rises to $4^{\circ}$ before the ice disappears, and which are well sheltered from winds, may not experience a complete vernal overturning under favorable weather conditions.

\section{OXYGEN}

Circulation periods.-During the autumnal and vernal periods of vertical circulation all of the dissolved gases, as well as other substances that may be held in solution, are uniformly distributed from surface to bottom; but during the succeeding stages there 
may be marked changes in the gaseous content of the different strata. As the water cools in the autumn its capacity for oxygen increases, and free exposure to the air enables it to obtain additional amounts of this gas as circulation proceeds. As a result, the lakes enter the winter stage of their cycle substantially saturated with oxygen at all depths; that is, with about $9.0 \mathrm{cc}$. to I0.0 cc. per liter of water. No winter observations were made on the Finger Lakes, but it is safe to assume from the results obtained on Wisconsin lakes that there is little change in the quantity of oxygen in the deeper lakes during the winter, more especially in those which show only a comparatively small decrease in the lower water in summer. In winter the life processes which furnish decomposable material are at a low ebb, and the temperature of the water is so low that decomposition goes on very slowly, even at the bottom, where organic material may be fairly abundant. In the shallower lakes, however, there may be a marked decrease of dissolved oxygen in the bottom stratum, and under favorable conditions it may even disappear entirely from some of the lower water.

At the close of the vernal period of vertical circulation the oxygen has a fairly uniform distribution from surface to bottom, but more or less marked changes take place in the different strata during the direct stratification stage, so that the history of the dissolved gases is different for the different zones. The maximum difference is found during August, and for this reason a single set of observations during this month, such as made on the Finger Lakes, makes it possible to give the history of the dissolved gases with a very considerable degree of accuracy for the whole stratification period.

In the epilimnion.-As already noted, the epilimnion is kept in circulation by the wind, which tends to keep the quantity of dissolved oxygen near the saturation point. But the amount is subject to variations in spite of this fact. As the temperature of the epilimnion rises in spring and early summer its capacity for holding oxygen in solution decreases so that the volume of this gas tends to decrease until the summer maximum of temperature is reached. But the loss of oxygen may not keep pace with the rise in temperature. That is, a certain quantity in excess of the amount required for saturation may remain for a while, since the water tends to retain the residual gas unless it is pretty thoroughly agitated by the wind. In such instances, however, the quantity of excess oxygen is never very great. This stratum is preeminently the zone of photosynthesis and in this process some oxygen is liberated by chlorophyllous organisms. If the epilimnion is well populated with such organisms and the conditions are favorable for photosynthesis this stratum may become supersaturated with the oxygen that is liberated. Another small amount is obtained from the nitrites and nitrates which serve as a source of nitrogen for the chlorophyllous organisms.

The appended table (table XVIII, p. 602) shows that at the time of these observations the epilimnion of all of the Finger Lakes contained between 6 and $7.4 \mathrm{cc}$. of dissolved oxygen; with the exception of Conesus Lake it was a little larger than the amount required for saturation, the maximum excess being about $x 2$ per cent. In most of the lakes a larger portion or perhaps all of this excess oxygen was most probably due to the photosynthetic activities of chlorophyl-bearing organisms since they were well 
populated with such forms. But in some of the larger and deeper lakes a portion or possibly all of the excess may have been due to the presence of residual gas, more especially since some of them, such as Owasco and Seneca, had a relatively small number of chlorophyllaceous organisms.

In addition to the processes which tend to keep the volume of oxygen at or above saturation in this stratum, there are others which tend to reduce it below that point. A certain amount is consumed in the respiration of the various organisms inhabiting this region, and another portion, perhaps much larger, is removed by the decomposition of organic material. The amount of oxygen actually held in solution by this water then is the resultant of the processes which tend to maintain an abundant supply and those which tend to exhaust it. If consumption exceeds the new supply, the amount falls below the saturation point as in Conesus Lake; but if the factors which tend to maintain saturation and to raise the amount above this point predominate, the opposite result is produced.

In the hypolimnion.-During the period of thermal stratification, the hypolimnion is cut off from contact with the air by the epilimnion and conditions are not favorable for photosynthesis in this stratum. As a result the only source of oxygen during this time is the small amount which diffuses down from the upper water. But this gas diffuses very slowly through water, its coefficient of diffusion being only 1.62 , so that only a small and negligible amount is obtained in this way. Thus the supply of dissolved oxygen of the lower water is limited to the amount which it possesses at the close of the vernal period of circulation. Any decrease during the summer remains as a deficiency until the autumnal overturn takes place and the normal amount is not regained until after complete autumnal circulation is established.

As might be expected from the above conditions, different lakes show wide differences with respect to the quantity of dissolved oxygen in the hypolimnion in late summer; but they readily fall into three groups. The first includes those lakes in which some or practically all of the hypolimnion is devoid of free oxygen in the later stage of the stratification period; the second comprises those lakes in which there is a marked decrease of dissolved oxygen in some or all of the hypolimnion but not an actual disappearance of it; and the third class includes those lakes in which the decrease of the oxygen in this stratum is comparatively slight. These differences in the dissolved oxygen content depend, in the main, upon two factors, viz, the amount of decomposition taking place in the hypolimnion (which may be characterized as the zone of decomposition) and upon the volume of this stratum. If the epilimnion contributes a large amount of decomposable material in the form of dead plankton organisms to the lower water and the volume of the hypolimnion is relatively small, most or practically all of the dissolved oxygen in the stratum may be consumed before the autumnal overturning. Before the oxygen all disappears, some of it is also consumed in the respiration of organisms which may occupy this region, such for example as fishes and plankton crustacea. But decomposition is a much more important factor in the removal of oxygen from this stratum. 
Conesus and Otisco Lakes are good representatives of this class. In the former all of the water below a depth of ro meters either possessed no free oxygen at all or contained only traces of it. The same was true of a few meters of the bottom water of Otisco Lake. (See table XvIIr, p. 602, fig. 9 and ro.) The oxygen disappears from the bottom water first because decomposable material is more abundant at that depth. This material is derived from plankton organisms and from shallow water and shore vegetation. The specific gravity of the plankton organisms is so low that they sink

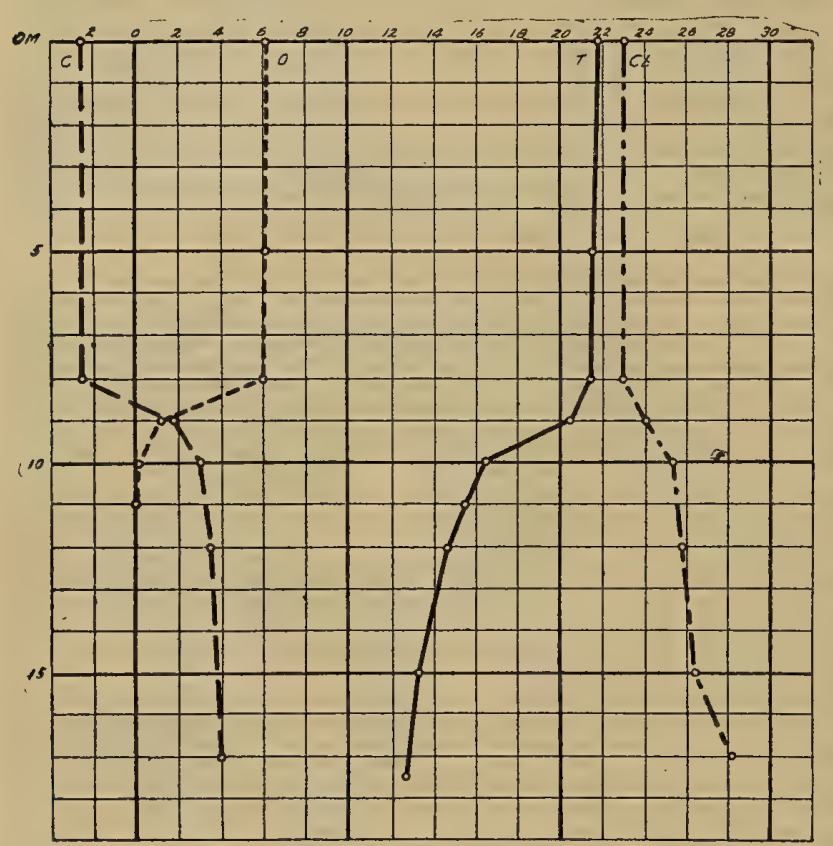

Frg. 9.-Conesus Lake, Aug. 25, 1910. The curves for dissolved gases are designated as follows: $C=$ carbon dioxide; that portion to the left of the zero line indicates the alkalinity and that to the right the free carbon dioxide; $\mathrm{Cb}=$ fixed carbon dioxide; $\mathrm{O}=0 \mathrm{xygen}$; and $\mathrm{T}=$ temperature. The vertical spaces represent the depth in meters and the horizontal spaces show the temperature in degrees centigrade and the cubic centimeters of gas per liter of water at normal temperature and pressure. The depths at which observations were made are indicated by small circles and these points have been connected directly without any attempt to round off the curves. through the cool, lower water very slowly and they thus pass through the earlier stages of decomposition at least before they reach the bottom. In this way they draw upon the oxygen supply at all depths in the hypolimnion so that, if such decomposing organisms are sufficiently numerous and the volume of this stratum is not too great, practically all of the dissolved oxygen may disappear from this region.

If the decomposable material derived from the epilimnion is not so abundant, or if the volume of the hypolimnion is relatively great, with a correspondingly large amount of oxygen, there is not a total exhaustion of this gas in any of this stratum, but only a marked decrease, such as was noted in Canadice and Hemlock Lakes. (See table xvirI, p. 602, and fig. II and 12.) Here the water below 18 meters contained less than 50 per cent of the quantity of oxygen required for saturation; the bottom water in the latter lake had as little as 8.4 per cent.

If a still smaller quantity of decomposable material is derived from the upper water, or if the volume of the hypolimnion is still larger, the decrease of oxygen is correspondingly smaller, as in Canandaigua, Cayuga, Keuka, Owasco, Seneca, and Skaneateles Lakes, which belong to the third class. (Table XVIII, p. 602, and fig. I $3^{-1}$ 8.) Perhaps Keuka Lake should be placed in the second class, since its bottom water contained less than two-thirds of the amount of oxygen required for saturation; but it 
has been placed in the third class because it belongs to the group of major lakes in other features.

The minimum amount of oxygen in these lakes was found at the bottom, and it varied from $5.57 \mathrm{cc}$. per liter of water in Keuka Lake to $8.45 \mathrm{cc}$. in Seneca Lake, or from 63.8 to 91.7 per cent of saturation. It will be noted that all of the members of this class are the larger and deeper lakes of the group-that is, those that have been designated as the major lakes. The volume of the hypolimnion of each is relatively large in comparison with the epilimnion, very large indeed in the deepest ones, and this large body of cool water is able to hold in solution a proportionally large quantity of oxygen, so large that the respiration of the organisms inhabiting it and the decomposition of the organic material which sinks into it from the upper water do not make extensive inroads upon the supply of free oxygen. The members of the first and second classes constitute the group of minor lakes. They are relatively small and shallow bodies of water, in which the volume of the epilimnion is large in proportion to that of the hypolimnion.

How large a proportion of the oxygen supply of the hypolimnion is lost during the summer depends upon the amount consumed in respiration and decomposition and upon the volume of this stratum. If the volume of the epilimnion is relatively. large in proportion to that of the hypolimnion and it is well populated with plankton organisms, so that it contributes a large amount of de-

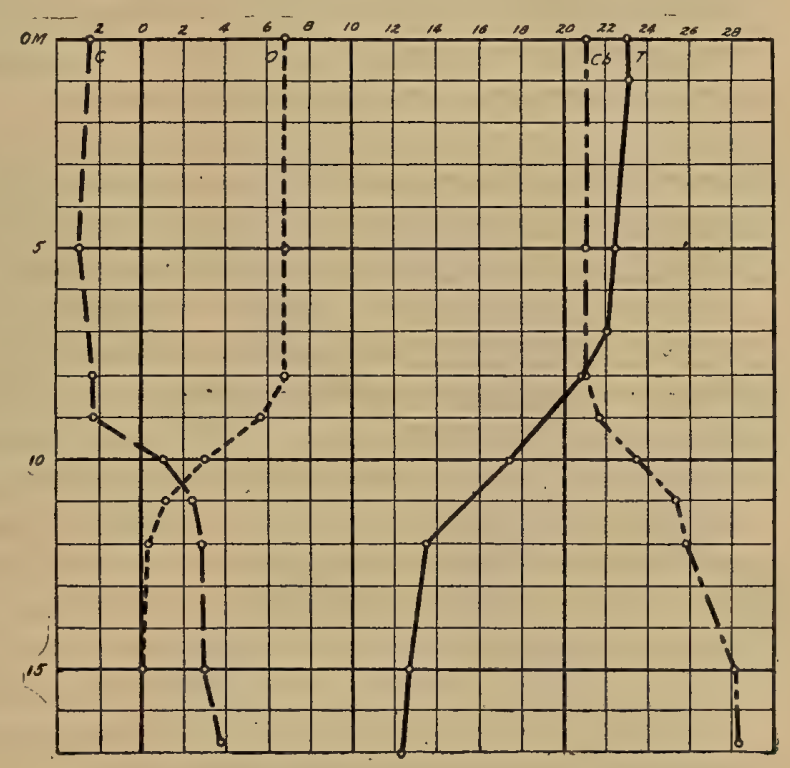

FIG. זo.-Dissolved gases, Otisco I,ake, Aug. 16, x9ro. For explanation, see fig. 9 , p. 580 . composable material to the latter, the dissolved oxygen is rapidly consumed, so that very little may be left in this stratum by midsummer. On the other hand, when the hypolimnion is relatively very large and the upper water contributes only a comparatively small amount of decomposable material, the total volume of oxygen suffers only a very small decrease.

In the thermocline. - The quantity of dissolved oxygen in the thermocline is dependent in the main upon the amount in the hypolimnion. If it is practically exhausted from the lower water, there is generally a rapid decrease of oxygen as we pass downward through the thermocline. In Conesus Lake, for example, the amount decreased from $6.0 \mathrm{cc}$. per liter of water at 8 meters to o.r I cc. at ro meters. In Otisco Lake it declined from $5.77 \mathrm{cc}$. at 9 meters to 0.34 cc. at $\mathrm{I} 2$ meters. (See table xviII, p. 602.) But lakes 
belonging to this class may have a large excess of oxygen in the thermocline; as much as $20.0 \mathrm{cc}$. per liter or more have been found in some of the small lakes of Wisconsin.

In lakes of the second class there may be either an appreciable decrease of oxygen in the thermocline, as in Green Lake, Wis., or the amount may be larger than that found in the epilimnion or the hypolimnion, as in Canadice and Hemlock Lakes. The oxygen curves of the latter lakes (fig. II and I2) show that the maximum amount of

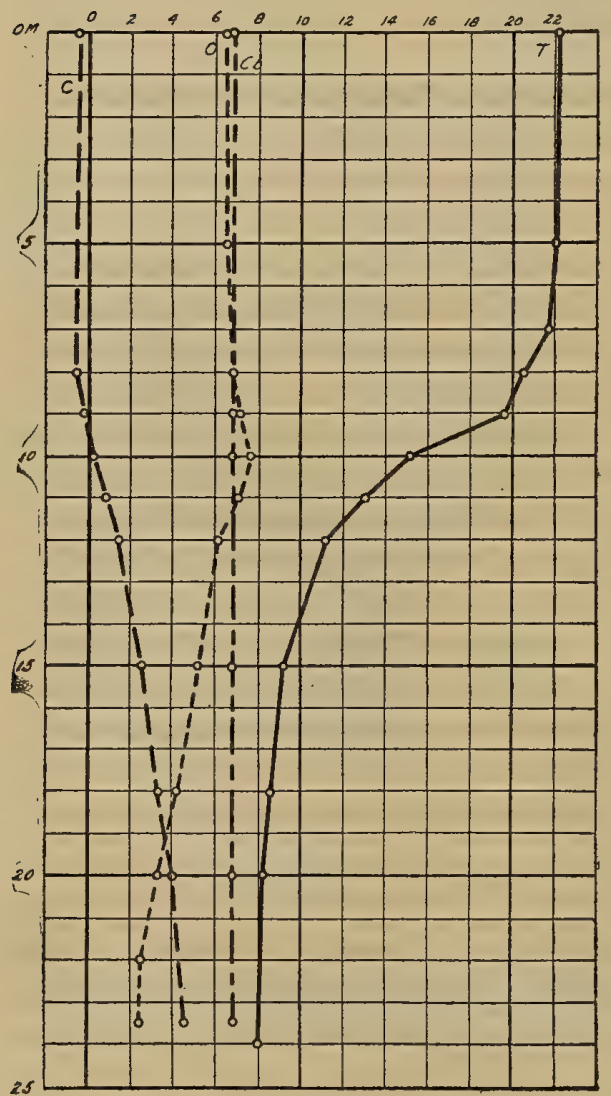

Fig. II.-Dissolved gases, Canadice I,ake, Aug. 24, 1910. For explanation, see fig. 9 , D. 580 .

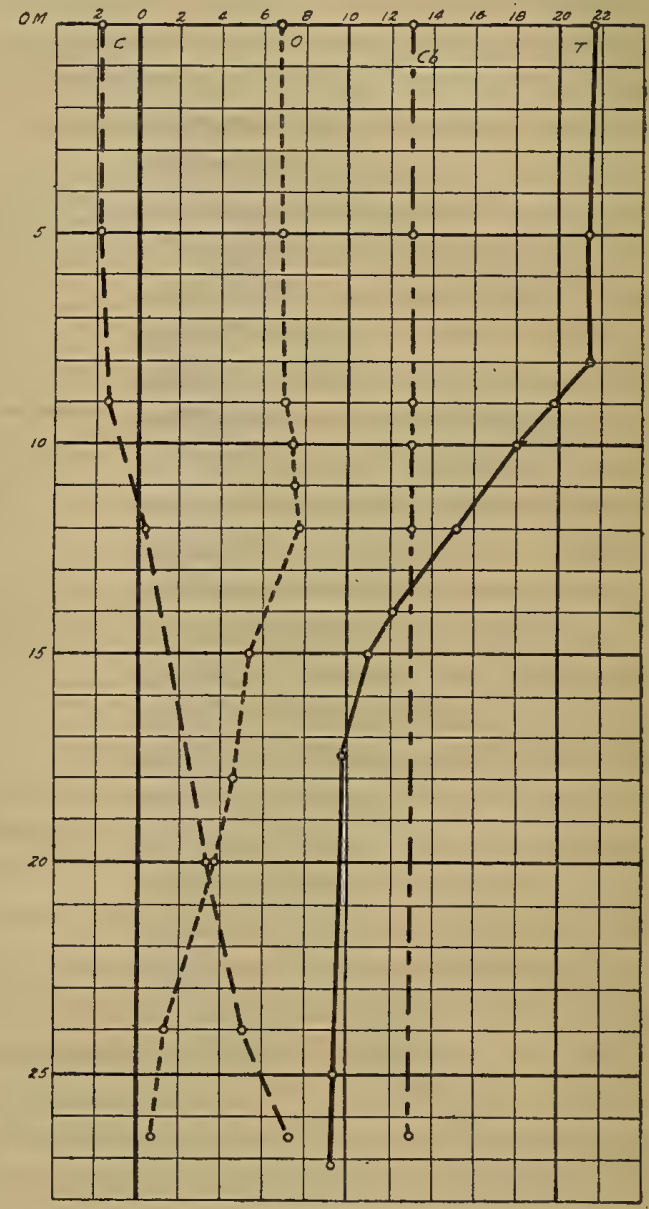

FIG. I2,-Dissolved gases, Hemlock Lake, Aug. 23, Igro. For explanation see fig. 9, p. 580 .

this gas was obtained in the thermocline, a small excess being present there. This increased quantity doubtless represented oxygen that had been liberated in this stratum by chlorophyllaceous organisms.

In the third class of lakes there was a larger quantity of oxygen in the thermocline than in the epilimnion, owing to the fact that this water was cooler, hence capable of holding a larger amount in solution. (See fig. 13-18.) 


\section{CARBON DIOXIDE.}

Carbon dioxide is readily soluble in water, but the total amount that may be found in a lake water depends chiefly upon the quantity of other substances present with which it is most generally combined. It exists in three different states. A part of it is in close chemical union with substances that are dissolved in the water, more especially calcium and magnesium, forming the carbonates of these substances. This is known as the fixed carbon dioxide. Another is in a fairly loose combination with the carbonates, converting them into bicarbonates. This constitutes the half-bound carbon dioxide. A third portion exists in an uncombined or free state, and is known as the free carbon dioxide.

Fixed carbon dioxide.-The quantity of fixed as well as of half-bound carbon dioxide depends upon the amount of calcium and magnesium that may be present in the water, and the amount of these substances, in turn, is dependent upon their relative abundance in the drainage basin. The normal carbonates of calcium and magnesium are only slightly soluble in pure water. Rainwater absorbs carbon dioxide from the air, and obtains still more from decomposing organic matter when it reaches the earth. When this water, which is charged with more or less free carbon dioxide, comes into contact with these normal carbonates, they are freely converted into bicarbonates, which readily pass into solution. Thus, if the water which falls upon the adjacent land and reaches the lake either by surface drainage or by percolating through the ground and finally emerging as a spring, comes into contact with an abundance of calcium and magnesium carbonates on its journey, the lake water will possess a relatively large amount of bicarbonates, and it will be classed as "hard"

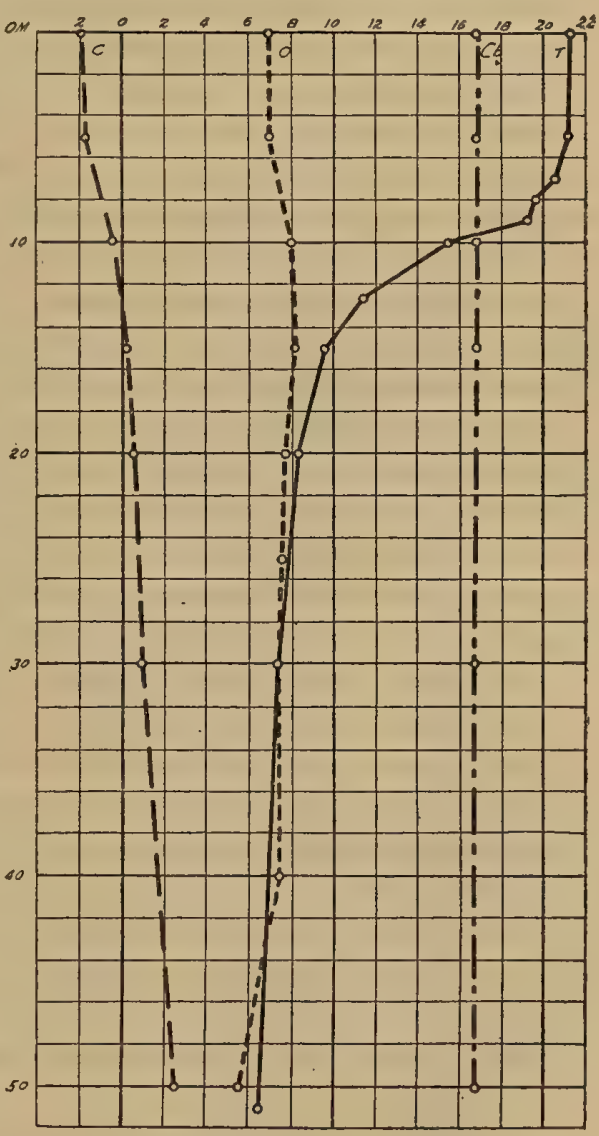

water. If, however, the inflowing water comes into contact with very small amounts of these normal carbonates, the quantity of bicarbonates will be small, hence the lake water will be "soft."

This serves to explain why there is such a marked difference in the quantity of fixed carbon dioxide in the waters of the Finger Lakes. It varied from a minimum of $6.8 \mathrm{cc}$. per liter of water in Canadice Lake to $24.0 \mathrm{cc}$. in Canandaigua Lake. (See table XviII, p. 602, and fig. 9-18.) In Hemlock Lake the fixed carbon dioxide amounted to $12.9 \mathrm{cc}$., 


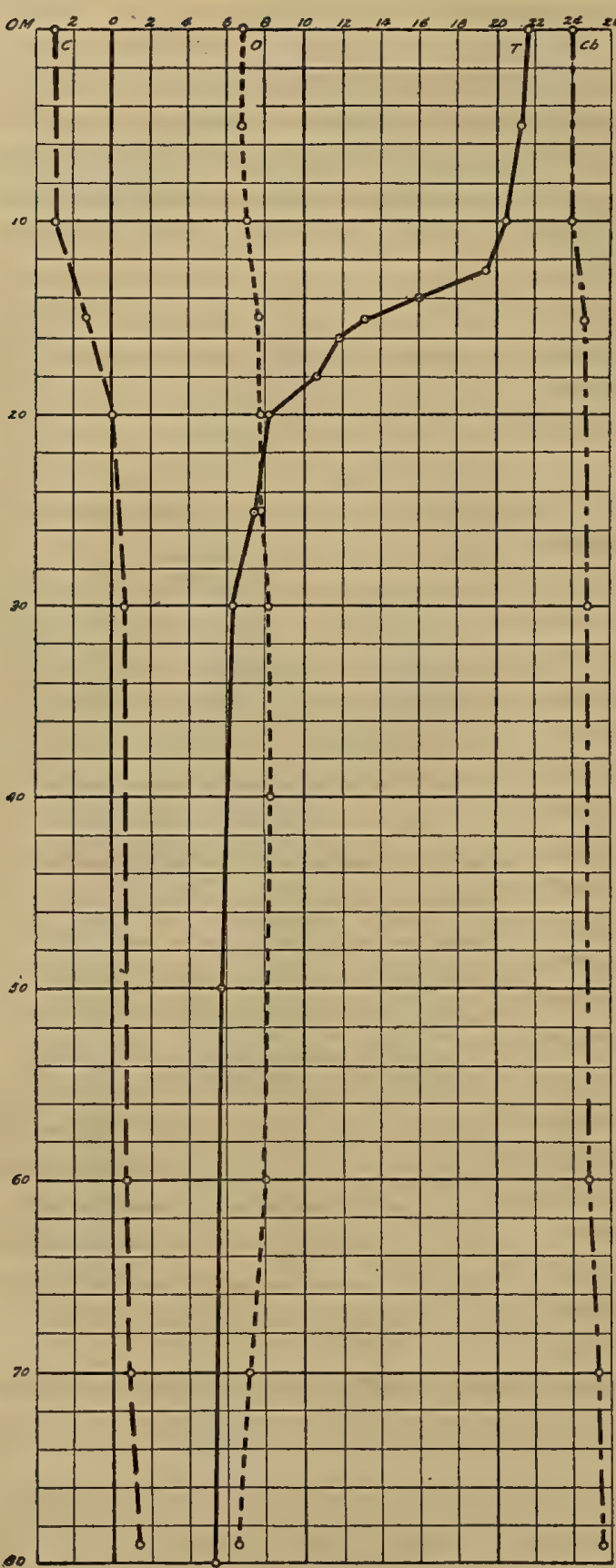

FiG. 14.-Dissolved gases, Canandaigua I,ake, Aug. 20, 1910 For explanation see fig. 9 , p. 580 . in Keuka Lake, 16.8 cc., while in the other lakes it varied from 2 r.o to $24.0 \mathrm{cc}$. In Conesus and Otisco Lakes there was an appreciable increase of this gas toward the bottom; in the former the bottom water contained 5.I cc. more than the surface and in the latter $7.3 \mathrm{cc}$.

A much greater range in the quantity of fixed carbon dioxide has been found in the waters of the Wisconsin lakes. In them the amount varies from a minimum of I.O cc. to a maximum of about $50.0 \mathrm{cc}$.

Half-bound carbon dioxide.-In neutral waters and in those which possess free carbon dioxide the half-bound carbon dioxide is assumed to be equal in amount to the fixed. But in waters which give an alkaline reaction with phenolphthalein there is an excess of fixed carbon dioxide which equals in amount the deficiency of the half-bound. From a biological standpoint the half-bound carbon dioxide is of very great importance since it serves as a source of carbon dioxide for the photosynthetic activities of chlorophyllous organisms. From four-fifths to five-sixths of it may be consumed in this process, but none of the fixed carbon dioxide is available. The free carbon dioxide may be consumed by the algæ, but if found at all in the upper water it is present very generally in relatively small amounts.

Free carbon dioxide. - There are four sources of free carbon dioxide in lake waters. They are the atmosphere, decomposition of organic material, the respiration of organisms, and spring or ground waters. This gas constitutes a small portion of the atmosphere, from three to four parts per 10,000 , so that where a water is freely exposed to the 
air it will be found to contain some free carbon dioxide. The amount, however, is small because it is absorbed only in proportion to its partial pressure. The decay of organic matter yields considerable carbon dioxide and, under favorable conditions, the water may become charged with fairly large amounts derived from this source. This is true especially of the bottom water. Spring waters are generally charged with free carbon dioxide, so that they contribute their quota.

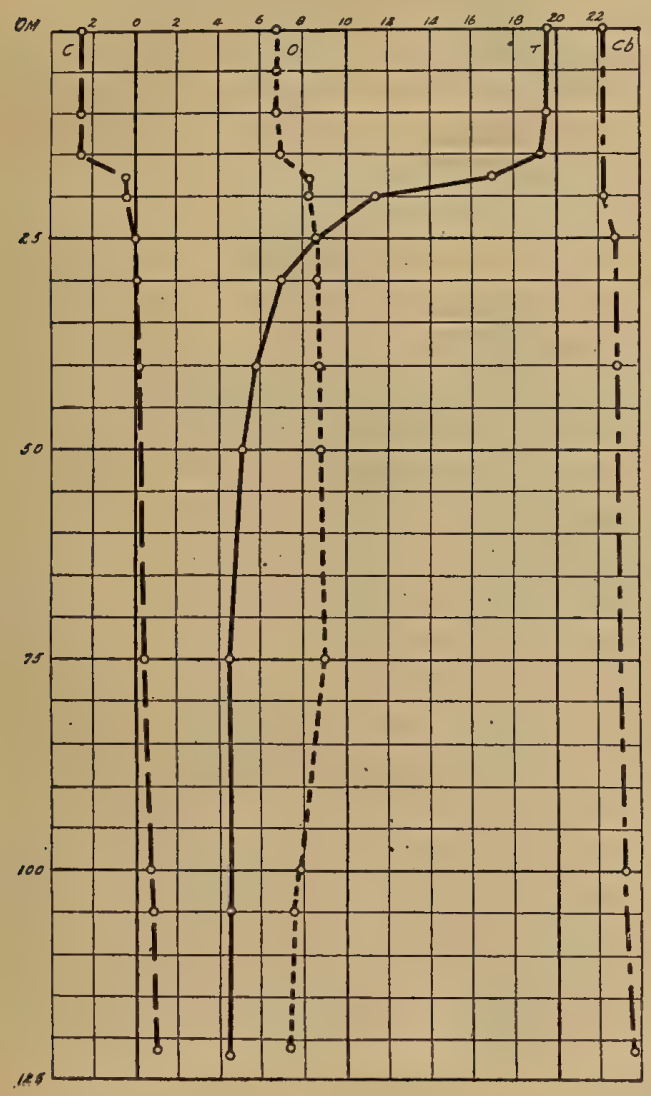

Fig. 15.-Dissolved gases, Cayuga Lake, Aug. II, Igro. For explanation see fig. 9 , p. 580 .

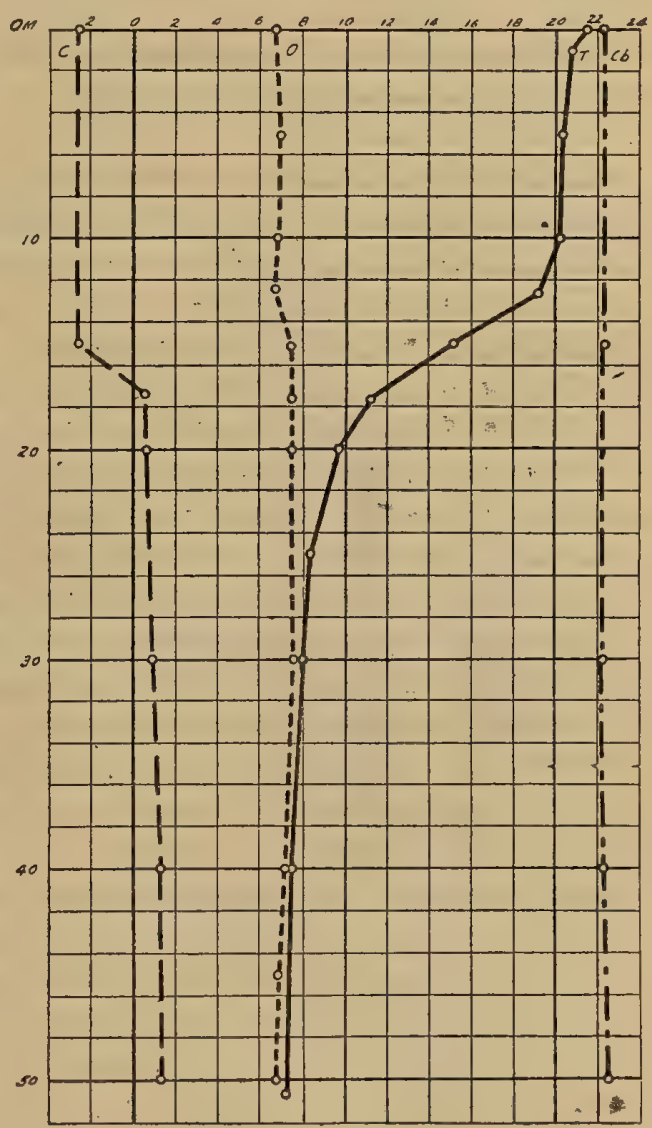

Fig. I6.-Dissolved gases, Owasco Lake, Aug. 13, rgxo. For explanation see fig. 9, p. 580 .

The quantity of free carbon dioxide in the epilimnion is subject to variations. The water of this stratum is kept in circulation by the wind and this process tends to maintain a normal amount of this gas; but the quantity derived from the respiration and the decomposition which take place in this layer tends to raise it above the saturation point. On the other hand, this region is preeminently the zone of photosynthesis and in this process carbon dioxide is consumed and oxygen is liberated. When this stratum is fairly well stocked with chlorophyllous organisms and conditions are 


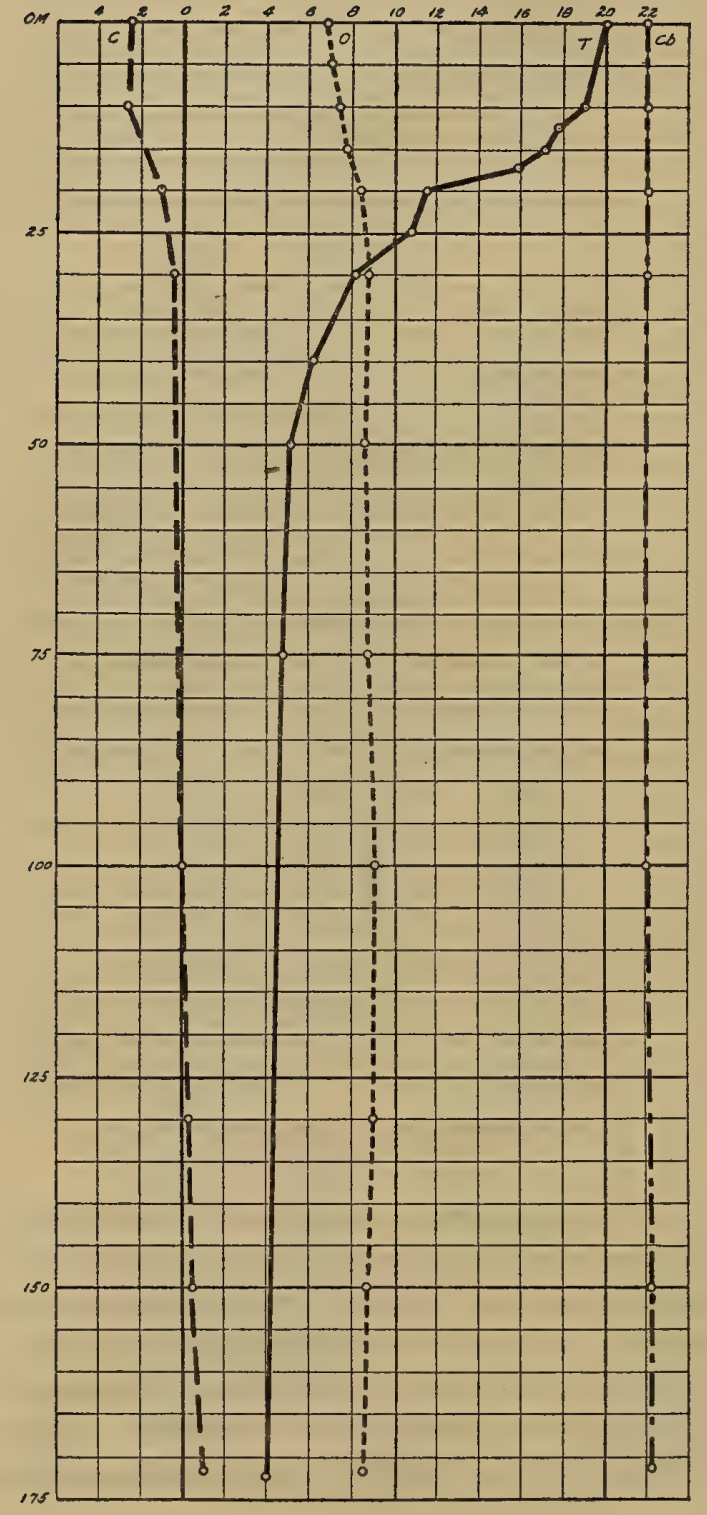

Fic. I7,-Dissolved gases, Seneca Lake, Aug. 4, rgro. For explanation see fig. 9, p. 580 .

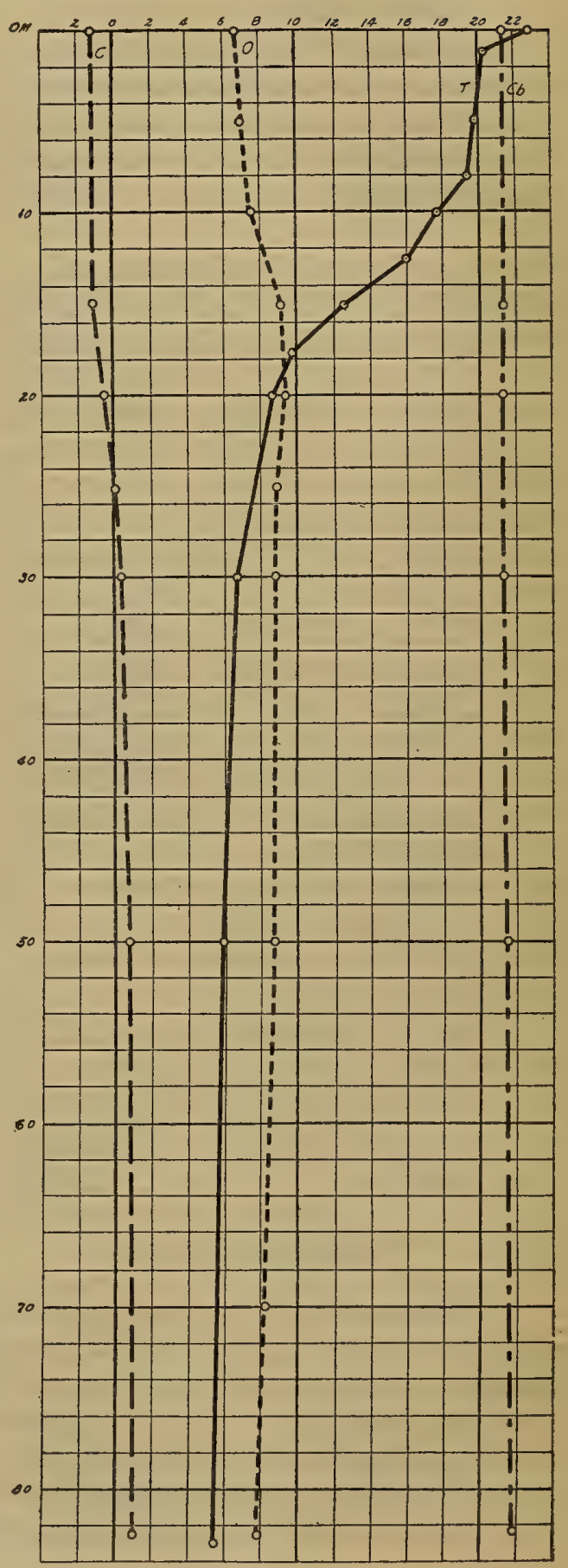

Fic. I8.-Dissolved gases, Skaneateles $L_{\text {,ake, Aug. I5, }}$ I9ro. For explanation see fig. 9, p. 580. 
favorable for their activities, the demand for carbon dioxide exceeds the supply of free gas and some of the half-bound carbon dioxide is consumed. This makes the water alkaline to phenolphthalein, since it leaves an excess of normal carbonate. The degree of alkalinity is measured by the amount of carbon dioxide that would be required to convert this normal carbonate to bicarbonate, and it is dependent upon several factors, chief among which are the free exposure to the atmosphere, decomposition, respiration, the abundance and activity of the algæ, and the weather conditions. Thus it will be seen that the status of the carbon dioxide in the epilimnion is the resultant of the activities of those agents which furnish a supply to this stratum and those which consume this gas.

The epilimnion in all of the Finger Lakes was alkaline, thus showing that not only the free, but also some of the half-bound carbon dioxide, had been consumed by the chlorophyl-bearing organisms. (See table XvirI, p. 602, and fig. 9-18.) The degree of alkalinity varied in the different lakes, ranging from a minimum of about $0.5 \mathrm{cc}$. in Canadice Lake to a maximum of $3.0 \mathrm{cc}$. in Canandaigua Lake; in five lakes the average amount was about $2.5 \mathrm{cc}$. In the carbon dioxide curves the alkaline stratum is indicated by that portion which lies to the left of the zero line and the degree of alkalinity is shown by the quantity of carbon dioxide required to make the water neutral.

The free carbon dioxide content of the thermocline depends upon the conditions which are found there for photosynthesis. In some lakes this stratum lies so near the surface that light conditions are favorable for this process and in such cases not only the free, but a large portion of the half-bound carbon dioxide may be removed by chlorophyllous organisms, thus making the stratum strongly alkaline. But in a large majority of cases conditions in this stratum are not favorable for photosynthesis and the water contains free carbon dioxide. This was true of all of the Finger Lakes.

The hypolimnion is a zone of decomposition, so that its water generally contains an abundance of free carbon dioxide. In the process of respiration also a certain amount of this gas is contributed to the water and some may reach this stratum from underground waters. The largest amount is found at the bottom of the lake, where decomposition is greatest owing to the presence of a large amount of organic material. The maximum quantity found in the bottom waters of the Finger Lakes varied from I:o cc, per liter in Cayuga Lake to 7.I cc. in Hemlock Lake.

\section{PLANKTON}

Methods of observation.-Plankton catches were obtained in the Finger Lakes at the same time that samples of water were procured. They were made either by means of a pump and hose or with a vertical closing net. The former method was used at all depths in Canadice, Conesus, and Hemlock Lakes, and in the upper 30 meters and 50 meters, respectively, of Cayuga and Seneca Lakes, while the latter method was employed below these depths in the last two lakes and at all depths in the other five lakes. For the purpose of counting, a catch was diluted to Io cc., of which $2 \mathrm{cc}$. were removed with a "stempel" pipette, and the crustacea and rotifers therein were counted. When $46512^{\circ}-14-5$ 
only a small number of the larger crustacea were present, the total number in the catch was determined by direct count. One cubic centimeter of the diluted material was then placed in a Sedgwick-Rafter counting cell, and the protozoa and algæ were enumerated in the usual manner. The results were reduced to the number of individuals per liter of .water, and the diagrams were platted on this basis. For table xIx the number of planktonts per liter was multiplied by a thousand in order to give the number per cubic meter of water.

Distribution of plankton organisms.-The vertical distribution of the various plankton organisms in the five lakes on which pump catches were made is shown in the accom-

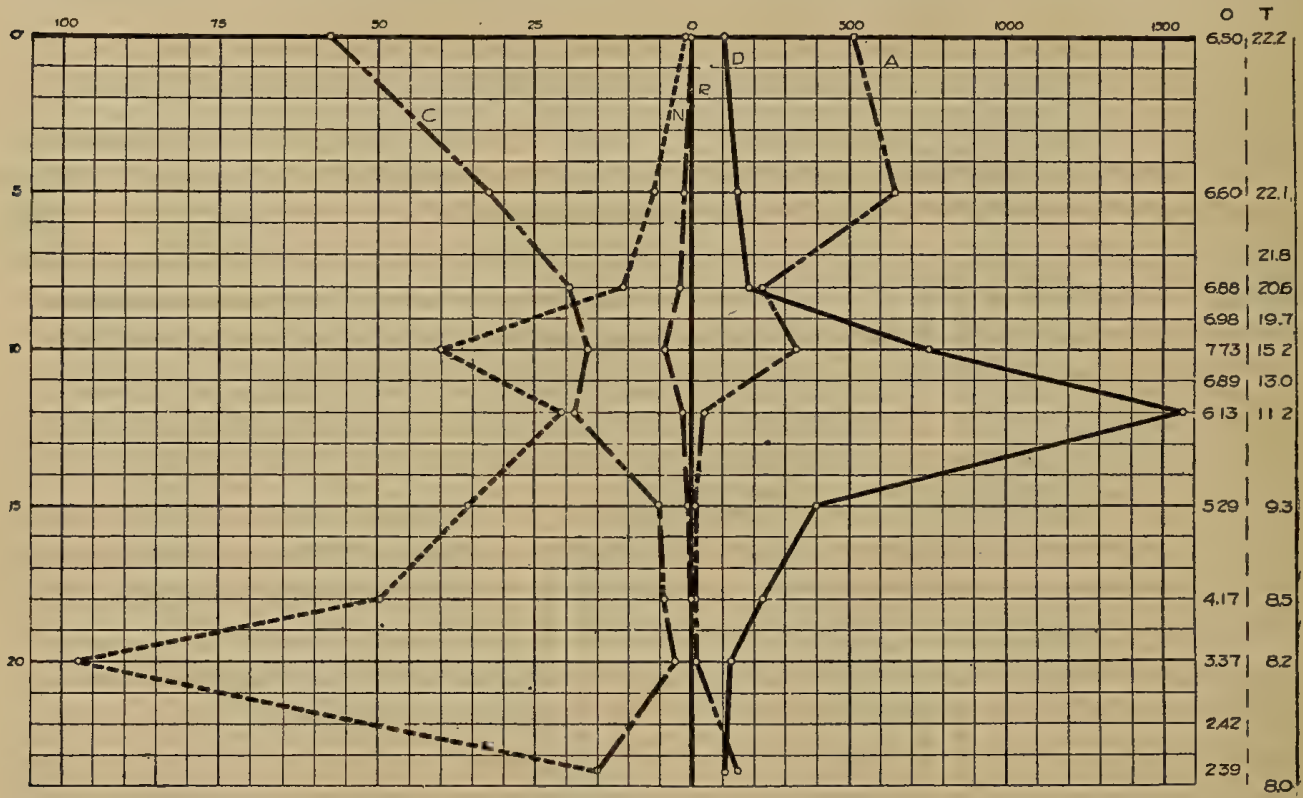

FIG. I9.-Vertical distribution of plankton organisms in Canadice Lake, Aug. 24, rgro. Scale, I vertical space-I meter; I horizontal space $=5$ crustacea, nauplii, and rotifers, and 100 algæ and diatoms per liter of water. Predominant forms: Cyclops, Diaptomus, Ceratium, and Asterionella. The column at the right marked $\mathrm{O}$ shows the quantity of dissolved oxygen at the various depths as indicated, and $T$ represents the temperature.

panying diagrams (fig. I9-23). These figures show the usual distribution of the chlorophyl-bearing portion of the plankton. That is, such organisms are confined chiefly to the epilimnion, where light conditions are most favorable for their photosynthetic activities. So much of the sun's energy is absorbed by the upper meters of water that only a very small portion generally penetrates as far as the thermocline and the hypolimnion, thus making these regions unfavorable for the forms which depend upon light for the manufacture of an important element of their food. But in some of the small lakes of Wisconsin, which are well protected from wind, the top of the thermocline lies at such a slight depth-only 3 to 4 meters below the surface-that enough light for the process of photosynthesis reaches this stratum. This is shown by the large excess of oxygen that is sometimes found in this layer. 
Some of the plankton algæ appear to be able to live saprophytically, and such forms could maintain themselves in this manner in the deeper water. Oscillatoria seems to show this tendency most frequently, and one of its usual distributions was shown in Keuka Lake, where the maximum number was found in the $5^{-20}$ meter stratum. (See table xix, p. 6o6.) In general, however, the presence of large numbers of phytoplanktonts below the thermocline is to be regarded as an indication of their senility.

The curves for zooplankton show two general types of vertical distribution. In one type the lower, as well as the upper, strata of the lake are well populated, as in Canadice and Hemlock Lakes (fig. I8, 19). A similar distribution was noted also in Keuka and

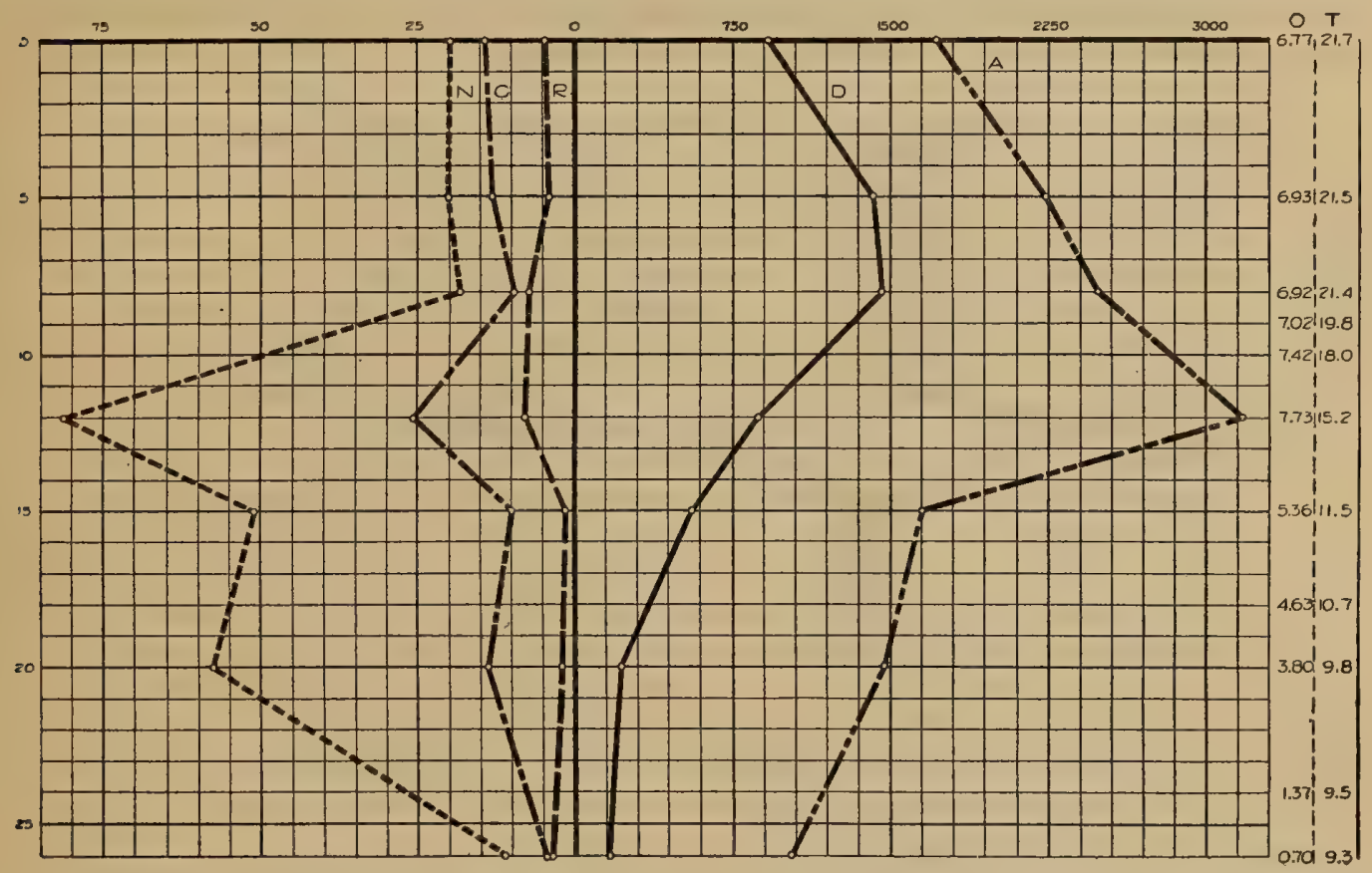

F1G. 20.-Vertical distribution of plankton organisms in Hemlock L,ake, Aug. 23, rgro. Scale, I vertical space=x meter; I horizontal space $=5$ crustacea, nauplii, and rotifers per liter of water and ${ }_{5} 5$ alga and diatoms. Predominant forms: Diaptomus, Ceratium, Coelosphorium, and A sterionelle. The column at the right marked $O$ shows the quantity of dissolved oxygen at the various depths as indicated, and $T$ represents the temperature.

Owasco Lakes. All of the various forms of plankton animals were not distributed throughout the depth of these lakes, since some of them habitually occupy the warmer water of the epilimnion, while others are confined chiefly to the thermocline and the hypolimnion. In the latter stratum the crustacean population consisted almost entirely of Diaptomus and Cyclops and their nauplii, while Polyarthra platyptera had the widest vertical distribution among the rotifers. In general, the forms which have a wide vertical distribution reach their maximum numbers either in the upper or the middle strata of the lake. The presence of a fairly large population in the lower water is dependent upon two factors, viz, an adequate amount of both dissolved oxygen and food 
in this region. Whenever the quantity of either falls below a certain amount, it affects the distribution of the organisms.

The second type of vertical distribution is characterized either by a very sparse population in a certain portion of the hypolimnion or by practically none at all. This is due either to a lack of dissolved oxygen or to a scarcity of food. In Conesus and Otisco Lakes, for example, the absence of organisms in the lower strata was caused by a lack of oxygen. (See fig. 20.) Results obtained on Wisconsin lakes show that the various zooplankton forms are capable of occupying water which has only a very small amount of dissolved oxygen, but a certain minimum quantity is necessary. The Cladocera and Diaptomi are only rarely found in water which has less than 0.2 to $0.3 \mathrm{cc}$. per liter, while the minimum for $C y c l o p s$ and nauplii is about $\mathrm{o.I}$ cc., and for rotifers from

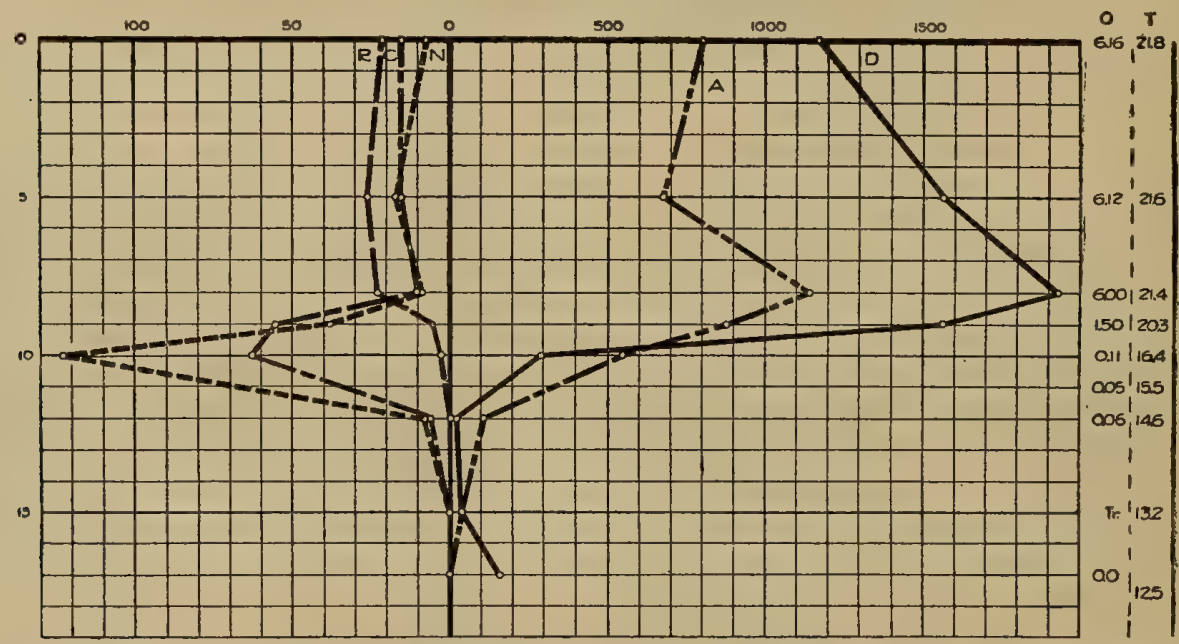

FirG. 2x.-Vertical distribution of plankton organisms in Conesus L,ake, Aug. 25, I.9ro. Scale, I vertical space $=1$ meter; $x$ horizontal space $=10$ crustacea, nauplii, and rotifers per liter of water and roo algæ and diatoms. Predominant forms: Cyclops, Polyarthra, Ceratium, Colosphorium, Fragilaria. The column at the right marked $O$ shows the quantity of dissolved oxygen at the various depths as indicated, and $T$ represents the temperature.

o.I to 0.2 cc. Several forms, however, such as Corethra larvæ, an ostracod, and a number of protozoa are able to live in water which contains no trace of free oxygen; but all of the limnetic zooplanktonts, except larval Corethra, require at least a small amount of this gas in a free state.

In Conesus Lake the maximum number of Diaptomi was found at 9 meters, where the water contained I.5 cc. of oxygen per liter. Cyclops and the nauplii reached their maximum numbers at a depth of Io meters, where this gas amounted to only o.I I cc.; only a few remained at 12 meters, where the quantity of oxygen was only 0.06 cc., and none was found below this depth.

In Cayuga and Seneca Lakes (fig. 2 I and 22) by far the larger portion of the hypolimnion had a very sparse population, being occupied by only a few crustacea, representatives of Cyclops, Diaptomus, and Limnocalanus, between 50 meters and the bottom. 
But the bottom stratum was more densely populated, possessing a larger number of Limnocalanus macrurus, as well as a small population of Mysis relicta. A similar distribution of the crustacea in the lower water was found also in Canandaigua and Skaneateles Lakes.

The limiting factor in these lakes was not the lack of dissolved oxygen in the lower water, since there was an abundance of it even at the bottom, but it was a scarcity of food. The chlorophyl-bearing portion of the plankton is the primary source of food for the rotifers and the crustacea, either directly or indirectly, and, as noted above, these organisms are confined chiefly to the epilimnion. This means substantially that the

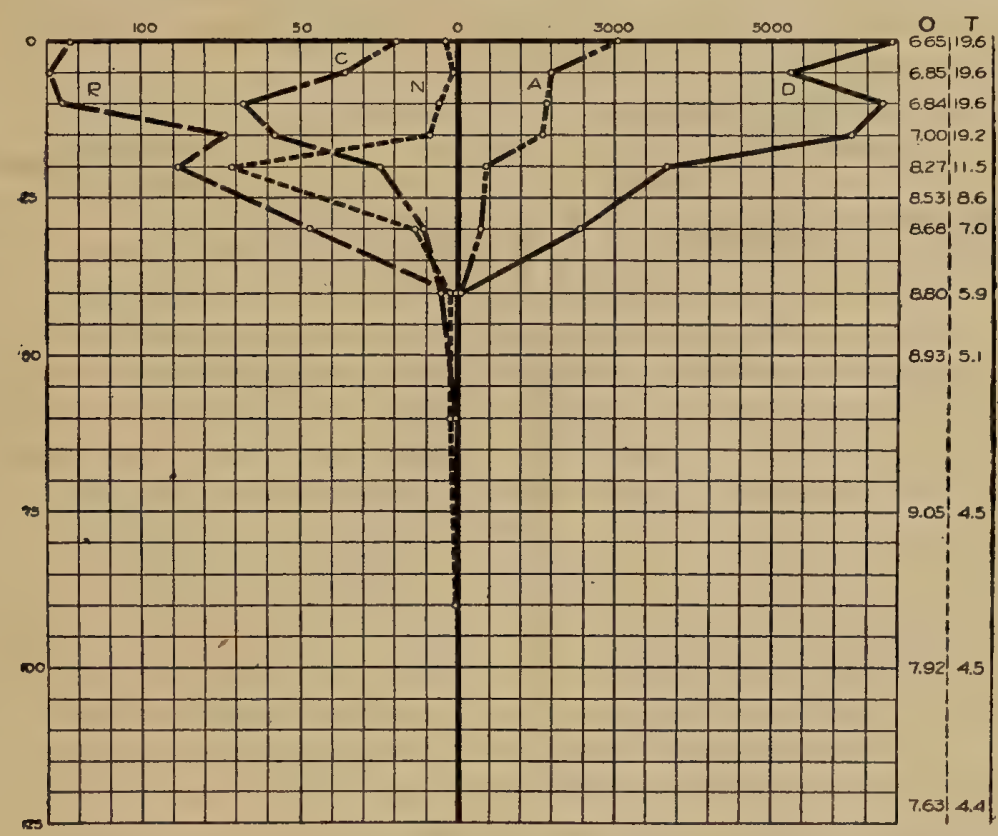

FIG. 22.-Vertical distribution of plankton organisms in Cayuga I,ake, Aug. I2, rgro. Scale, I vertical space = 5 meters; 1 bori zontal space = Io crustacea, nauplii, and rotifers per liter of water and 600 algre and diatoms. Predominant forms: Bosmina, Polyarthra, Ceratium, and Asterionella. The column at the right marked $O$ shows the quantity of dissolved oxygen at the various depths as indicated, and $T$ represents the temperature.

zooplankton, not only of the upper water, but also at all other depths, is dependent upon the food supply of the epilimnion. The zooplanktonts which occupy the epilimnion have the first choice of this food, and those in the hypolimnion must be content with that which reaches them from the upper water.

Granting that the lower water has an abundance of dissolved oxygen, the density of its population depends upon the food supply, which, in turn, is dependent upon the excess produced by the epilimnion and upon the volume of the hypolimnion. The excess of food produced by the upper water depends upon the productivity of that stratum and upon the amount consumed by the zooplankton therein. The largest excess of 
course will be obtained from a large population of chlorophyl-bearing organisms and a small number of consumers. With a given amount of excess food the relative abundance depends upon the volume of the hypolimnion; the larger the volume of the water the smaller the relative abundance of food, and vice versa.

These two types of vertical distribution have been noted also in the Wisconsin lakes. Only a comparatively small number of these bodies of water show the first type of distribution. Among those showing the second type the scarcity or absence of rotifers and crustacea in the lower strata is due in all cases to the lack of oxygen, with the exception of Green Lake, in which an insufficient supply of food is the important factor.

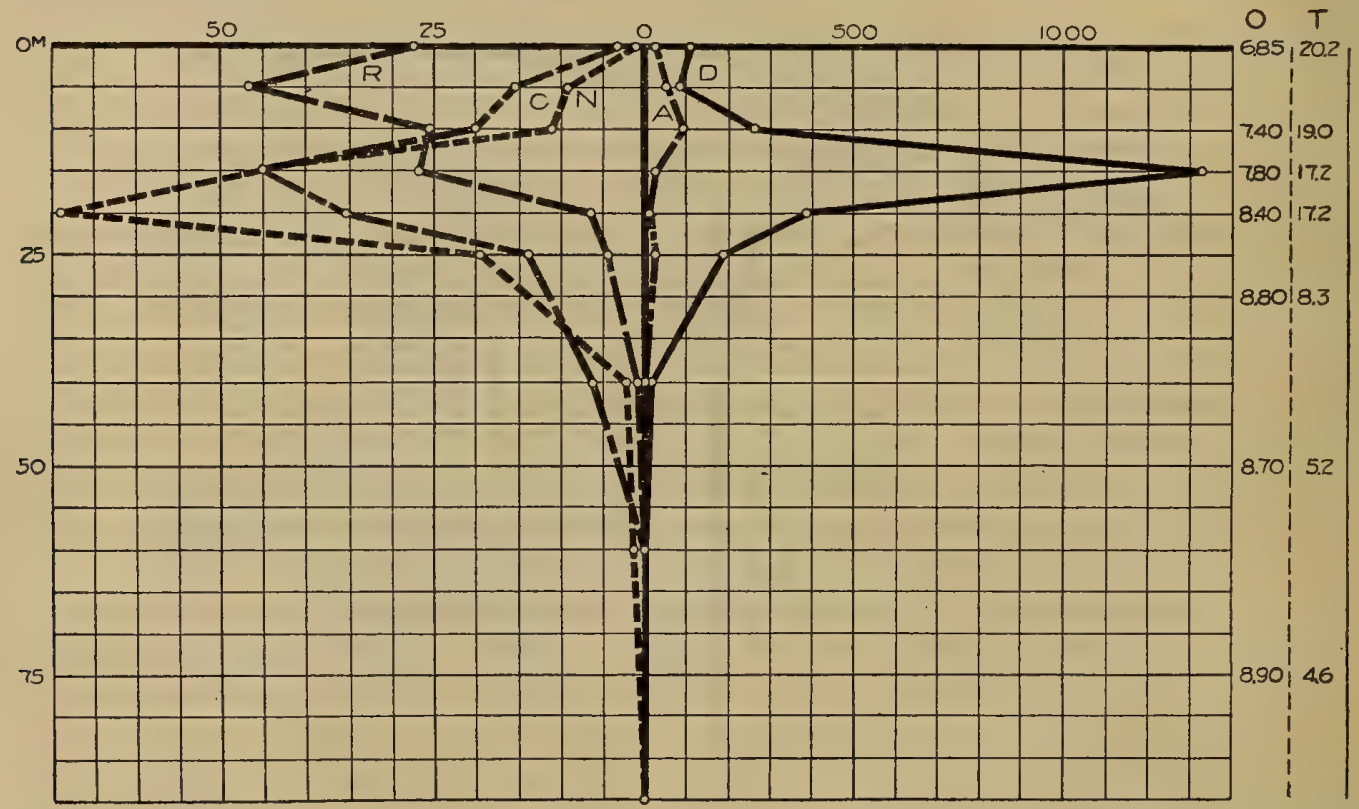

Frc. 23.-Vertical distribution of plankton organisms in Seneca Lake, Aug. 4, rgro. Scale, $x$ vertical space $=5$ meters; $r$ horizontal space $=5$ crustacea, nauplii, and rotifers per liter of water and 100 algæ and diatoms. Predominant forms: $C y c l o p s, P o l y-$ arthra, Ceratium, and Asterionella. Below go meters the organisms were too few to indicate in the diagram. The column at the right marked $O$ shows the quantity of dissolved oxygen at the various depths as indicated, and $T$ represents the temperature.

Taking into account the results obtained both on the Wisconsin lakes and on the Finger Lakes, it appears that when the hypolimnion is well populated the maximum depth of the lake does not exceed 40 to 50 meters. On the other hand, when the maximum depth reaches 70 meters or more a certain portion of the hypolimnion has a sparse population. The upper part of this stratum may possess a fairly large population, since it lies near the source of the food, and the bottom stratum may also be fairly well populated, but between these two regions lies a zone which is poor in zooplankton, owing to the scarcity of food. The thickness of this poorly populated zone depends upon the maximum depth of the lake and also upon the relative amount of food contributed to the hypolimnion by the upper water. 
The Finger Lakes differ widely in area, depth, gas content, etc., but there was no corresponding qualitative difference in the plankton. For the most part the same forms were present in all of the lakes, but the relative abundance of the various forms varied greatly in the different lakes. The most prominent qualitative differences were the absence of Daphnia in Seneca Lake and the absence of Limnocalanus and Mysis in the smaller and shallower lakes.

Phytoplankton.-Three different classes of algæ were represented in the plankton of the Finger Lakes, viz, the Chlorophyceæ by Staurastrum; the Bacillarieæ or diatoms by Melosira, Cyclotella, Tabellaria, Fragilaria, Synedra, Asterionella, and Navicula; and the Myxophyceæ, or blue-green algæ by Anabaena, Aphanizomenon, Lyngbya, Oscillatoria, Calosphcerium, Clathrocystis, Gloeocapsa, and Aphanocapsa. These forms were confined chiefly to the epilimnion where light conditions were most favorable for the process of photosynthesis. In some of the lakes, however, relatively large numbers of phytoplanktonts were found in the thermocline and even in the upper portion of the hypolimnion. In Cayuga Lake, for example, there were more than a thousand Asterionellas per liter of water at a depth of 30 meters and in Skaneateles Lake this same form numbered $\mathrm{I}, \mathrm{I} 6 \mathrm{I}$ per liter in the $30-50$ meter stratum, more than five times as many as were found in the o-ro meter stratum. The presence of this form in such large numbers in the deeper water where light conditions were not so favorable for photosynthesis was most probably due to the fact that they were senile individuals. Both lakes had a fairly high degree of transparency, a Secchi's disk disappearing from view at a depth of 5.I meters in Cayuga Lake and at 10.3 meters in Skaneateles Lake, but it is doubtful whether enough light reached these organisms to enable them to carry on the process of photosynthesis to any considerable extent.

The circulation of the water of the epilimnion tends to produce a uniform distribution of the phytoplankton in this stratum, but the diagrams (fig. 18-22) indicate that such a result was not attained, since all of the curves representing algæ show a point of maximum density of population.

In Canandaigua and Otisco Lakes the blue-green algæ predominated, with Clathrocystis and Colospharium as the most abundant forms. Clathrocystis was the predominant alga in Owasco Lake. Diatoms were most abundant in the other seven lakes, with Asterionella, Fragilaria, and Tabellaria as the predominant forms.

Zooplankton.-Ceratium was found in all of the Finger Lakes, and was most abundant in Cayuga, where 2,525 individuals per liter of water were found at the surface. Hemlock Lake ranked second, with a maximum number of 1,645 individuals per liter at a depth of 12 meters. The smallest number was found in Owasco Lake, and Seneca Lake came next in order. Owing to the fact that this is a chlorophyllous organism, it has been included in the curves showing the blue-green algæ in the diagrams.

Dinobryon appeared in the plankton of 7 of the 10 lakes, but it was scarce in all except Owasco, where it was much more abundant than any of the other small organisms. 
Mallomonas was found in three lakes, viz, Canadice, Conesus, and Otisco. In Canadice and Otisco Lakes it showed the peculiar distribution which has been noted by Whipple; ${ }^{a}$ that is, it was found only in a middle stratum in the lake. In the former lake it was found almost exclusively in the ro- 5 meter stratum, only a few being at the bottom. There was a maximum number of 2, x ro individuals per liter of water at Io meters. In Otisco Lake it was confined to the 9-12 meter stratum, while in Conesus Lake it occupied only the epilimnion or o-8 meter stratum.

Colonies of Vorticella, attached to colonies of Anabaena or some other alga, were found in small numbers in Canadice, Cayuga, Conesus, and Seneca Lakes. The largest number was noted in a surface catch from Cayuga Lake, I 3 colonies per liter of water. In all of these lakes except Seneca, Vorticella was confined to the upper ro meters or less, a few being noted at 5 meters in the latter lake.

Among the rotifers Polyarthra was the only form which was found in all of the lakes. It was most abundant in Cayuga Lake. One catch showed an average of 240 individuals per liter in the o-5 meter stratum. Next in order were Seneca Lake, with an average of 23 individuals per liter in the upper 15 meters, and Conesus, with an average of 23 for the upper 8 meters. In all cases Polyarthra was more abundant in the epilimnion than below this stratum.

Anurce cochlearis was present in all but three lakes, Conesus, Owasco, and Skaneateles. It was not as abundant as Polyarthra. The largest catch showed only 53 individuals per liter. This catch was obtained in Cayuga Lake at a depth of 20 meters. Seneca Lake was next in order, with a maximum number of 40 per liter of water at 5 meters in one evening catch. In all of the other lakes no catch showed more than 4 individuals per liter. In both Cayuga and Seneca Lakes Anuraea cochlearis was found chiefly in the upper 20 meters of water.

Asplanchna likewise was most abundant in Cayuga and Seneca Lakes. The maximum number of 26 individuals per liter of water was found at a depth of 5 meters in Cayuga Lake, while a catch at this same depth in Seneca Lake showed I5. A very few individuals were found in Keuka, Owasco, and Skaneateles Lakes, and none in the other lakes. It was confined chiefly to the epilimnion.

Notholca longispina was present in all of the lakes except Owasco and Skaneateles. The largest number, 4 per liter, was found at a depth of 12 meters in Hemlock Lake.

Conochilus was found in all except three lakes, Canadice, Conesus, and Otisco, but it was present in very small numbers and always in the epilimnion.

Anuraea aculeata appeared in the catches from five lakes, but its maximum number was less than 3 individuals per liter of water.

The catches from Cayuga and Seneca Lakes contained a few Ploesoma, the largest number being 6 per liter.

A few specimens of Triarthra were found in Cayuga, Hemlock, and Keuka Lakes.

In counting the copepods no attempt was made to enumerate the different species of Diaptomus and Cyclops separately. The former genus was represented in all of the 
lakes. Two species, $D$. minutus and $D$. sicilis, were found in Cayuga and Seneca Lakes, but only the former species was present in the other lakes. In its vertical distribution, Diaptomus was found at all depths where the water contained a sufficient amount of dissolved oxygen. In Conesus and Otisco Lakes it did not occupy the bottom water, owing to the absence of oxygen, but the maximum number in both was obtained just above the low oxygen zone. The largest number in Conesus Lake, 43 individuals per liter, was found at 9 meters where the water contained I. $5 \mathrm{cc}$. of oxygen, but the number fell below I per liter at Io meters where the water contained only o. I I cc. of free oxygen per liter. In Otisco Lake the largest number was found in the 9-12 meter stratum where the oxygen decreased from $5.8 \mathrm{cc}$. at 9 meters to $0.34 \mathrm{cc}$. at 12 meters.

The largest catch of Diaptomus was obtained at the surface of Canadice Lake, 48 individuals per liter. This was a rather unusual distribution, since this form usually avoids a few meters of the upper water in the daytime. The second largest catch was that on Conesus Lake, noted above. In Seneca Lake the maximum number, 20 per liter, was found at 50 meters. In both Seneca and Cayuga Lakes, Diaptomus showed a diurnal movement of about ro meters.

Representatives of the genus Cyclops were found in all of the lakes. In Seneca and Cayuga Lakes this form was most abundant in the upper 50 meters, although it extended to the bottom. In some lakes, however, it was confined entirely to the upper water. In Canandaigua Lake it was not found below I 5 meters; in Skaneateles Lake, not below the 20-30-meter stratum; and in Owasco Lake, not below the Io-I 5-meter layer. This was a rather unusual distribution, since in general Cyclops seems to experience no difficulty in occupying much deeper water than is found in these lakes. Their absence from the lower water was not due to a scarcity of dissolved oxygen, because there was an abundance of it in the bottom water of these lakes, in fact almost or quite as much as at the surface.

In Keuka Lake Cyclops was most abundant in the upper ro meters, but in Canadice and Hemlock Lakes it was distributed rather uniformly from surface to bottom. In Conesus Lake its distribution was similar to that which has been found frequently in some of the Wisconsin lakes, viz, a fairly uniform distribution in the epilimnion with a maximum number in the thermocline, where there is a rapid decrease of the oxygen. The maximum number, 62 per liter, was found at ro meters, where the dissolved oxygen amounted to only o.I I cc. per liter. But in Otisco Lake, where there was also a rapid decrease of dissolved oxygen in the thermocline, no such phenomenon was found, there being a fairly uniform distribution in the epilimnion with only a small number below this stratum.

Limnocalanus in small numbers was found in five lakes-Cayuga, Seneca, Canandaigua, Skaneateles, and Owasco. It was confined to the hypolimnion, or lower stratum, of all of these lakes. A very few specimens of Epischura were obtained in Keuka and Owasco Lakes.

The copepod nauplii showed great diversity in their vertical distribution. They were found at all depths in the majority of the lakes, but they were more abundant 
in the upper strata, say, in the upper 20 or 30 meters of the deeper lakes and in the upper Io or 5 meters of the shallower ones. There was one marked exception to this. In Canadice Lake the maximum number was found at a depth of 20 meters, within 4 meters of the bottom. In Conesus and Otisco Lakes the distribution was similar to that which has been found in some of the Wisconsin lakes. That is, the maximum number was found in the thermocline, where there was only a small amount of dissolved oxygen. For example, there were 123 individuals per liter at a depth of ro meters in Conesus Lake where the oxygen amounted to only o.I I cc. per liter of water.

The cladoceran population of Seneca Lake was characterized by the absence of Daphnia and by the relative abundance of Bosmina. The latter occupied the upper 50 meters of water and the largest number, 3 I individuals per liter, was found at a depth of 5 meters in an evening catch. The only other Cladocera represented in the plankton catches of Seneca Lake were Ceriodaphnia and Polyphemus pediculus, but only a very small number of each was found. Daphnia was absent from the regular plankton hauls on Cayuga Lake, but a few specimens of $D$. hyalina were found in one of the townet catches. Bosmina was found at all depths in Cayuga Lake, but it was most abundant in the upper 30 meters. The maximum number, 66 individuals per liter of water, was obtained in a morning catch at a depth of ro meters. Ceriodaphnia and Polyphemus pediculus were also represented in the plankton of Cayuga Lake, but they were not noted in any other lakes.

Daphnia longispina var. hyalina was represented in all of the lakes except Seneca. It was confined chiefly to the epilimnion of the various lakes and was most abundant in Hemlock Lake. Daphnia pulex was present in Canadice and Conesus Lakes. It was scarce in the former but a little more abundant than $D$. hyalina in the latter.

A few Daphnia retrocurva were found in the I2-meter catch of Hemlock Lake. Diaphanosoma was noted in Canadice, Canandaigua, Hemlock, Otisco, Owasco, and Skaneateles Lakes, and was confined to the epilimnion. It was most abundant in Canandaigua Lake, where it averaged about three individuals per liter in the upper I 5 meters.

Bosmina was obtained in all of the lakes except Canadice, Conesus, and Otisco. It was most abundant in Cayuga Lake and Seneca came next. Only a relatively small number was obtained in the other five lakes.

A few specimens of Leptodora hyalina were found in each of the lakes except Conesus and Seneca.

Specimens of Mysis relicta were taken with townets in the lower water of Canandaigua, Cayuga, Keuka, and Seneca Lakes. 


\section{APPENDIX.-STATISTICAL TABLES.}

\section{HYDROGRAPHIC DETAILS OF THE NEW YORK LAKES.}

In tables $\mathrm{XV}$ and $\mathrm{xVI}$ are given the details of the hydrography of the New York lakes. The figures are given both on the metric system and on the foot and mile system (table XvI). All measurements and all primary computations are made on the metric system. The areas given for the lake basins at 25 feet, 50 feet, etc., are derived not from replatting the soundings and drawing a new set of contours, but from the hypsographic curves constructed from the measurements on the metric system.

In the tables on the metric system columns $2-4$ give the areas of the lake basin and the length of contours at the depths stated in column $I$. In the subsequent columns the areas, volumes, and slopes are those between the depths stated in column 5 .

Volumes are usually stated to tenths of a million cubic meters.

The formulas used in computation will be found on p. 538 .

The general results of the hydrography are given in table I, p. 537.

TABLE XV.-HydRographic DETAILS.

CANADICE LAKE

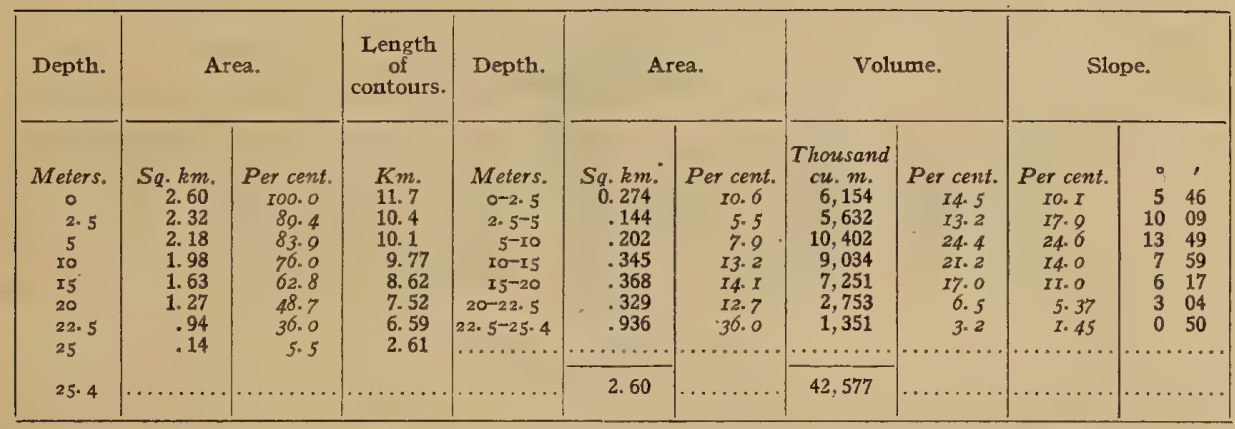

OTISCO LAKE.

[Measurements to causeway near south end.]

\begin{tabular}{|c|c|c|c|c|c|c|c|c|c|c|}
\hline $\begin{array}{r}0 \\
5 \\
10 \\
15\end{array}$ & $\begin{array}{l}6.84 \\
4.77 \\
4.10 \\
3.52\end{array}$ & $\begin{array}{r}100.0 \\
69.7 \\
50.9 \\
51.5\end{array}$ & $\begin{array}{l}16.6 \\
12.7 \\
12.1 \\
10.5\end{array}$ & $\begin{array}{c}0-5 \\
5-10 \\
10-x 5 \\
15-20.1\end{array}$ & $\begin{array}{l}2.07 \\
0.67 \\
0.58 \\
3.52\end{array}$ & $\begin{array}{r}30.3 \\
0.8 \\
8.5 \\
51.5\end{array}$ & $\begin{array}{r}28,850 \\
22,160 \\
19,040 \\
6,390\end{array}$ & $\begin{array}{r}37.7 \\
29.0 \\
24.9 \\
8.4\end{array}$ & $\begin{array}{r}3.5 \\
18.5 \\
10.5 \\
1.5\end{array}$ & $\begin{array}{rr}2 & 02 \\
10 & 29 \\
11 & 02 \\
0 & 52\end{array}$ \\
\hline & & & & & 6.84 & & 76,440 & & & \\
\hline
\end{tabular}

CANANDAIGUA LAKE

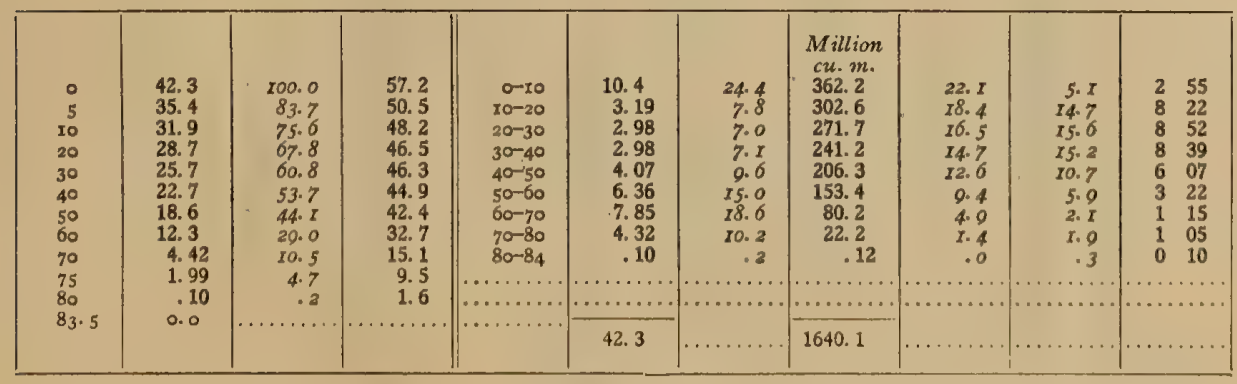


TABLE XV.-HyDROGRAPHIC DETAYIS-Continued.

CAYUGA IAKE

\begin{tabular}{|c|c|c|c|c|c|c|c|c|c|c|c|}
\hline $\begin{array}{c}\text { Depth. } \\
\text { Meters. } \\
\therefore\end{array}$ & \multicolumn{2}{|c|}{ Area. } & $\mid \begin{array}{c}\begin{array}{c}\text { Length } \\
\text { of } \\
\text { contours. }\end{array} \\
K m .\end{array}$ & Depth. & \multicolumn{2}{|c|}{ Area. } & \multicolumn{2}{|c|}{ Volume. } & \multicolumn{3}{|c|}{ Slope. } \\
\hline $\begin{array}{c}\text { Meters. } \\
0 \\
5 \\
10 \\
20 \\
30 \\
40 \\
50 \\
60 \\
70 \\
80 \\
90 \\
100 \\
110 \\
120 \\
125 \\
130 \\
132.6\end{array}$ & $\begin{array}{r}\text { Sq. } \mathrm{km} . \\
172.1 \\
138.7 \\
124.8 \\
112.0 \\
104.0 \\
93.9 \\
81.9 \\
73.6 \\
65.8 \\
58.7 \\
50.7 \\
42.3 \\
33.9 \\
16.0 \\
7.4 \\
0.8 \\
0.0\end{array}$ & $\begin{array}{c}\text { Per cent. } \\
\text { roo. } \\
78.9 \\
72.5 \\
65.1 \\
60.5 \\
54.6 \\
47.6 \\
42.8 \\
38.2 \\
34.1 \\
29.5 \\
24.6 \\
19.7 \\
9.3 \\
4.3 \\
0.4\end{array}$ & $\begin{array}{r}K m . \\
153.8 \\
116.5 \\
100.9 \\
93.3 \\
90.8 \\
86.4 \\
83.9 \\
80.4 \\
76.3 \\
72.4 \\
68.9 \\
58.2 \\
53.9 \\
39.4 \\
30.3 \\
6.2\end{array}$ & $\begin{array}{c}\text { Meters. } \\
0-10 \\
10-20 \\
20-30 \\
30-40 \\
40-50 \\
50-60 \\
60-70 \\
70-80 \\
80-90 \\
90-100 \\
100-110 \\
110-120 \\
120-130 \\
130-133\end{array}$ & $\begin{array}{r}\text { Sq. } \mathrm{km} . \\
47.4 \\
12.7 \\
8.0 \\
10.1 \\
12.0 \\
8.3 \\
7.8 \\
7.1 \\
8.0 \\
8.4 \\
8.4 \\
17.9 \\
15.3 \\
0.8 \\
\ldots \ldots\end{array}$ & $\begin{array}{r}\text { Per cent. } \\
27.5 \\
7.4 \\
4.6 \\
5.9 \\
7.0 \\
4.8 \\
4.6 \\
4.1 \\
4.6 \\
4.9 \\
4.9 \\
10.4 \\
8.9 \\
0.4 \\
\ldots . . .\end{array}$ & $\begin{array}{c}\text { Thousand } \\
\text { cu. m. } \\
1,435.7 \\
1,183.4 \\
1,080.2 \\
989.6 \\
878.7 \\
777.3 \\
696.4 \\
622.0 \\
546.8 \\
464.8 \\
380.5 \\
244.2 \\
79.1 \\
0.7 \\
\ldots \ldots \ldots\end{array}$ & \begin{tabular}{|r|} 
Per cont. \\
15.4 \\
12.6 \\
11.5 \\
10.6 \\
9.4 \\
8.3 \\
7.4 \\
6.6 \\
5.8 \\
5.0 \\
4.7 \\
2.6 \\
0.8 \\
$\ldots \ldots \ldots$
\end{tabular} & 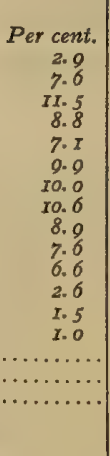 & $\begin{array}{l}0 \\
1 \\
4 \\
6 \\
5 \\
4 \\
5 \\
5 \\
6 \\
5 \\
4 \\
3 \\
1 \\
0 \\
0 \\
\ldots\end{array}$ & $\begin{array}{l}4 \\
40 \\
21 \\
34 \\
02 \\
04 \\
39 \\
43 \\
03 \\
05 \\
21 \\
47 \\
30 \\
52 \\
34 \\
\ldots \ldots\end{array}$ \\
\hline
\end{tabular}

KEUKA LAKE.

\begin{tabular}{|c|c|c|c|c|c|c|c|c|c|c|c|}
\hline 0 & 47.0 & 100.0 & 111.2 & o-ro & 7.30 & 15.6 & 432.6 & 30.2 & 12.4 & 7 & 04 \\
\hline Io & 39.7 & 84.4 & 99.5 & $10-20$ & 5.49 & $I x \cdot 7$ & 368.8 & 25.7 & 17.7 & 10 & 02 \\
\hline 20 & 34.2 & 72.8 & 95.8 & $20-30$ & 7. 79 & 16.6 & 302.0 & $2 I . I$ & $I I: 7$ & 6 & 40 \\
\hline 30 & 26.4 & 56.2 & 86.4 & $30-40$ & 11.30 & 24.0 & 204.7 & $r 4.4$ & $6 . I$ & 3 & 29 \\
\hline 40 & 15.1 & $32 . I$ & 50.4 & $40-50$ & 7.92 & 16.9 & 108.8 & $7 \cdot 4$ & 5.3 & 3 & 02 \\
\hline \multirow{3}{*}{$\begin{array}{l}50 \\
55.8\end{array}$} & 7. 17 & 15. $z$ & 35.8 & $5^{\circ}-57$ & 7.17 & 15.2 & 16.7 & I. 2 & 1.4 & 0 & 48 \\
\hline & 0.0 & & & & & & 政 & & & & \\
\hline & & & & & 47.0 & & $1,433.7$ & & & & \\
\hline
\end{tabular}

OWASCO LAKE

\begin{tabular}{|c|c|c|c|c|c|c|c|c|c|c|c|}
\hline $\begin{array}{l}0 \\
10 \\
20 \\
30 \\
40 \\
50\end{array}$ & $\begin{array}{c}26.7 \\
21.3 \\
17.0 \\
14.6 \\
10.2 \\
3.68\end{array}$ & $\begin{array}{r}100.0 \\
79.8 \\
63.8 \\
54.8 \\
38.4 \\
13.8\end{array}$ & $\begin{array}{l}41.6 \\
37.3 \\
33.9 \\
20.0 \\
22.1 \\
13.7\end{array}$ & $\begin{array}{r}0-10 \\
10-20 \\
20-30 \\
30-40 \\
40-50 \\
50-54\end{array}$ & $\begin{array}{l}5.38 \\
4.27 \\
2.41 \\
4.37 \\
6.57 \\
3.68\end{array}$ & $\begin{array}{r}20.1 \\
16.0 \\
9.0 \\
16.4 \\
24.6 \\
13.8\end{array}$ & $\begin{array}{c}\text { Million } \\
\text { cu. m. } \\
238.3 \\
191.3 \\
158.1 \\
122.8 \\
66.9 \\
3.31\end{array}$ & $\begin{array}{r}30.5 \\
24.5 \\
20.3 \\
15.7 \\
8.6 \\
0.4\end{array}$ & $\begin{array}{r}7.3 \\
8.3 \\
13.2 \\
6.0 \\
2.7 \\
2.7\end{array}$ & $\begin{array}{l}4 \\
4 \\
7 \\
3 \\
I \\
I\end{array}$ & $\begin{array}{l}\text { II } \\
44 \\
36 \\
26 \\
33 \\
33\end{array}$ \\
\hline & & & & & 26.68 & & 780.7 & & & & \\
\hline
\end{tabular}

SENECA LAKE.

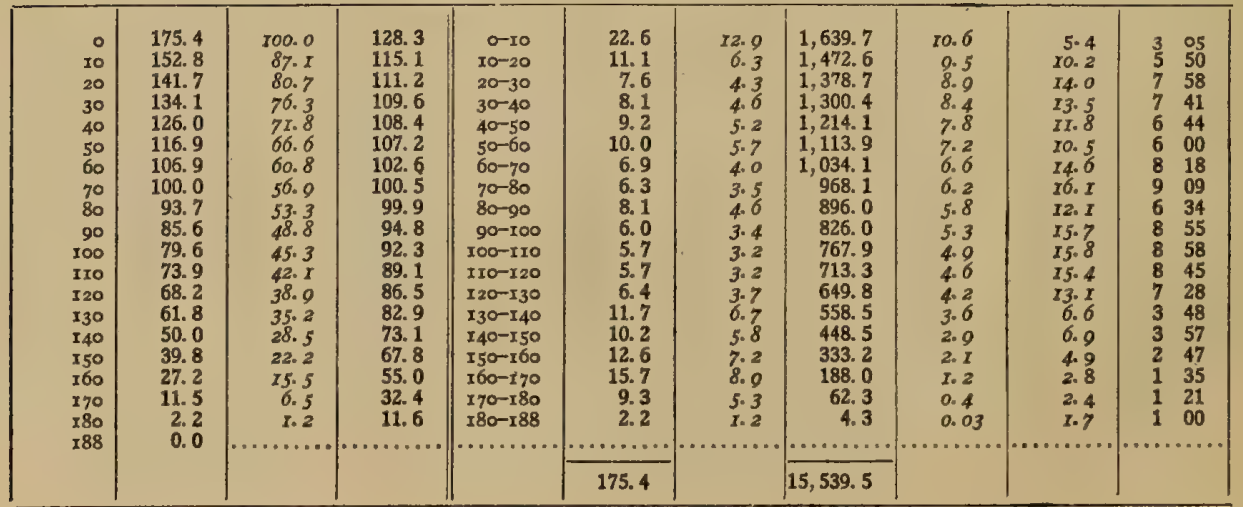


A LIMNOLOGICAL STUDY OF THE FINGER LAKES.

TABLE XV.-Hydrographic Detail,S-Continued.

SKANEATELES LAKE.

\begin{tabular}{|c|c|c|c|c|c|c|c|c|c|c|c|}
\hline $\begin{array}{c}\text { Depth. } \\
\text { Meters. } \\
0 \\
\text { Io }\end{array}$ & \multicolumn{2}{|c|}{ Area. } & $\begin{array}{c}\text { L,ength } \\
\text { of } \\
\text { contours. }\end{array}$ & Depth. & \multicolumn{2}{|c|}{ Area. } & \multicolumn{2}{|c|}{ Volume. } & \multicolumn{3}{|c|}{ Slope. } \\
\hline $\begin{array}{r}\text { Meters. } \\
0 \\
10 \\
20 \\
30 \\
40 \\
50 \\
60 \\
70 \\
80 \\
85 \\
90\end{array}$ & $\begin{array}{c}\text { Sq. } \mathrm{km} . \\
35.9 \\
27.1 \\
24.2 \\
21.7 \\
19.6 \\
16.8 \\
14.0 \\
10.3 \\
5.26 \\
2.31 \\
0.03\end{array}$ & $\begin{array}{c}\text { Per cent. } \\
100.0 \\
75.5 \\
.67 .3 \\
60.5 \\
54.6 \\
46.7 \\
38.9 \\
28.7 \\
14.6 \\
6.4 \\
.008\end{array}$ & $\begin{array}{r}K m . \\
52.0 \\
45.2 \\
43.8 \\
42.0 \\
40.3 \\
38.9 \\
36.1 \\
30.3 \\
31.0 \\
14.6 \\
0.8\end{array}$ & $\begin{array}{l}\text { Meters. } \\
\text { o-10 } \\
10-20 \\
20-30 \\
30-40 \\
40-50 \\
50-60 \\
60-70 \\
70-80 \\
80-85 \\
85-90.5\end{array}$ & $\begin{array}{c}S q . \mathrm{km} . \\
8.82 \\
2.93 \\
2.42 \\
2.14 \\
2.84 \\
2.80 \\
3.65 \\
5.05 \\
2.95 \\
2.57 \\
\ldots \ldots \ldots \\
\ldots . . .\end{array}$ & $\begin{array}{c}\text { Per cent. } \\
24.5 \\
8.2 \\
6.7 \\
6.0 \\
7.9 \\
7.8 \\
10.2 \\
14.1 \\
8.2 \\
6.4\end{array}$ & $\begin{array}{c}\text { Thousand } \\
\text { cu. } m . \\
314.0 \\
256.3 \\
229.4 \\
206.5 \\
181.6 \\
153.8 \\
121.1 \\
76.4 \\
18.4 \\
5.3 \\
\ldots \ldots \ldots \\
1,562.8\end{array}$ & $\begin{array}{c}\text { Per cent. } \\
20.1 \\
16.4 \\
14.7 \\
13.2 \\
11.6 \\
9.8 \\
7.7 \\
4.9 \\
1.2 \\
0.3\end{array}$ & $\begin{array}{c}\text { Per cent. } \\
5.51 \\
15.1 \\
17.7 \\
19.2 \\
13.9 \\
13.9 \\
9.1 \\
6.1 \\
3.9 \\
1.7\end{array}$ & $\begin{array}{r}0 \\
3 \\
8 \\
10 \\
10 \\
7 \\
7 \\
5 \\
3 \\
2 \\
0\end{array}$ & $\begin{array}{l}. \\
09 \\
35 \\
02 \\
52 \\
55 \\
55 \\
12 \\
29 \\
14 \\
58\end{array}$ \\
\hline
\end{tabular}

Table XVI.-Areja and Volume of the Lakes in Miles, Acres, and Fetet.

CANADICE LAKE,

\begin{tabular}{|c|c|c|c|c|c|c|c|c|}
\hline Depth. & \multicolumn{3}{|c|}{ Area. } & Depth. & \multicolumn{2}{|c|}{ Area. } & \multicolumn{2}{|c|}{ Volume, } \\
\hline $\begin{array}{r}\text { Feet. } \\
0 \\
25 \\
50 \\
75 \\
83\end{array}$ & $\begin{array}{r}S q . \\
1.00 \\
.80 \\
.63 \\
.34\end{array}$ & $\begin{array}{r}\text { Acres. } \\
642 \\
512 \\
404 \\
217\end{array}$ & $\begin{array}{c}\text { Per cent. } \\
\text { roo. } \\
70.8 \\
62.0 \\
33.8\end{array}$ & $\begin{array}{l}\text { Feet. } \\
0-25 \\
25-50 \\
50-75 \\
75-83\end{array}$ & $\begin{array}{r}\text { Acres. } \\
130 \\
108 \\
187 \\
217 \\
\ldots \ldots \ldots \\
642\end{array}$ & $\begin{array}{c}\text { Per cent. } \\
20.3 \\
16.8 \\
20.1 \\
33.8\end{array}$ & 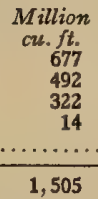 & $\begin{array}{r}\text { Per cent. } \\
45 . x \\
32.7 \\
20.4 \\
.9\end{array}$ \\
\hline
\end{tabular}

CANANDAIGUA LARE.

\begin{tabular}{|r|r|r|r||r|r|r|r|r|}
\hline 0 & 16.3 & 10,440 & 100.0 & $0-50$ & 2,890 & 27.7 & 19,390 & 33.3 \\
50 & 11.8 & 7,550 & 72.3 & $50-100$ & 1,250 & 12.0 & 14,460 & 24.9 \\
100 & 9.84 & 6,300 & 60.2 & $100-150$ & 1,260 & 12.0 & 12,240 & 21.0 \\
150 & 7.87 & 5,040 & 48.3 & $150-200$ & 2,200 & 21.5 & 8,925 & 15.3 \\
200 & 4.44 & 2,840 & 27.4 & $200-250$ & 990 & 9.5 & 3,045 & 5.2 \\
250 & 2.90 & 1,850 & 17.7 & $250-274$ & 1,850 & 17.7 & 130 & .2 \\
274 & $\ldots \ldots \ldots \ldots$ & $\ldots \ldots \ldots \ldots$ & $\ldots \ldots \ldots \ldots$ & $\ldots \ldots \ldots \ldots$ & $\ldots \ldots \ldots$ & $\ldots \ldots \ldots \ldots$ & $\ldots \ldots \ldots \ldots$ & $\ldots \ldots \ldots$ \\
& & & & & 10,440 & & 58,190 & \\
\hline
\end{tabular}

CAYUGA LAKE.

\begin{tabular}{|c|c|c|c|c|c|c|c|c|}
\hline 0 & 66.4 & 42,520 & 100.0 & $0-50$ & 13,440 & $3 x .6$ & 77,465 & 23.2 \\
\hline 50 & 45.4 & 29,080 & 68.3 & $50-100$ & 3,490 & 8.2 & 59,460 & $x 7.8$ \\
\hline 200 & 40.0 & 25,590 & 60.2 & $100-150$ & 4,100 & 0.6 & 51,160 & I5. 3 \\
\hline 150 & 33.6 & 21,490 & 50.6 & $150-200$ & 3,500 & 8.2 & 42,940 & 12.9 \\
\hline 200 & 28.1 & 17,990 & 42.3 & $200-250$ & 2,820 & 6.7 & 36,070 & 10.0 \\
\hline 250 & 23.7 & 15,170 & 35.7 & $250-300$ & 2,910 & 6.8 & 29,815 & 8.0 \\
\hline 300 & 19.2 & 12,260 & 28.8 & $300-350$ & 3,170 & 7.5 & 23,165 & 6.0 \\
\hline 350 & 14.2 & 9,090 & $2 I .4$ & $350-400$ & 5,980 & I4. I & 11,065 & $3 \cdot 3$ \\
\hline 400 & 4.90 & 3,110 & 7.3 & $400-435$ & 3,110 & $7 \cdot 3$ & 1,628 & .4 \\
\hline \multirow[t]{2}{*}{435} & & & & & . & & . & \\
\hline & & & & & 42,520 & & 332,788 & \\
\hline
\end{tabular}


TABLE XVI.-AREA and Volume of THE LAKES in Miles, ACres, and Feet-Continued.

KEUKA IAKE.

\begin{tabular}{|c|c|c|c|c|c|c|c|c|}
\hline Depth. & \multicolumn{3}{|c|}{ Area. } & Depth. & \multicolumn{2}{|c|}{ Area. } & \multicolumn{2}{|c|}{ Volume. } \\
\hline $\begin{array}{r}\text { Feet. } \\
0 \\
50 \\
100 \\
150 \\
183\end{array}$ & $\begin{array}{c}\text { Sq. mi. } \\
18.1 \\
14.2 \\
9.96 \\
4.09\end{array}$ & $\begin{array}{r}\text { Acres. } \\
11,610 \\
9,090 \\
6,370 \\
2,620\end{array}$ & $\begin{array}{c}\text { Per cent. } \\
\text { roo. } \\
78.4 \\
54.9 \\
22.5\end{array}$ & $\begin{array}{l}\text { Feet. } \\
0-50 \\
50-100 \\
100-150 \\
150-186\end{array}$ & $\begin{array}{r}\text { Acres. } \\
2,520 \\
2,720 \\
3,750 \\
2,620\end{array}$ & $\begin{array}{c}\text { Per cent. } \\
21.7 \\
23.5 \\
32.3 \\
22.6\end{array}$ & $\begin{array}{c}\text { Million } \\
\text { cu. } f t . \\
22,675 \\
16,775 \\
9,380 \\
1,370\end{array}$ & $\begin{array}{c}\text { Per cent. } \\
45.2 \\
33.4 \\
18.7 \\
2.7\end{array}$ \\
\hline & & & & & 11,610 & & 50,200 & \\
\hline
\end{tabular}

OTISCO LAKE.

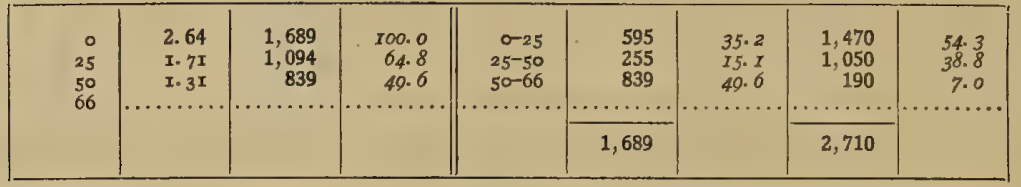

OWASCO IAKE.

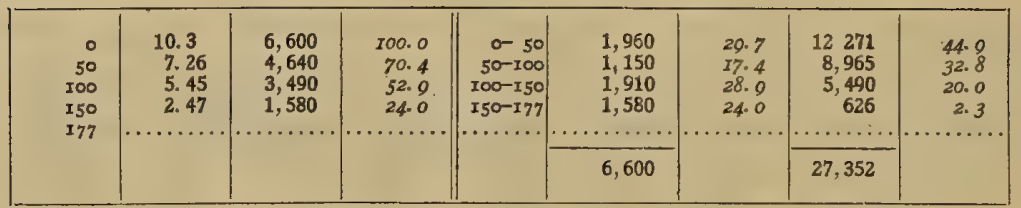

SENECA LAKE.

\begin{tabular}{|c|c|c|c|c|c|c|c|c|}
\hline 。 & 67.7 & 43,330 & 100.0 & $0-50$ & 7,120 & 16.4 & 86,165 & 15.7 \\
\hline 50 & 56.6 & 36,210 & 83.6 & $50-100$ & 3,210 & 7.4 & 75,265 & 13.8 \\
\hline 100 & 51.6 & 33,000 & 76.2 & $100-150$ & 3,160 & $7 \cdot 3$ & 66,725 & 12.2 \\
\hline 150 & 46.6 & 29,840 & 68.9 & $150-200$ & 3,630 & 8.4 & 60,980 & $I I .2$ \\
\hline 200 & 41.0 & 26,210 & 60.5 & $200-250$ & 3,550 & 8. 2 & 54,210 . & 0.0 \\
\hline 250 & 37.0 & 23,660 & 54.6 & $250-300$ & 2,760 & 6.4 & 48,305 & 8.9 \\
\hline 300 & 32.7 & 20,900 & 48.2 & $300-350$ & 2,180 & 5.0 & 43,110 & 7.9 \\
\hline 350 & 29.3 & 18,720 & 43.2 & $350-400$ & 2,220 & 5. I & 38,330 & 7.0 \\
\hline 400 & 25.8 & 16,500 & $38 . I$ & $400-450$ & 2,410 & 5.6 & 32,155 & 5.9 \\
\hline 450 & 20.5 & 13,090 & 30.2 & $450-500$ & 3,950 & 0.1 & 24,100 & 4.4 \\
\hline 500 & 14.3 & 9,140 & $2 I . I$ & $500-550$ & 5,340 & $12: 3$ & 13,050 & 2.4 \\
\hline \multirow{4}{*}{$\begin{array}{l}550 \\
600 \\
618\end{array}$} & 5.84 & 3,800 & 7.7 & $550-600$ & 2,290 & $5 \cdot 3$ & 3,410 & 0.6 \\
\hline & 2. 35 & 1,510 & 0.3 & $600-6 \times 8$ & 1,510 & 3.5 & & \\
\hline & & & & & & & & \\
\hline & & & & & 43,330 & & 545,845 & \\
\hline
\end{tabular}

SKANEATELES LAKE.

\begin{tabular}{|c|c|c|c|c|c|c|c|c|}
\hline 0 & 13.9 & 8,900 & 100.0 & $0-50$ & 2,550 & 28.6 & 16,495 & 20.8 \\
\hline 50 & 9. 92 & 6,350 & 71.5 & $50-x 00$ & 1,010 & 11.4 & 12,695 & 23.0 \\
\hline 100 & 8. 34 & 5,340 & 60.2 & $100-150$ & 890 & 10.0 & 10,800 & $x 0.5$ \\
\hline 150 & 6.95 & 4,450 & 50.1 & $150-200$ & 1,090 & 12.3 & 8,465 & 15.6 \\
\hline 200 & 5.25 & 3,360 & 37.9 & $200-250$ & 1,580 & 17.7 & 5,480 & 0.0 \\
\hline 250 & 2. 78 & 1,780 & $\ldots$ & $250-297$ & 1,780 & 20.0 & 1,220 & 2. 2 \\
\hline \multirow[t]{2}{*}{297} & & & . & & . & & & \\
\hline & & & & & 8,900 & & 55,155 & \\
\hline
\end{tabular}




\section{TEMPERATURE OBSERVATIONS.}

The temperatures observed in I9Io are stated, with the gases, in table xvm, and are shown in figures 8-I7. The bottom temperatures, stated in table $\mathrm{mi}$, are derived from these observations, the temperature curve being extended, if necessary, to the deepest water.

TABLE XVII.-TEMPERATURE OBSERVATIONS.

WINTER TEMPERATURES, XgXI, $x 9 x 2$.

\begin{tabular}{|c|c|c|c|c|c|c|}
\hline \multirow[b]{2}{*}{$\begin{array}{l}\text { Depth, } \\
\text { meters. }\end{array}$} & \multirow{2}{*}{$\begin{array}{l}\text { Cayuga, } \\
\text { Feb. I3, } \\
\text { I } 911 \text {; } \\
\text { foggy, } \\
\text { calm. }\end{array}$} & \multicolumn{2}{|c|}{ Owasco. } & \multirow{2}{*}{$\begin{array}{l}\text { Seneca, } \\
\text { Feb. Io, } \\
\text { Igri; } \\
\text { clear, } \\
\text { light } \\
\text { south. }\end{array}$} & \multicolumn{2}{|c|}{ Skaneateles. } \\
\hline & & $\begin{array}{l}\text { Feb. II, } \\
\text { I9II; } \\
\text { snow, ice; } \\
\text { II cm. }\end{array}$ & $\begin{array}{l}\text { Mar. I, } \\
\text { I912; } \\
\text { clear, ice; } \\
52 \mathrm{~cm} .\end{array}$ & & $\begin{array}{c}\text { Feb. II, } \\
\text { I9II; } \\
\text { clear, ice; } \\
6-8 \mathrm{~cm} .\end{array}$ & $\begin{array}{l}\text { Mar. 7, } \\
\text { I9I } 2 ; \\
\text { clear, ice; } \\
50 \mathrm{~cm} .\end{array}$ \\
\hline 。 & $2 . \infty$ & a. Io & 0.80 & 3.25 & o. 70. & I. $\infty$ \\
\hline 5 & .......... & .70 & I. 30 & & ...... & 2. 20 \\
\hline Io & 2. 10 & .70 & I. 30 & $3 \cdot 30$ & .70 & 2. 25 \\
\hline 20 & $\ldots \ldots \ldots \ldots$ & $\ldots .$. & I. 40 & $3 \cdot 40$ & I. $\infty$ & 2. 40 \\
\hline 30 & 2.30 & .75 & x. 60 & $\ldots . .$. & I. 20 & 2. 40 \\
\hline 40 & $\ldots \ldots \ldots$ & .80 & 2.00 & $\ldots \ldots$ & $\ldots \ldots \ldots$ & 2. 50 \\
\hline 50 & .. & $a_{1 . \infty 0}$ & $b_{2.25}$ & & CI. 20 & 2. 60 \\
\hline 60 & 2. 50 & ......... & $\ldots \ldots$ & & .......... & 2. 70 \\
\hline 70 & ........ & $\ldots \ldots \ldots$ & $-8=a_{0}$ & $\ldots$. & & 3.00 \\
\hline 80 & - & $\ldots \ldots \ldots$ & $\ldots$ & 3.40 & & $d_{3.10}$ \\
\hline 90 & $\ldots \ldots \ldots$ & $\ldots \ldots \ldots$ & n...... & $\ldots \ldots \ldots$ & $\ldots \ldots$ & $\ldots \ldots \ldots$ \\
\hline 100 & .......... & & & & & \\
\hline 105 & 2. 75 & . & & $\cdots \cdots$ & $\cdots \cdot$ & $\ldots \ldots \ldots$ \\
\hline $\begin{array}{l}\text { Ioo } \\
\text { Mud... }\end{array}$ & . & I. 2 & $\ddot{e}_{2.60}$ & $\cdots \cdots$ & & \\
\hline & & & & & & \\
\hline
\end{tabular}

SUMMER TEMPERATURES, I9II, I9ז2.

\begin{tabular}{|c|c|c|c|c|c|c|c|c|}
\hline $\begin{array}{l}\text { Depth, } \\
\text { meters. }\end{array}$ & $\begin{array}{l}\text { Canan- } \\
\text { daigua, } \\
\text { Sept 4, } \\
\text { rgrI; } \\
\text { clear, } \\
\text { calm; } \\
\text { mean of } \\
4 \text { series. }\end{array}$ & $\begin{array}{c}\text { Cayuga, } \\
\text { Sept. 2, } \\
\text { rgri; } \\
\text { clear, } \\
\text { fresh S. } \\
\text { wind. }\end{array}$ & $\begin{array}{l}\text { Keuka, } \\
\text { Sept. 5, } \\
\text { I9ri; } \\
\text { part } \\
\text { cloudy; } \\
\text { light S. } \\
\text { wind. }\end{array}$ & $\begin{array}{c}\text { Owasco, } \\
\text { Sept. } 3 \text {, } \\
\text { Igrx; } \\
\text { clear, } \\
\text { light N. } \\
\text { wind. }\end{array}$ & $\begin{array}{l}\text { Owasco, } \\
\text { Sept. I3, } \\
\text { I912; } \\
\text { clear, } \\
\text { calm. }\end{array}$ & $\begin{array}{c}\text { Seneca, } \\
\text { Sept. I, } \\
\text { IgII; } \\
\text { hazy, } \\
\text { light S. } \\
\text { or calm. }\end{array}$ & $\begin{array}{l}\text { Skane- } \\
\text { ateles, } \\
\text { Sept. 3, } \\
\text { rgrı; } \\
\text { clear, } \\
\text { fresh } \\
\text { NW. } \\
\text { wind. }\end{array}$ & $\begin{array}{l}\text { Skane- } \\
\text { ateles, } \\
\text { Oct. I8 } \\
\text { I912; } \\
\text { clear, } \\
\text { calm. }\end{array}$ \\
\hline 0 & 20.7 & 20.0 & 20.6 & 19.8 & I9. 6 & 20.0 & I9. 6 & I4. 0 \\
\hline 5 & 19.8 & ..... & 20.4 & 19. 7 & I9. 3 & 19.4 & I9. 6 & I3. 8 \\
\hline I0 & I9. 5 & Ig. 8 & 20.0 & I9. 5 & 19.2 & rg.0 & 19. 5 & 13. 7 \\
\hline II & & ....... & 19. 5 & & 19.0 & & .......... & $\ldots \ldots \ldots$ \\
\hline 12 & 18.3 & & 14.9 & 19.3 & 18.8 & I8. 8 & .. & 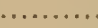 \\
\hline$I_{3}$ & $\ldots . .$. & ...... & I2. I & I9. I & 18. 4 & ......... & ......... & ..... \\
\hline 14 & ...... & 19.6 & I0. 3 & 17.3 & 18.3 & & $\ldots .$. & $\cdots$ \\
\hline 15 & x. 7 & I9. 0 & 9. 4 & 16.6 & 18.2 & I8. 4 & I9. 3 & I3. 6 \\
\hline I6 & 12.2 & 18. 5 & $\ldots$ & 15.9 & 17.0 & 17.3 & 18.8 & ....... \\
\hline$x 7$ & II. 5 & I6. I & $7 \cdot 3$ & $x 5.4$ & $x_{5} .8$ & I4. 9 & I7. 5 & ...... \\
\hline 28 & 10.6 & 13.8 & ..... & $\times 3.0$ & $\ldots \ldots .$. & I2. 3 & 16.4 & ...... \\
\hline 19 & $\ldots .$. & I1. 5 & $\ldots \ldots$ & 12.5 & $\ldots \ldots \ldots$ & II. I & 14.7 & .......... \\
\hline 20 & $7 \cdot 7$ & I0. $x$ & 6. 7 & 9. I & II. 9 & 10.2 & $x_{3} \cdot 3$ & I3. 5 \\
\hline 25 & 5.6 & 7.9 & 5.8 & 7.6 & 9. I & 6.8 & $7 \cdot 7$ & I3. 5 \\
\hline 30 & $5 \cdot 2$ & 5.9 & 5.6 & 6.6 & 8. 3 & 5.8 & 6.5 & 10. 3 \\
\hline 40 & 4. 6 & 4.8 & 5.0 & 5.5 & 7.6 & 4.8 & 5. 7 & 6.8 \\
\hline 50 & 4.6 & 4. 5 & $e_{4.8}$ & $e_{5.3}$ & e 7.3 & $4 \cdot 3$ & 5. 5 & 6.5 \\
\hline 60 & $4 \cdot 4$ & 4. 5 & ............ & $\ldots . . . .$. & .......... & & & 6.4 \\
\hline 70 & $4 \cdot 3$ & $4 \cdot 4$ & ......... & $\because \ldots \ldots \ldots$ & $\ldots \ldots \ldots$ & $4 \cdot 2$ & $f_{4 \cdot 7}$ & 6.3 \\
\hline 80 & $\theta_{4 \cdot 3}$ & $4 \cdot 2$ & L & an. & .......... & $4 \cdot 2$ & ...... & $h_{6.3}$ \\
\hline 100 & $\ldots \ldots \ldots$ & 4.1 & $\ldots \ldots$ & $\ldots \ldots$ & $\ldots \ldots \ldots$ & 4. I & $\ldots \ldots \ldots$ & $\ldots \ldots \ldots$ \\
\hline 520 & 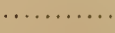 & $i_{4.1}$ & & & $\ldots \ldots \ldots$ & $4 \cdot 1-$ & 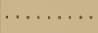 & \\
\hline 164 & & & & & & $4.0+$ & & \\
\hline $\begin{array}{c}c \\
\text { cove } \\
d\end{array}$ & $\begin{array}{l}\text { meters. } \\
\text { meters. } \\
\text { Mandans } \\
\text { i by ice. } \\
\text { meters. }\end{array}$ & $\begin{array}{l}\text { Lake } \\
\text { eth, }\end{array}$ & part & a, De & er water & & \multicolumn{2}{|c|}{$\begin{array}{l}\text { e } 49 \text { meters. } \\
\text { f } 69 \text { meters. } \\
\text { o } 73 \text { meters. } \\
\text { h } 80 \text { meters. } \\
\text { i I2I meters. }\end{array}$} \\
\hline
\end{tabular}




\section{DISSOLVED GASES.}

The depth is given in meters, the temperature in degrees centigrade, and the gases in cubic centimeters per liter of water. The last column shows the per cent of saturation of the oxygen. In the free carbon dioxide, a minus sign indicates that the water was alkaline, a plus sign that it was acid, and neut. that it was neutral to phenolphthalein. The degree of alkalinity or acidity is indicated by the number of cutic centimeters of carbon dioxide that would have to be added or removed to make the water neutral.

TABLE XVIII.-OBSERVATION ON Gases.

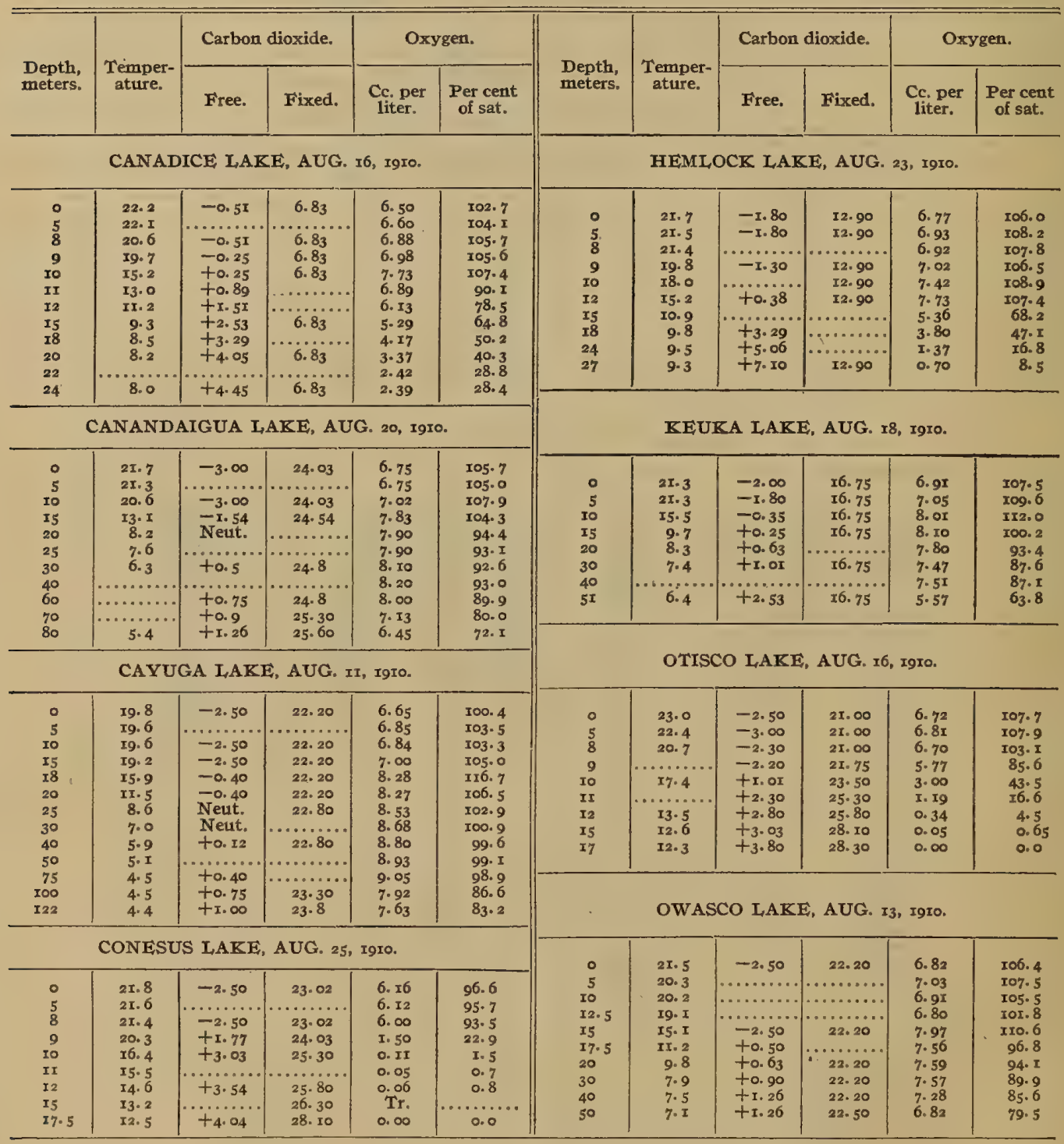


A LIMNOLOGICAL STUDY OF THE FINGER LAKES.

TABLE XVIII.-OBSERVATIONS ON Gases-Continued.

\begin{tabular}{|c|c|c|c|c|c|c|c|c|c|c|c|}
\hline \multirow{2}{*}{$\begin{array}{l}\text { Depth, } \\
\text { meters. }\end{array}$} & \multirow{2}{*}{$\begin{array}{l}\text { Temper- } \\
\text { ature. }\end{array}$} & \multicolumn{2}{|c|}{ Carbon dioxide. } & \multicolumn{2}{|c|}{ Oxygen. } & \multirow{2}{*}{$\begin{array}{l}\text { Depth, } \\
\text { meters. }\end{array}$} & \multirow{2}{*}{$\begin{array}{l}\text { Temper- } \\
\text { ature. }\end{array}$} & \multicolumn{2}{|c|}{ Carbon dioxide. } & \multicolumn{2}{|c|}{ Oxygen. } \\
\hline & & Free. & Fixed. & $\begin{array}{l}\text { Cc. per } \\
\text { liter. }\end{array}$ & $\begin{array}{l}\text { Per cent } \\
\text { of sat. }\end{array}$ & & & Free. & Fixed. & $\begin{array}{l}\text { Cc. per } \\
\text { liter. }\end{array}$ & $\begin{array}{l}\text { Per cent } \\
\text { of sat. }\end{array}$ \\
\hline \multicolumn{6}{|c|}{ SENECA I,AKE, AUG. 3 , IgIO. } & \multicolumn{6}{|c|}{ SKANEATELES LAKE, AUG. 15, I9IG. } \\
\hline 。 & 20.2 & -2.50 & 22.00 & 6.85 & 104.6 & $\circ$ & 22.7 & $-\mathrm{x} .25$ & 21.25 & 6.75 & 107.6 \\
\hline 5 & 19.6 & $\ldots \ldots \ldots$ & $\ldots . . .$. & $7 . \infty$ & $105 \cdot 7$ & 5 & 19.8 & $\ldots \ldots \ldots$ & …... & 7.02 & 106.4 \\
\hline 10 & 19.0 & -2.50 & 22.00 & 7.40 & 110.6 & To & $I 7.8$ & & $\ldots . .$. & $7.5 x$ & $I 09.8$ \\
\hline 15 & $17 \cdot 2$ & ........... & $\ldots \ldots$ & 7.80 & II 2.8 & I5 & 12.6 & $-\mathrm{X} .25$ & 21.25 & 9. $x_{5}$ & 120.6 \\
\hline 20 & II. 6 & $-x . \infty$ & 22.00 & 8.40 & 108.4 & 20 & 8.6 & -0.55 & 21.25 & 9.20 & III.0 \\
\hline 30 & 8.3 & -0.50 & $22 . \infty 0$ & 8.80 & 105.4 & 25 & & Neut. & & 8.88 & I04. 9 \\
\hline 50 & 5.2 & $\ldots \ldots \ldots$ & $\ldots \ldots \ldots$ & 8.70 & 99.0 & 30 & 6.8 & +0.25 & $21 \cdot 25$ & 8. 77 & IOI. 4 \\
\hline 75 & 4.6 & & & 8.90 & $97 \cdot 5$ & 50 & $5 \cdot 9$ & +0.75 & 21.40 & 8.65 & 97.9 \\
\hline 100 & $\ldots .$. & Neut. & 22.00 & 9.00 & 98.4 & 70 & & & & 8. 24 & 92.8 \\
\hline 130 & ..... & +0.25 & 22.20 & 9. 10 & 99.2 & 83 & $5 \cdot 5$ & $+x . \infty$ & 21.80 & 7.89 & 88.4 \\
\hline$\times 50$ & ..... & +0.40 & 22.20 & 8.55 & 93.0 & & & & & & \\
\hline 173 & 4.2 & $+x .26$ & 22.20 & 8.45 & 91.7 & & & & & & \\
\hline
\end{tabular}

\section{DISTRIBUTION OF PLANKTON.}

Table $\mathrm{xIX}$ shows the vertical distribution of the various plankton organisms, giving the number of individuals per cubic meter of water at the different depths. The members grouped in the different columns are indicated as follows: I. Cladocera, $\mathrm{B}=$ Bosmina, $\mathrm{C}=$ Ceriodaphnia, $\mathrm{D}=$ Daphnia, Di= Diaphanosoma, $\mathrm{L}=$ Leptodora, $\mathrm{P}=$ Polyphemus; 2. Copepoda, $\mathrm{C}=$ Cyclops, $\mathrm{D}=$ Diaptomus, $\mathrm{E}=$ Epischura, $\mathrm{L}=$ Limnocalanus; 3. Nauplii; 4. Rotifera, An=Anurea, $\mathrm{As}=$ Asplanchna, $\mathrm{C}=$ Conochilus, $\mathrm{N}=$ Notholca, $\mathrm{Pl}=$ Ploesoma, $\mathrm{P}=$ Polyarthra, $\mathrm{T}=$ Triarthra; 5 . Protozoa, $\mathrm{C}=$ Ceratium, $\mathrm{D}=$ Dinobryon, $\mathrm{M}=$ Mallomonas, $\mathrm{V}=$ Vorticella; 6 . Green and blue-green algæ, $\mathrm{An}=$ Anabaena, $\mathrm{Ap}=A$ phanocapsa, $\mathrm{Aph}=$ A phanizomenon, $\mathrm{C}=$ Clathrocystis, $\mathrm{Coe}=$ Calosphorium, $\mathrm{G}=$ Gloeocapsa, $\mathrm{L}=$ Lyngbya, $\mathrm{O}=$ Oscil latoria, $\mathrm{S}=$ Staurastrum; 7 . Diatoms, $\mathrm{A}=$ Asterionella, $\mathrm{C}=$ Cyclotella, $\mathrm{F}=$ Fragilaria, $\mathrm{M}=$ Melosira, $\mathrm{N}=$ Navicula, $\mathrm{S}=$ Synedra, $\mathrm{T}=$ Tabellaria.

When present in relatively small numbers, some forms showed an irregular distribution-that is, they were not noted at certain depths, but were found both above and below these depths. This does not mean, however, that they were entirely absent at the intermediate levels, but that they were not found in that portion of the catch which was counted.

Table XIX.-Analysis of Plankton Catches.

CANADICE LAKE, AUG. 24, 1910

\begin{tabular}{|c|c|c|c|c|c|c|c|c|c|c|c|c|c|}
\hline \multirow[t]{2}{*}{ Depth, meters. } & \multicolumn{2}{|c|}{ Cladocera. } & \multicolumn{2}{|c|}{ Copepoda. } & \multirow{2}{*}{$\begin{array}{r}\text { Nauplii. } \\
700\end{array}$} & \multicolumn{2}{|c|}{ Rotifera. } & \multicolumn{2}{|c|}{ Protozoa. } & \multicolumn{2}{|c|}{$\begin{array}{c}\text { Green and } \\
\text { blue-green } \\
\text { algz. }\end{array}$} & \multicolumn{2}{|c|}{ Diatoms. } \\
\hline & $\left\{\begin{array}{l}\mathrm{D} \\
\mathrm{Di}\end{array}\right.$ & $\begin{array}{l}3,650 \\
x, 400\end{array}$ & $\begin{array}{l}\text { C } \\
\text { D }\end{array}$ & $\begin{array}{r}2,800 \\
48,600\end{array}$ & & & & $\underset{\mathbf{V}}{\mathbf{C}}$ & $\begin{array}{r}252,000 \\
5,700\end{array}$ & $\begin{array}{l}\text { An } \\
\text { Ap }\end{array}$ & $\begin{array}{r}6,400 \\
42,200 \\
189,000\end{array}$ & $\mathbf{A}$ & $\begin{array}{l}63,300 \\
42,300\end{array}$ \\
\hline $8 \ldots$ & $\left\{\begin{array}{l}\mathrm{D} \\
\mathbf{D} i\end{array}\right.$ & $\begin{array}{l}2,100 \\
2,800\end{array}$ & $\begin{array}{l}\mathrm{C} \\
\mathrm{D}\end{array}$ & $\begin{array}{r}2,100 \\
\times 2,100\end{array}$ & 10,700 & $\mathbf{P}$ & $x, 4 \infty$ & $\begin{array}{l}\text { C } \\
\text { V }\end{array}$ & $\begin{array}{r}63,300 \\
700\end{array}$ & $\stackrel{A n}{C}$ & $\begin{array}{r}700 \\
168,800\end{array}$ & $A$ & $x 89,900$ \\
\hline & $\{\mathrm{D}$ & 700 & $\begin{array}{l}\mathrm{C} \\
\mathrm{D}\end{array}$ & $\begin{array}{r}2,800 \\
13,800\end{array}$ & 40,000 & $\mathbf{P}$ & 4,200 & $\begin{array}{l}\mathbf{C} \\
\mathbf{D} \\
\mathbf{M}\end{array}$ & $\begin{array}{r}84,400 \\
168,800 \\
2,810,000\end{array}$ & $\begin{array}{l}\mathrm{C} \\
\mathrm{G}\end{array}$ & $\begin{array}{l}42,200 \\
42,200\end{array}$ & $A$ & 759,600 \\
\hline
\end{tabular}

$46512^{\circ}-14-6$ 
Table XIX.-Analysis of Plankton Catches-Continued.

CANADICE LAKE, AUG. 24, 1910-Continued.

\begin{tabular}{|c|c|c|c|c|c|c|c|c|c|c|c|c|c|}
\hline \multirow[t]{2}{*}{ Depth, meters. } & \multicolumn{2}{|c|}{ Cladocera. } & \multicolumn{2}{|c|}{ Copepoda. } & \multirow{2}{*}{$\begin{array}{r}\text { Nauplii. } \\
20,700\end{array}$} & \multicolumn{2}{|c|}{ Rotifera. } & \multicolumn{2}{|c|}{ Protozoa. } & \multicolumn{2}{|c|}{$\begin{array}{c}\text { Green and } \\
\text { blue-green } \\
\text { algie. }\end{array}$} & \multicolumn{2}{|c|}{ Diatoms. } \\
\hline & $\{\mathrm{D}$ & 700 & $\begin{array}{l}\text { C } \\
\text { D }\end{array}$ & $\begin{array}{r}5,000- \\
12,800\end{array}$ & & $\frac{\text { An }}{N}$ & $\begin{array}{r}\mathbf{4}, 400 \\
200\end{array}$ & $\begin{array}{l}\mathrm{C} \\
\mathbf{M}\end{array}$ & $\begin{array}{r}21,100 \\
126,600\end{array}$ & $\begin{array}{l}\mathrm{C} \\
\mathrm{G}\end{array}$ & $\begin{array}{l}2,100 \\
2,100\end{array}$ & A & $x, 561,400$ \\
\hline I5: & $\{\mathbf{D}$ & $700^{\circ}$ & D & 4,200 & 35,700 & $\mathbf{N}$ & 700 & $\mathbf{M}$ & 42,200 & $\begin{array}{l}\mathrm{C} \\
\mathbf{G}\end{array}$ & $\begin{array}{r}1,400 \\
700\end{array}$ & A & 400,900 \\
\hline I8.. & $\{\mathrm{D}$ & 200 & D & 4,200 & 49,200 & & & C & 21,100 & $\begin{array}{l}\text { C } \\
\text { G }\end{array}$ & $\begin{array}{l}200 \\
200\end{array}$ & A & 232,100 \\
\hline 20. & & & $\{\mathrm{D}$ & 2,800 & 97,100 & & & c & $7, \infty 00$ & & & $\stackrel{A}{T}$ & $\begin{array}{r}\text { I05, } 500 \\
2 \mathrm{I}, 100\end{array}$ \\
\hline $23 \cdot 5 \ldots$ & & & $\left\{\begin{array}{l}C \\
D\end{array}\right.$ & $\begin{array}{l}6,400 \\
9,200\end{array}$ & 15,700 & & & $\begin{array}{l}\mathrm{C} \\
\mathrm{M}\end{array}$ & $\begin{array}{r}147,700 \\
2 I, 100\end{array}$ & & & A & 163,300 \\
\hline
\end{tabular}

CANANDAIGUA LAKE, AUG. 20, xgro.

\begin{tabular}{|c|c|c|c|c|c|c|c|c|c|c|c|c|c|}
\hline $0-5 \ldots$ & $\left\{\begin{array}{l}B \\
D \\
D i\end{array}\right.$ & $\begin{array}{r}260 \\
920 \\
3,270\end{array}$ & $\begin{array}{l}\text { C } \\
\text { D }\end{array}$ & $\begin{array}{r}4,500 \\
14,200\end{array}$ & 18,500 & $\begin{array}{l}\mathrm{C} \\
\mathrm{P}\end{array}$ & $\begin{array}{r}130 \\
1,300\end{array}$ & c & 23,200 & $\begin{array}{l}A p \\
C \\
S\end{array}$ & $\begin{array}{r}\mathrm{II}, 600 \\
6 \mathrm{I}, 900 \\
3,800\end{array}$ & $\stackrel{A}{F}$ & $\begin{array}{r}34,800 \\
3,800\end{array}$ \\
\hline 5 -Іе.... & $\left\{\begin{array}{l}B \\
D \\
D i\end{array}\right.$ & $\begin{array}{r}260 \\
x, 600 \\
2,500\end{array}$ & $\begin{array}{l}\text { C } \\
\text { D }\end{array}$ & $\begin{array}{l}3,700 \\
7,200\end{array}$ & 5,900 & $\begin{array}{l}\mathrm{C} \\
\mathbf{P}\end{array}$ & $\begin{array}{r}130 \\
2,100\end{array}$ & c & 92,900 & $\begin{array}{l}\text { Ap } \\
\text { C } \\
\text { Coe }\end{array}$ & $\begin{array}{r}\text { II, } 600 \\
58,000 \\
3,800\end{array}$ & $\mathrm{~A}$ & $\begin{array}{r}34,800 \\
200\end{array}$ \\
\hline ro-I5. & $\left\{\begin{array}{l}\mathrm{B} \\
\mathrm{D} \\
\mathrm{Di}\end{array}\right.$ & $\begin{array}{r}260 \\
1,300 \\
2,750\end{array}$ & $\begin{array}{l}\text { C } \\
\text { D }\end{array}$ & $\begin{array}{l}2,400 \\
7,600\end{array}$ & 2,150 & $\begin{array}{l}\text { C } \\
\mathbf{N} \\
\mathbf{P}\end{array}$ & $\begin{array}{l}520 \\
130 \\
650\end{array}$ & $\begin{array}{l}\text { C } \\
\text { D }\end{array}$ & $\begin{array}{r}50,300 \\
7,700\end{array}$ & $\begin{array}{l}\text { Ap } \\
\text { C } \\
\text { Coe }\end{array}$ & $\begin{array}{r}3,800 \\
54,200 \\
23,600\end{array}$ & $\underset{\mathbf{T}}{\mathbf{A}}$ & $\begin{array}{r}50,300 \\
3,800\end{array}$ \\
\hline $15-20 .$. & $\left\{\begin{array}{l}\text { B } \\
\text { D } \\
\text { Di }\end{array}\right.$ & $\begin{array}{l}130 \\
130 \\
260\end{array}$ & D & $4, \mathrm{rgo}$ & 390 & $\stackrel{c}{\mathrm{P}}$ & $\begin{array}{l}520 \\
200\end{array}$ & C & 3,800 & $\begin{array}{l}\text { An } \\
\text { Ap } \\
\text { C } \\
\text { Coe }\end{array}$ & $\begin{array}{r}7,700 \\
7,700 \\
15,500 \\
42,600\end{array}$ & $\frac{\mathbf{A}}{\mathrm{T}}$ & $\begin{array}{l}2,100 \\
\mathbf{I}, 200\end{array}$ \\
\hline $20-3$ & $\left\{\begin{array}{l}\mathrm{B} \\
\mathrm{D} \\
\mathrm{L}\end{array}\right.$ & $\begin{array}{r}100 \\
2,230 \\
30\end{array}$ & $\begin{array}{l}\mathbf{D} \\
\mathbf{L}\end{array}$ & $\begin{array}{r}I, 640 \\
460\end{array}$ & & $\mathrm{~N}$ & $\mathbf{1} 30$ & C & 3,800 & $\begin{array}{l}\text { An } \\
\text { Ap } \\
\text { C } \\
\text { Coe }\end{array}$ & $\begin{array}{l}1,900 \\
7,700 \\
7,700 \\
7,700\end{array}$ & & \\
\hline $30-40$. & $\left\{\begin{array}{l}B \\
D\end{array}\right.$ & $\begin{array}{l}200 \\
590\end{array}$ & $\begin{array}{l}\mathbf{D} \\
\mathbf{L}\end{array}$ & $\begin{array}{l}400 \\
x_{30}\end{array}$ & 65 & $\begin{array}{l}\mathrm{C} \\
\mathrm{N}\end{array}$ & $\begin{array}{r}65 \\
130\end{array}$ & C & $\mathbf{x}, 900$ & $\begin{array}{l}\mathrm{Ap} \\
\mathrm{C} \\
\mathrm{C}_{\mathrm{oe}}\end{array}$ & $\begin{array}{l}\mathrm{X}, 900 \\
\mathrm{x}, 900 \\
3,800\end{array}$ & $\mathbf{F}$ & $I, 900$ \\
\hline $40-60$. & $\left\{\begin{array}{l}B \\
D\end{array}\right.$ & $\begin{array}{r}230 \\
25\end{array}$ & $\begin{array}{l}D \\
\mathbf{L}\end{array}$ & $\begin{array}{l}360 \\
x 00\end{array}$ & 25 & C & 130 & & & $\begin{array}{l}\text { Ap } \\
\text { C } \\
\text { Coe }\end{array}$ & $\begin{array}{l}2,900 \\
2,900 \\
I, 900\end{array}$ & $\underset{T}{\mathrm{~A}}$ & $\begin{array}{l}960 \\
960 \\
960\end{array}$ \\
\hline $60-70$. & $\{B$ & 130 & $\begin{array}{l}\mathbf{D} \\
\mathbf{L}\end{array}$ & $\begin{array}{r}400 \\
\times 30\end{array}$ & & $\begin{array}{l}\mathbf{C} \\
\mathbf{P}\end{array}$ & $\begin{array}{l}65 \\
30\end{array}$ & C & $\mathbf{x}, 900$. & $\begin{array}{l}\text { C } \\
\text { Coe }\end{array}$ & $\begin{array}{l}\mathrm{I}, 900 \\
3,800\end{array}$ & & \\
\hline $70-80$ & $\{B$ & 200 & $\underset{\mathbf{L}}{\mathbf{D}}$ & $\begin{array}{l}850 \\
200\end{array}$ & & & & C & $x, 900$ & $\begin{array}{l}\text { Ap } \\
\text { Coe }\end{array}$ & $\begin{array}{l}\mathrm{r}, 900 \\
3,800\end{array}$ & & \\
\hline
\end{tabular}

CAYUGA I,AKE, AUG. I2, I9ro.

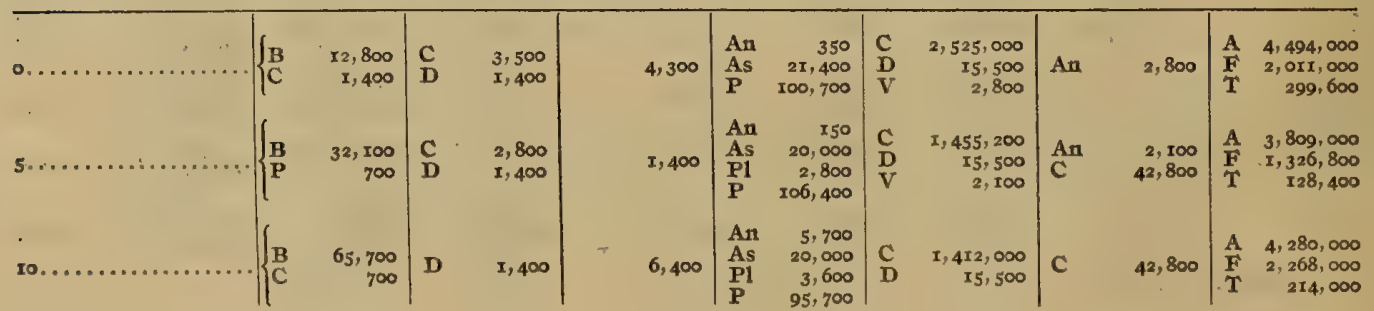


A LIMNOLOGICAL STUDY OF THE FINGER LAKES.

Table XIX.-Analysis of Plankton Catches-Continued,

CAYUGA LAKE, AUG. 12, 19xo-Continued.

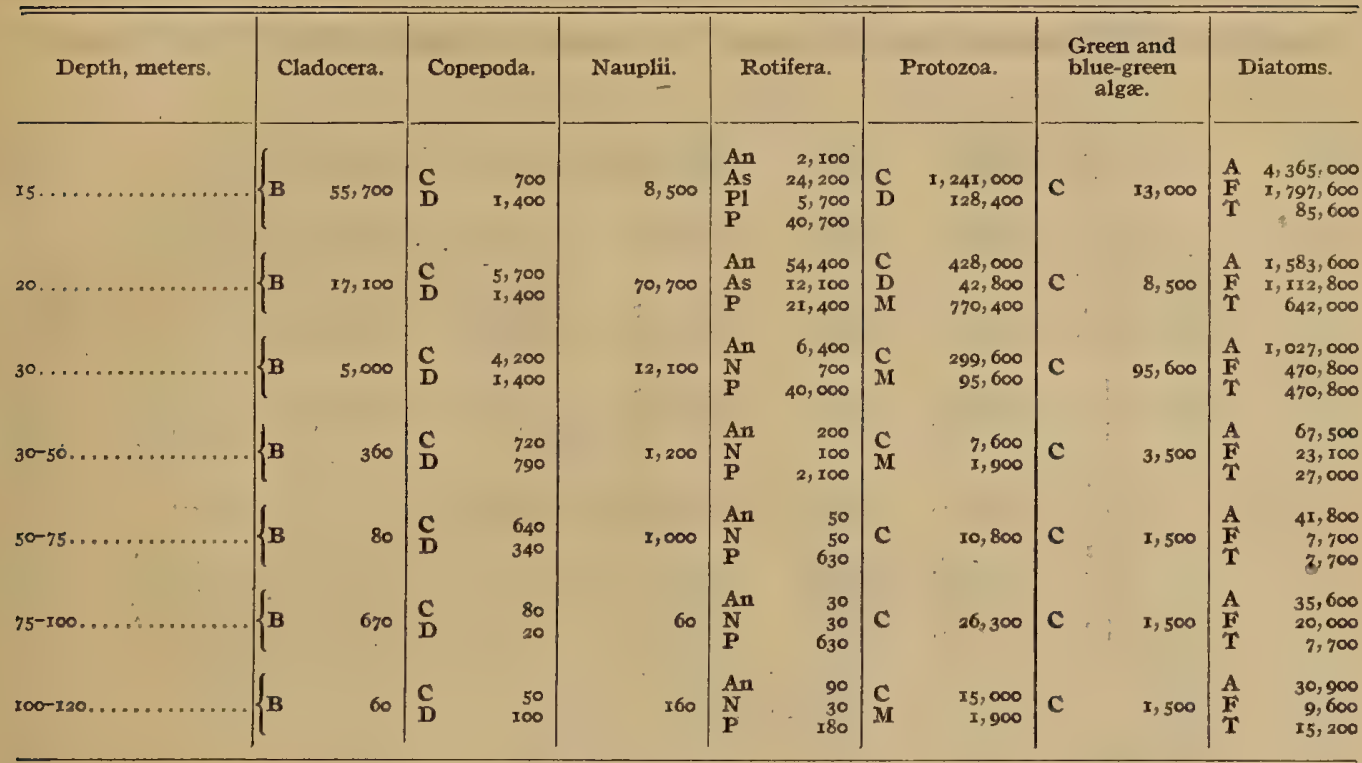

CONESUS LAKE, AUG. 25, 1910.

\begin{tabular}{|c|c|c|c|c|c|c|c|c|c|c|c|c|c|}
\hline $0, \ldots . .$. & $\{\mathbf{D}$ & $10,7 \infty$ & C & 5,000 & 8,000 & $\mathbf{P}$ & 20,700 & $\begin{array}{l}\mathrm{C} \\
\mathbf{D} \\
\mathbf{M} \\
\mathbf{V}\end{array}$ & $\begin{array}{r}464,200 \\
42,200 \\
24,400 \\
1,400\end{array}$ & $\begin{array}{l}\text { An } \\
\text { Aph } \\
\text { C } \\
\text { Coe } \\
\text { G }\end{array}$ & $\begin{array}{r}1,400 \\
42,200 \\
84,400 \\
126,600 \\
42,300\end{array}$ & $\mathbf{A}$ & $\begin{array}{r}42,200 \\
I, 139,400\end{array}$ \\
\hline $5 \ldots$. & $\{\mathrm{D}$ & 7,100 & C & $8, \infty 00$ & $x 5,700$ & $\stackrel{\mathbf{N}}{\mathbf{P}}$ & $\begin{array}{r}700 \\
25,700\end{array}$ & $\begin{array}{l}\mathbf{C} \\
\mathbf{M}\end{array}$ & $\begin{array}{r}211, \infty 00 \\
42,200\end{array}$ & $\begin{array}{l}\text { An } \\
\text { Coe } \\
I \\
S\end{array}$ & $\begin{array}{r}84,400 \\
295,400 \\
42,200 \\
42,200\end{array}$ & $\underset{\mathbf{F}}{\mathbf{A}}$ & $\begin{array}{r}42,200 \\
\text { I, } 434,800\end{array}$ \\
\hline 9. . & $\{\mathrm{D}$ & 5,700 & $\begin{array}{l}\mathrm{C} \\
\mathbf{D}\end{array}$ & $\begin{array}{r}6,400 \\
43,500\end{array}$ & 38,400 & $\underset{P}{\text { An }}$ & $\begin{array}{r}700 \\
4,200\end{array}$ & $\begin{array}{l}c \\
M\end{array}$ & $\begin{array}{r}422,000 \\
84,400\end{array}$ & $\begin{array}{l}\text { Coe } \\
\text { S }\end{array}$ & $\begin{array}{r}379,800 \\
42,200\end{array}$ & $\stackrel{A}{\mathbf{F}}$ & $\begin{array}{r}84,400 \\
I, 477,000\end{array}$ \\
\hline 10. & $\{D$ & 50 & $\begin{array}{l}\mathrm{C} \\
\mathbf{D}\end{array}$ & $\begin{array}{r}62,700 \\
700\end{array}$ & 122,800 & $\begin{array}{l}\text { An } \\
\mathbf{N} \\
\mathbf{P}\end{array}$ & $\begin{array}{r}700 \\
700 \\
x, 400\end{array}$ & C & 337,600 & $\underset{\text { S }}{\text { Coe }}$ & $\begin{array}{r}x 26,600 \\
42,200\end{array}$ & $\mathbf{F}$ & 295,400 \\
\hline $15 \ldots \ldots \ldots$ & & & & 400 & & $\begin{array}{l}\mathbf{N} \\
\mathbf{P}\end{array}$ & $\begin{array}{l}30 \\
30\end{array}$ & C & $2 \pi, 100$ & Coe & $21, x \infty$ & $F$ & 42,200 \\
\hline$I 7.5 \ldots \ldots .$. & & & & & & & & $\{\mathrm{c}$ & 42,200 & $\begin{array}{l}\text { Coe } \\
\text { S }\end{array}$ & $\begin{array}{r}826,600 \\
2,100\end{array}$ & $\mathbf{F}$ & 2,100 \\
\hline
\end{tabular}


Table XIX.-Analysis of Plankton Catches-Continued.

HEML,OCK LAKE, AUG. 23, 1910.

\begin{tabular}{|c|c|c|c|c|c|c|c|c|c|c|c|c|c|}
\hline \multirow[t]{2}{*}{ Depth, meters. } & \multicolumn{2}{|c|}{ Cladocera. } & \multicolumn{2}{|c|}{ Copepoda. } & \multirow{2}{*}{$\begin{array}{l}\text { Nauplii. } \\
\\
\text { 19, } 300\end{array}$} & \multicolumn{2}{|c|}{ Rotifera. } & \multicolumn{2}{|c|}{ Protozoa. } & \multicolumn{2}{|c|}{$\begin{array}{l}\text { Green and } \\
\text { blue-green } \\
\text { algæ. }\end{array}$} & \multicolumn{2}{|c|}{ Diatoms. } \\
\hline & $\left\{\begin{array}{l}B \\
D \\
D i\end{array}\right.$ & $\begin{array}{r}50 \\
7,800 \\
x, 700\end{array}$ & $\begin{array}{l}\mathbf{C} \\
\mathbf{D}\end{array}$ & $\begin{array}{l}2,860 \\
2,500\end{array}$ & & $\stackrel{\text { An }}{\mathbf{P}}$ & $\begin{array}{r}300 \\
4,300\end{array}$ & c & $I, 055, \infty 00$ & $\begin{array}{l}\text { Aph } \\
\text { C } \\
\text { Coe }\end{array}$ & $\begin{array}{r}42,200 \\
84,400 \\
337,600\end{array}$ & $\frac{A}{\mathrm{~F}}$ & $\begin{array}{r}738,500 \\
147,700 \\
42,200\end{array}$ \\
\hline & $\left\{\begin{array}{l}\mathrm{D} \\
\mathrm{Di} \\
\mathrm{L}\end{array}\right.$ & $\begin{array}{r}5,000 \\
500 \\
200\end{array}$ & $\begin{array}{l}\mathrm{C} \\
\mathrm{D}\end{array}$ & $\begin{array}{l}5,000 \\
2,800\end{array}$ & 20,000 & $\begin{array}{l}\mathrm{C} \\
\mathbf{P}\end{array}$ & $\begin{array}{r}100 \\
4,300\end{array}$ & C & $1,477, \infty 00$ & $\begin{array}{l}\text { C } \\
\text { Coe }\end{array}$ & $\begin{array}{r}42,200 \\
464,200\end{array}$ & $\underset{T}{\mathbf{F}}$ & $\begin{array}{r}\text { I, } 266,000 \\
42,200 \\
126,600\end{array}$ \\
\hline . & $\left\{\begin{array}{l}\mathrm{D} \\
\mathrm{Di}\end{array}\right.$ & $\begin{array}{r}5,700 \\
700\end{array}$ & $\begin{array}{l}\mathrm{C} \\
\mathrm{D}\end{array}$ & $\begin{array}{l}\mathbf{I}, 400 \\
\mathbf{x}, 400\end{array}$ & $18, \infty 00$ & $\begin{array}{l}\text { C } \\
\mathbf{N} \\
\mathbf{P}\end{array}$ & $\begin{array}{l}I, 400 \\
2,800 \\
2,800\end{array}$ & c & $x, 566,400$ & $\begin{array}{l}\text { C } \\
\text { Coe }\end{array}$ & $\begin{array}{r}42,200 \\
295,400\end{array}$ & $\frac{\mathbf{A}}{\mathbf{T}}$ & $\begin{array}{l}970,600 \\
337,600 \\
\mathbf{r} 26,600\end{array}$ \\
\hline & $\{\mathbf{D}$ & 7,100 & $\begin{array}{l}\text { C } \\
\text { D }\end{array}$ & $\begin{array}{r}10,7 \infty \\
8, \infty \infty 0\end{array}$ & $8 x, 400$ & $\begin{array}{l}\mathbf{C} \\
\mathbf{N} \\
\mathbf{P} \\
\mathrm{T}\end{array}$ & $\begin{array}{r}700 \\
4,200 \\
700 \\
2,100\end{array}$ & c & $I, 645,800$ & $\begin{array}{l}\text { c } \\
\text { Coe }\end{array}$ & $\begin{array}{r}42,200 \\
I, 097,200\end{array}$ & $\underset{T}{\mathbf{F}}$ & $\begin{array}{l}379,800 \\
337,600 \\
168,800\end{array}$ \\
\hline & $\left\{\begin{array}{l}\mathbf{B} \\
\mathbf{D}\end{array}\right.$ & $\begin{array}{l}x, \infty \infty \\
2,100\end{array}$ & $\begin{array}{l}\mathrm{C} \\
\mathrm{D}\end{array}$ & $\begin{array}{l}2,800 \\
2,800\end{array}$ & 50,700 & $\frac{\text { An }}{N}$ & $\begin{array}{l}700 \\
700\end{array}$ & c & $844, \infty 00$ & Coe & 422,000 & A & $\begin{array}{l}\mathbf{I} 26,600 \\
465,300\end{array}$ \\
\hline & $\left\{\begin{array}{l}\mathbf{B} \\
\mathbf{D}\end{array}\right.$ & $\begin{array}{l}\text { I50 } \\
\text { I50 }\end{array}$ & $\begin{array}{l}\mathrm{C} \\
\mathrm{D}\end{array}$ & $\begin{array}{r}3,600 \\
10,000\end{array}$ & 57,100 & $\mathbf{N}$ & 2,100 & c & $633, \infty 00$ & Coe & 590,800 & A & $\begin{array}{r}x 26,600 \\
84,400\end{array}$ \\
\hline 26 & $\{\mathbf{D}$ & 300 & $\begin{array}{l}\mathrm{C} \\
\mathrm{D}\end{array}$ & $\begin{array}{r}700 \\
2,800\end{array}$ & II, 400 & $\mathrm{~T}$ & 4,200 & C & $211, \infty 00$ & Coe & $7 x 7,400$ & A & $\begin{array}{r}r, \infty 00 \\
168,800\end{array}$ \\
\hline
\end{tabular}

KEUKA L,AKE, AUG. 18, xgro.

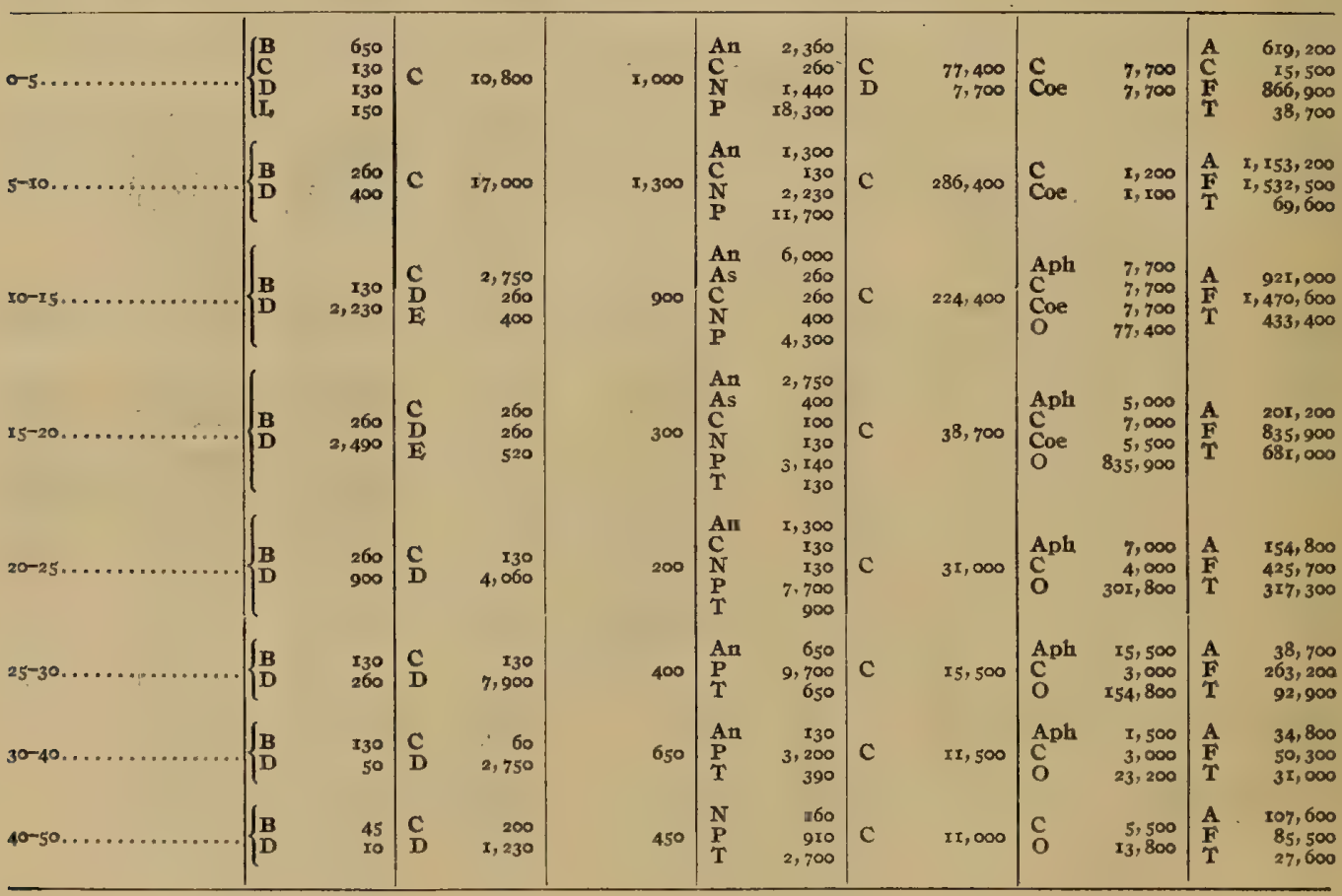


A LIMNOLOGICAL STUDY OF THE FINGER LAKES.

TABle XIX. - Analysis of Plankton Catches-Continued.

O'TISCO LAKE, AUG. 16, 29 ro.

\begin{tabular}{l} 
Depth, meters. \\
\hline
\end{tabular}

OWASCO LAKE, AUG, 13, 1910.

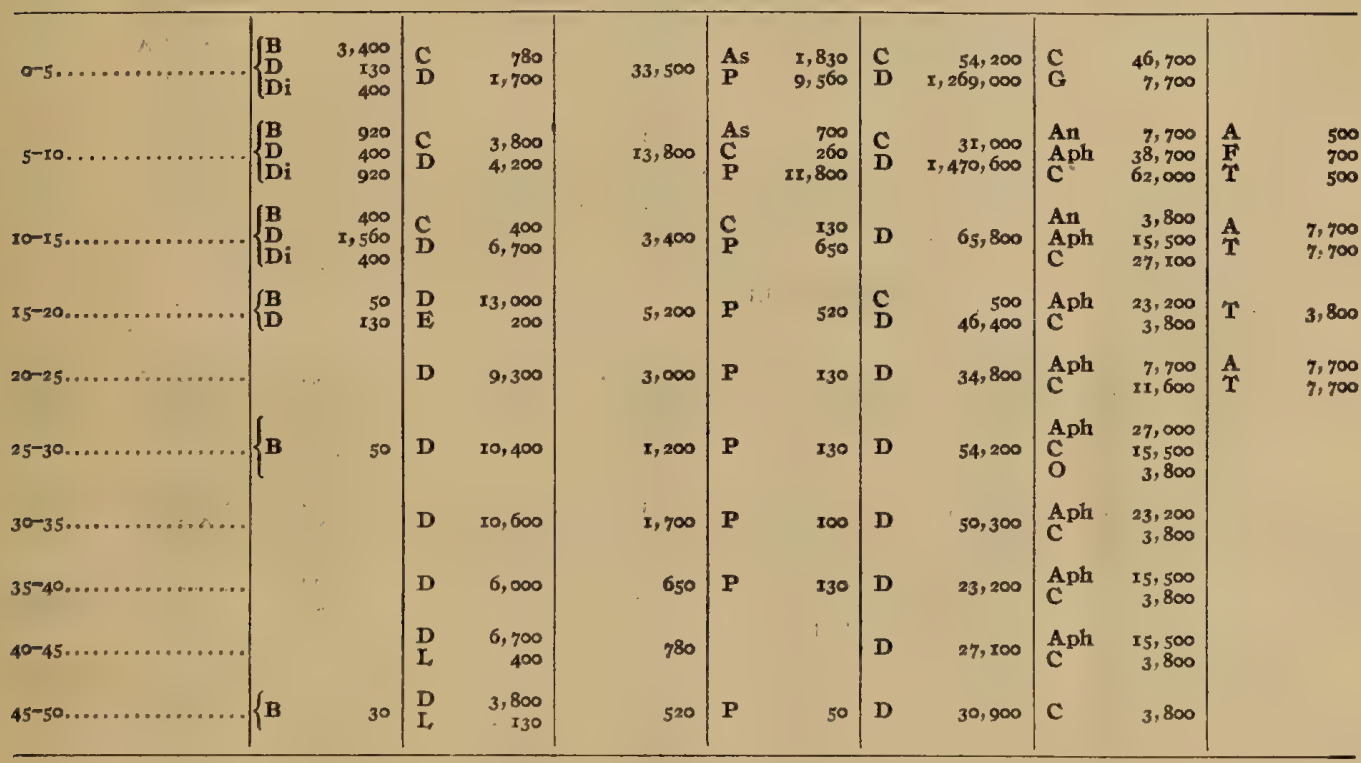

SENECA LAKE, AUG, 4, I9Io.

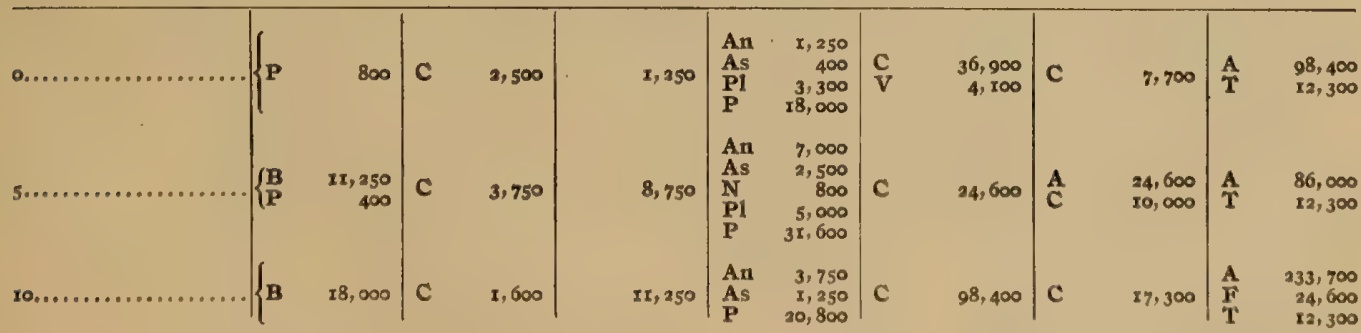


Table XIX.-Analysis of Plankton Catches-Continued.

SENECA LAKE, AUG. 4, rgro-Continued.

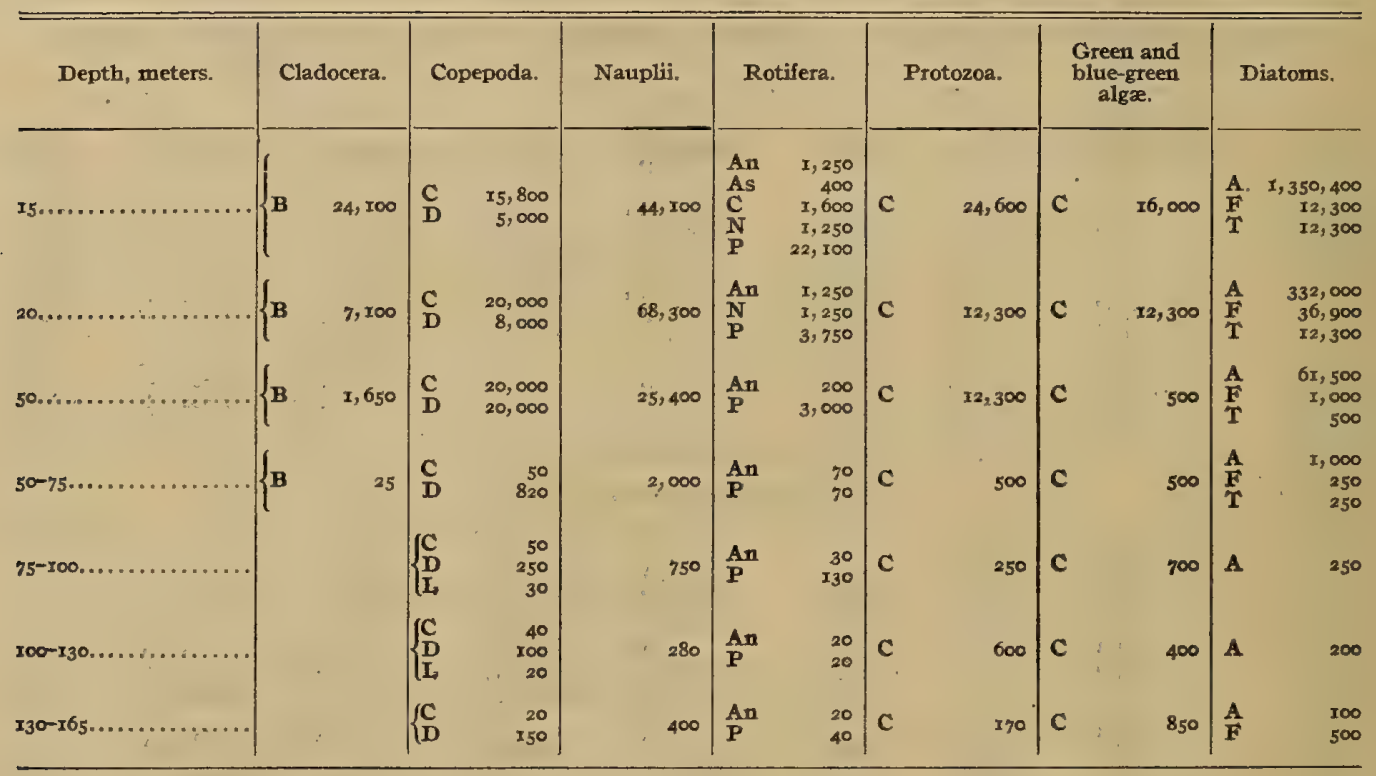

SKANEATELES LAKE, AUG. 15, 19 ro.

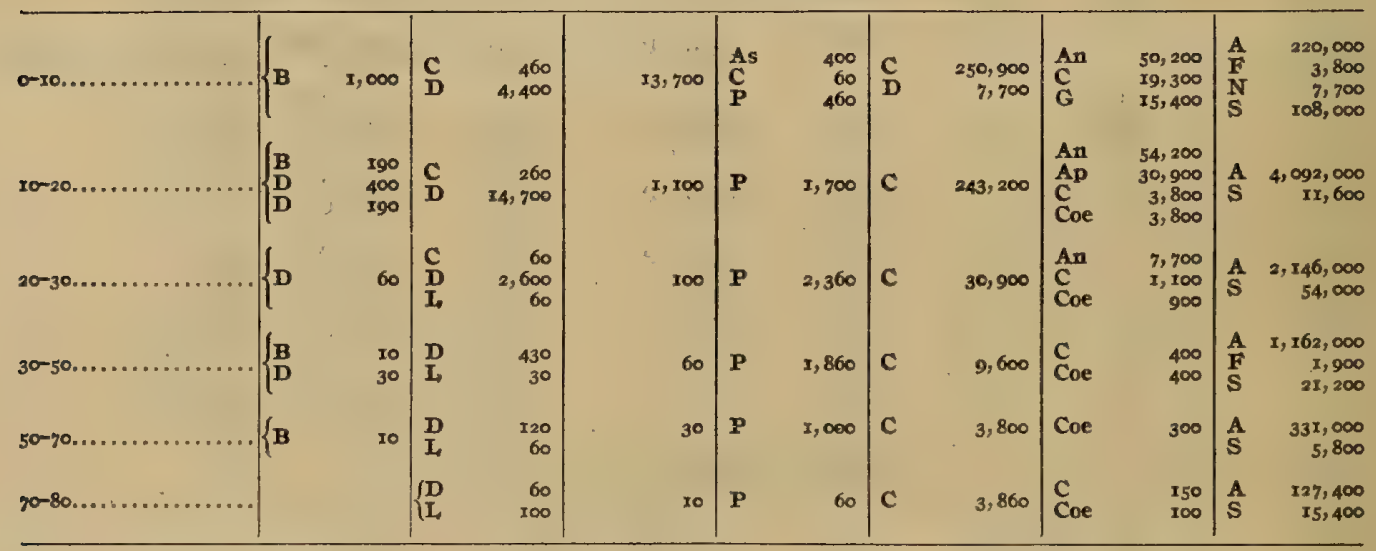




\section{TRANSPARENCY.}

The transparency of the water was determined in Igro by means of a Secchi's disk about ro centimeters in diameter. The depth at which this disk disappeared from view was as follows:

TABt, XX. - TransParency OF WATER.

\begin{tabular}{|c|c|c|c|}
\hline Lakes. & $\begin{array}{l}\text { Trans- } \\
\text { parency. }\end{array}$ & Lakes. & $\begin{array}{c}\text { Trans- } \\
\text { parency. }\end{array}$ \\
\hline
\end{tabular}

OXYGEN ABSORPTION.

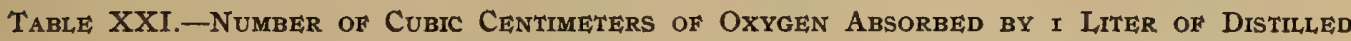
Water at Diffreent Temperatures from a Free Dry ATMOSphere of 760 mm. Pressure.

\begin{tabular}{|c|c|c|c|c|c|c|c|c|c|c|}
\hline Temp. & 0 & $\mathbf{x}$ & 2 & 3 & 4 & 5 & 6 & 7 & 8 & 9 \\
\hline-2 & 10. 880 & $10.85^{\circ}$ & 10.820 & I0. 790 & 10.760 & 10.730 & 10. 700 & 10.670 & 10.640 & $10.6 \mathrm{ro}$ \\
\hline-1 & 10. 580 & 10. $55 \mathrm{I}$ & 10. 522 & I0. 493 & xo. 464 & 10. 435 & 10. 406 & I0.337 & 10. 348 & 10. 319 \\
\hline - & 10. 290 & 10. 263 & 10.236 & 10. 209 & 10. 182 & 10. 155 & 10. 128 & Io. ror & 10.074 & 10.047 \\
\hline I & 10.020 & 9.993 & 9.966 & 9.939 & 9.912 & $9.88_{5}$ & 9.858 & $9.83 x$ & 9.804 & 9.777 \\
\hline 2 & 9.750 & 9. 725 & 9. 700 & 9.675 & 9.650 & 9.625 & 9.600 & 9. 575 & 9. $550^{\circ}$ & 9.525 \\
\hline 3 & 9. 500 & 9.476 & $9 \cdot 452$ & $9 \cdot 428$ & 9.404 & 9.380 & $9 \cdot 35^{6}$ & 9. 332 & 9.308 & 9. 284 \\
\hline 4 & 9.260 & 9.237 & 9. 2 E4 & 9. $r g x$ & 9. 168 & 9. 145 & 9. 122 & 9.099 & 9.076 & 9.053 \\
\hline $\begin{array}{l}5 \\
6\end{array}$ & $\begin{array}{l}9.030 \\
8.810\end{array}$ & $9 . \infty 8$ & $\begin{array}{l}8.986 \\
8.768\end{array}$ & 8. 964 & $\begin{array}{l}8.942 \\
8.726\end{array}$ & 8. 920 & $\begin{array}{l}8.898 \\
8.68\end{array}$ & $\begin{array}{l}8.876 \\
8.663\end{array}$ & 8.854 & $\begin{array}{l}8.832 \\
8.621\end{array}$ \\
\hline $\begin{array}{l}0 \\
7\end{array}$ & $\begin{array}{l}8.8100 \\
8.600\end{array}$ & $\begin{array}{l}8.789 \\
8.580\end{array}$ & $\begin{array}{l}8.708 \\
8.560\end{array}$ & $\begin{array}{l}8.747 \\
\text { 8. } 540\end{array}$ & $\begin{array}{l}8.720 \\
8.520\end{array}$ & $\begin{array}{l}8.705 \\
8.500\end{array}$ & $\begin{array}{l}8.084 \\
8.480\end{array}$ & $\begin{array}{l}8.603 \\
8.460\end{array}$ & $\begin{array}{l}8.042 \\
8.440\end{array}$ & $\begin{array}{l}8.021 \\
8.420\end{array}$ \\
\hline 8 & 8. 400 & 8. $38 \mathrm{I}$ & 8. 362 & 8. 343 & 8. 324 & 8. 305 & 8. 286 & 8. 267 & 8.248 & 8.229 \\
\hline 9 & 8.210 & 8. $x 91$ & 8. $x 72$ & 8. 153 & 8. 134 & 8. II5 & 8. 096 & 8.077 & 8.058 & 8.039 \\
\hline Io & 8.026 & 8.002 & 7.984 & $7 \cdot 966$ & $7 \cdot 94^{8}$ & $7.93^{\circ}$ & $7 \cdot 912$ & 7.894 & 7.876 & 7.859 \\
\hline II & 7.840 & 7.824 & 7.808 & 7. 792 & $7 \cdot 776$ & 7.760 & $7 \cdot 744$ & 7.728 & 7.712 & 7.696 \\
\hline 12 & 7.680 & 7.664 & 7.648 & $7 \cdot 632$ & 7.616 & 7.600 & $7 \cdot 584$ & 7. 568 & $7 \cdot 542$ & 7.526 \\
\hline$x_{3}$ & $7 \cdot 520$ & $7 \cdot 505$ & 7.490 & 7.475 & $7 \cdot 460$ & $7 \cdot 445$ & $7 \cdot 430$ & $7.4 \times 5$ & $7 \cdot 400$ & $7 \cdot 385$ \\
\hline 14 & $7 \cdot 370$ & 7.355 & $7 \cdot 340$ & $7 \cdot 325$ & $7 \cdot 310$ & $7 \cdot 295$ & 7.280 & 7.265 & 7.250 & $7 \cdot 235$ \\
\hline 15 & $7 \cdot 220$ & 7.206 & $7 \cdot 192$ & 7.178 & 7. 164 & $7 \cdot x_{50}$ & $7 \cdot 136$ & $7 \cdot 122$ & 7.108 & 7. 094 \\
\hline 16 & 7.080 & 7.066 & 7.052 & 7.038 & 7.024 & 7.010 & 6.996 & 6.982 & 6.968 & 6.954 \\
\hline 17 & 6.940 & 6.927 & 6.914 & 6. 901 & 6.888 & 6.875 & 6.862 & 6.849 & 6.836 & 6.823 \\
\hline 18 & 6.810 & 6. 798 & 6. 786 & 6. 774 & 6. 762 & 6.750 & 6. 738 & 6. 726 & 6. $7 \times 4$ & 6. 702 \\
\hline I9 & 6.690 & 6. 678 & 6.666 & 6.654 & 6.642 & 6.630 & 6.618 & 6. 606 & 6.594 & 6.582 \\
\hline 20 & 6. 570 & 6. 559 & 6. $54^{8}$ & 6. 537 & 6. 526 & 6.515 & 6. 504 & 6. 493 & $6.48 z$ & $6.47 \mathrm{I}$ \\
\hline 21 & 6.460 & 6. 449 & 6. 438 & 6. 427 & $6.4 \times 6$ & 6.405 & 6. 394 & 6.383 & 6. 372 & $6.36 \mathrm{x}$ \\
\hline 22 & 6.350 & 6.339 & 6. 328 & 6. 317 & 6. 306 & 6.295 & 6. 284 & 6. 273 & 6. 262 & 6. 251 \\
\hline 23 & 6. 240 & 6. 230 & 6. 220 & 6. 210 & 6.200 & 6. 190 & $6 . \times 80$ & 6. I70 & 6.160 & 6. I50 \\
\hline 24 & $6 . \times 40$ & 6. 130 & 6. $x 20$ & 6. Iro & 6.100 & 6.090 & 6.080 & 6.070 & 6.060 & 6.050 \\
\hline 25 & $6.04 \circ$ & 6.030 & 6.020 & 6. oxo & 6.000 & $5 \cdot 990$ & 5.980 & 5.970 & 5.960 & 5.950 \\
\hline 26 & 5.940 & $5 \cdot 930$ & 5.920 & 5.910 & 5.900 & 5.890 & 5.880 & 5.870 & 5.860 & 5.850 \\
\hline 27 & 5.840 & 5.831 & 5.822 & $5.8 \times 3$ & 5.804 & 5.795 & $5 \cdot 786$ & 5. 777 & $5 \cdot 768$ & 5.759 \\
\hline 28 & 5.750 & 5. $74 \mathrm{I}$ & $5 \cdot 732$ & $5 \cdot 723$ & $5 \cdot 714$ & $5 \cdot 705$ & 5.696 & 5.687 & 5.678 & 5.669 \\
\hline 29 & 5.660 & 5.651 & $5 \cdot 542$ & 5.633 & $5 \cdot 624$ & $5.6 \times 5$ & 5.606 & 5.597 & 5.588 & 5.579 \\
\hline 30 & $5 \cdot 570$ & 5. $56 \mathrm{I}$ & $5 \cdot 552$ & $5 \cdot 543$ & $5 \cdot 534$ & $5 \cdot 525$ & $5 \cdot 516$ & 5. 507 & 5.498 & $5 \cdot 489$ \\
\hline
\end{tabular}











\section{OWASCO LAKE}

Topography from maps of the United States Geological Survey, 1909 Hydrography from survey by Cornell University, 1896-1897 Contour interval $\left\{\begin{array}{l}\text { Topography, } 20 \text { feet } \\ \text { Hydrography, } 50 \text { feet }\end{array}\right.$

, Scale $625 \frac{1}{2000}$
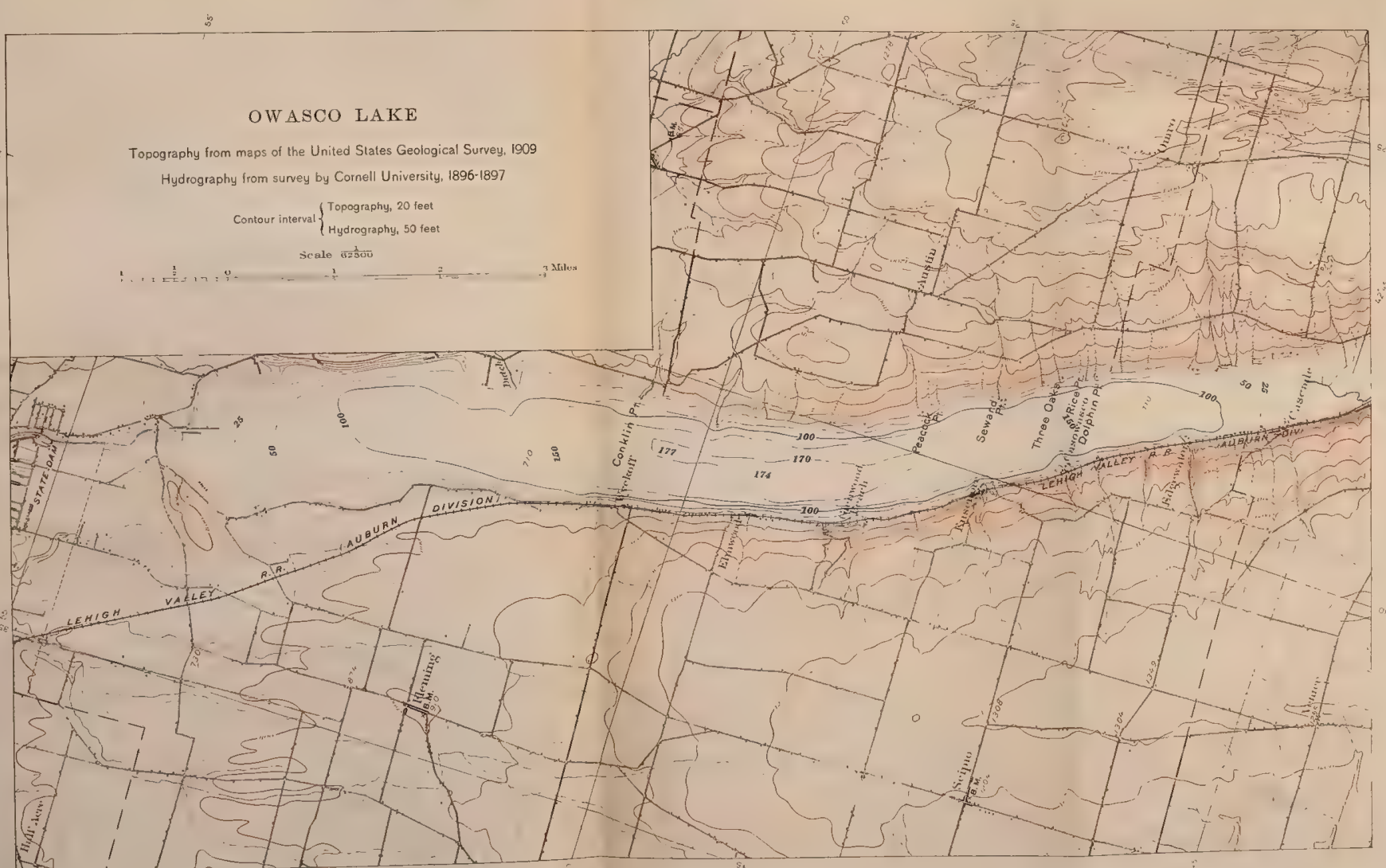





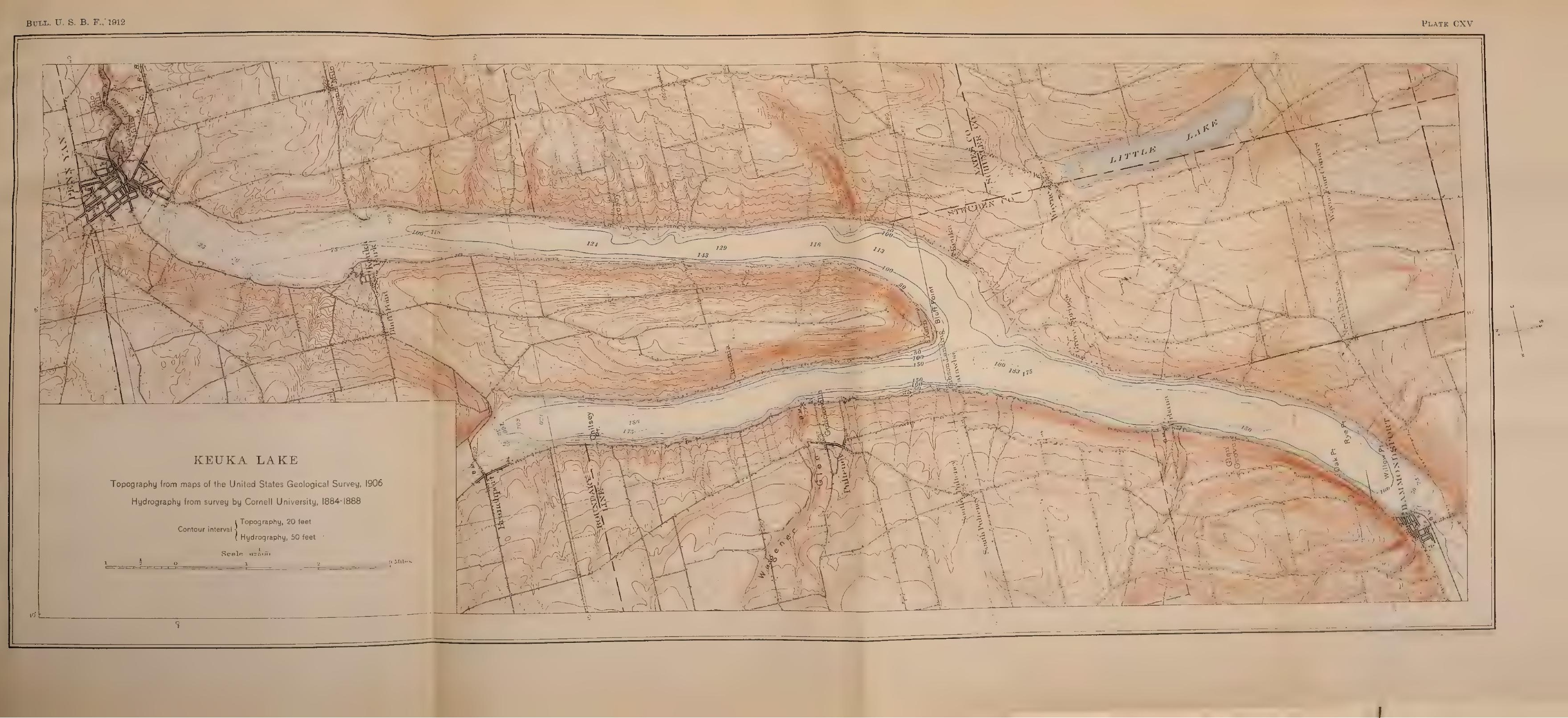





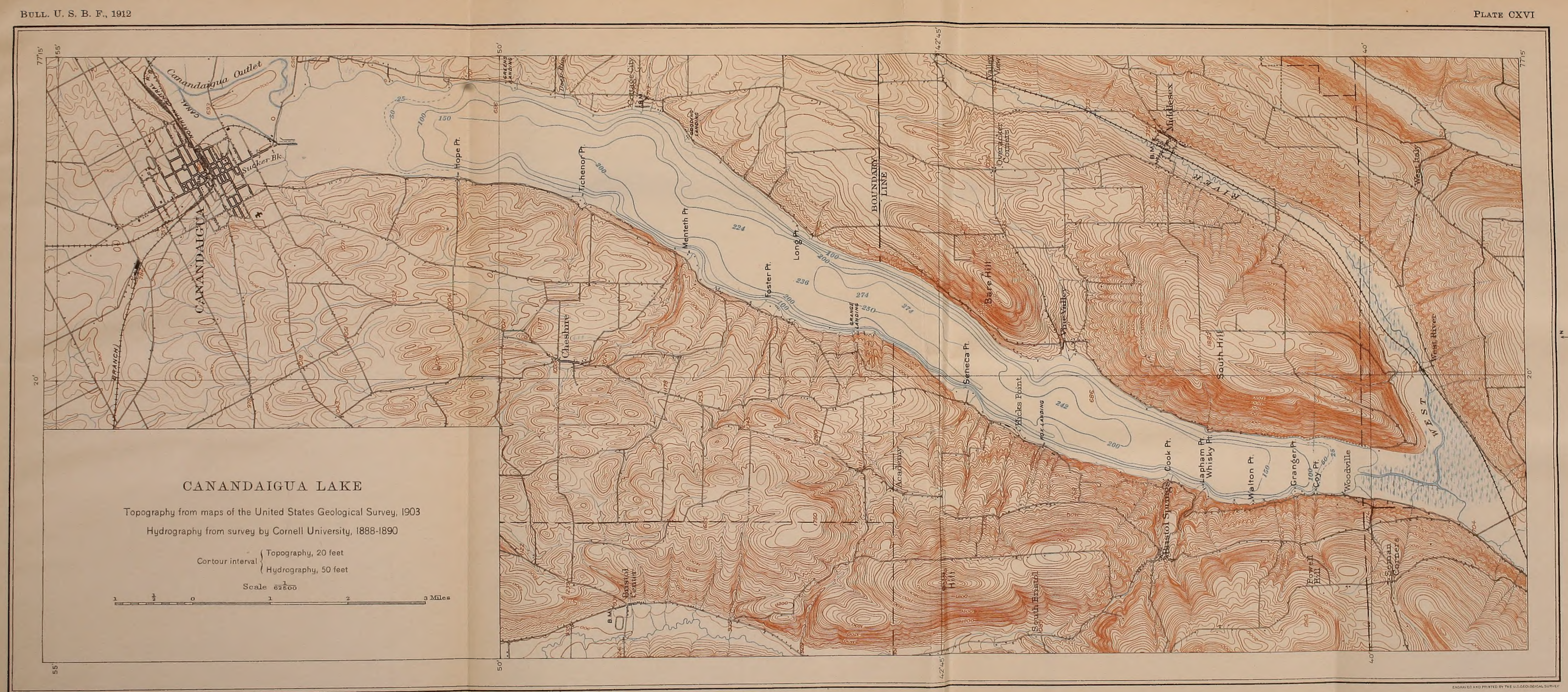




00297141636 